\title{
HgCdTe Detector Reliability Study for the GOES Program
}

\author{
David G. Seiler \\ George G. Harman \\ Jeremiah R. Lowney \\ Santos Mayo \\ Walter S. Liggett, Jr.
}

U.S. DEPARTMENT OF COMMERCE National Institute of Standards and Technology

Gaithersburg, MD 20899

September 1991

U.S. DEPARTMENT OF COMMERCE Robert A. Mosbacher, Secretary NATIONAL INSTITUTE OF STANDARDS AND TECHNOLOGY John W. Lyons, Director

100

.456 \#4687

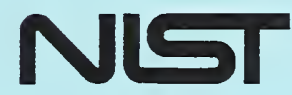





\section{HgCdTe Detector Rellability Study for the GOES Program}

\section{David G. Seiler George G. Harman Jeremiah R. Lowney Santos Mayo}

Semiconductor Electronics Division Electronics and Electrical Engineering Laboratory

Walter S. Liggett, Jr.

Statistical Engineering Division Computing and Applied Mathematics Laboratory

U.S. DEPARTMENT OF COMMERCE National Institute of Standards and Technology

Gaithersburg, MD 20899

September 1991

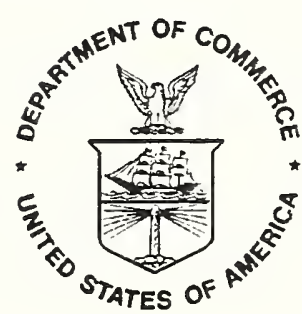

U.S. DEPARTMENT OF COMMERCE Robert A. Mosbacher, Secretary NATIONAL INSTITUTE OF STANDARDS AND TECHNOLOGY

John W. Lyons, Director 



\section{HgCdTe Detector Reliability Study for the GOES Program}

\section{TABLE OF CONTENTS}

Page

EXECUTIVE SUMMARY

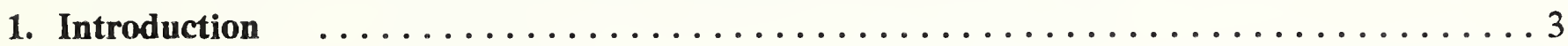
A. Background 3
B. Summary of $\mathrm{HgCdTe}$ Detector Degradation/Instability Problems $\ldots \ldots \ldots 6$

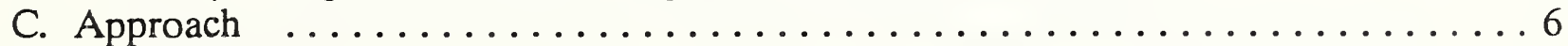
D. Outline of Report $\ldots \ldots \ldots \ldots \ldots \ldots \ldots \ldots \ldots \ldots \ldots \ldots \ldots \ldots \ldots$

2. Tutorial on HgCdTe Infrared Detectors $\ldots \ldots \ldots \ldots \ldots \ldots \ldots \ldots \ldots$

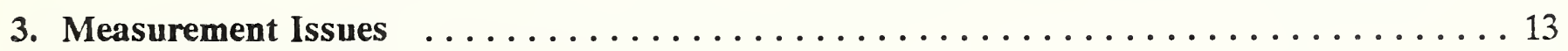

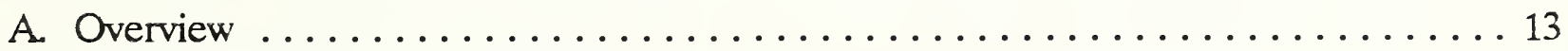

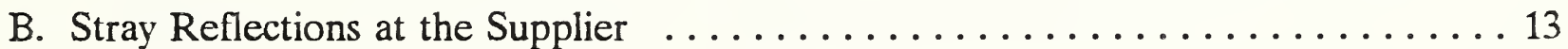
C. ITT Measurements . . . . . . . . . . . . . . . . . . . . . . 14
D. Optical Signals Measured from Sounder Contact Areas . . . . . . . . . . . . . 14
E. Definition of Key Detector Parameters and Related Concerns . . . . . . . . . 14

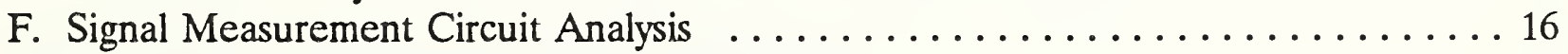
G. Summary of Measurement Issues Covered $\ldots \ldots \ldots \ldots \ldots \ldots \ldots \ldots \ldots \ldots$

4. Summary of Available Data . . . . . . . . . . . . . . . . . . . 19

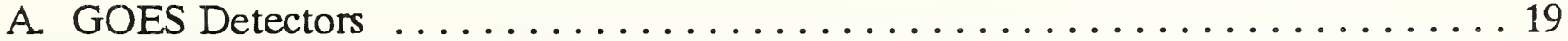
B. Measurement Results on Imager Detectors $\ldots \ldots \ldots \ldots \ldots \ldots \ldots \ldots$
C. Published Data on Similar Types of Detectors $\ldots \ldots \ldots \ldots \ldots \ldots \ldots \ldots \ldots$

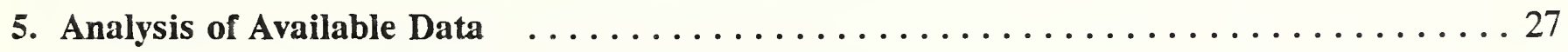

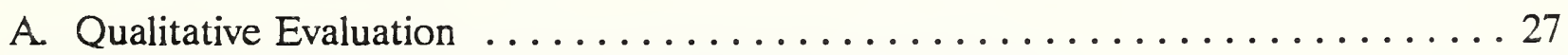

B. Statistical Analysis of the $11-\mu \mathrm{m}$ Detector Measurements .............. 31

6. Critical Analysis to Determine and Understand Stability/Degradation Issues . . . . . . 37
A. Detector Assembly - Workmanship Reliability Assessment, Wire
Pull Tests, and Proposed Mechanisms to Explain the Degradation . . . . . . . . 37
B. A Brief Summary of Some Diagnostic Tests Performed by Other

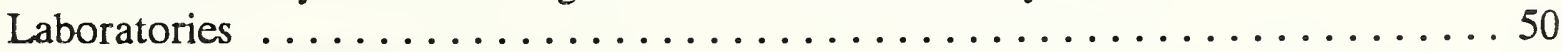

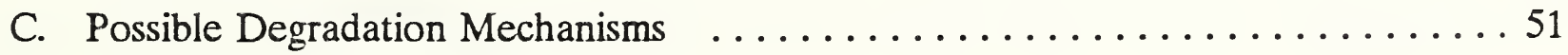


TABLE OF CONTENTS (cont'd).

Page

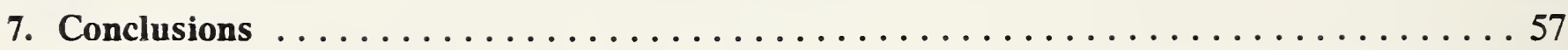

8. Recommendations for Future Work on New Detectors for the GOES Program . . . . . . 59

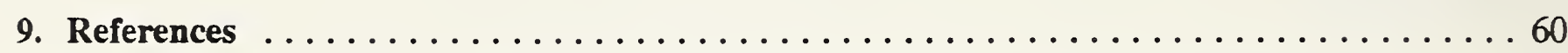

\section{APPENDICES}

A. Interim Report Submitted Earlier to NOAA: Signal Reduction/Instability Analysis of Four HgCdTe Detectors for the GOES Program . . . . . . . . . . 61

B. Tables of Room Temperature Resistances of Imager Detectors at Various Dates

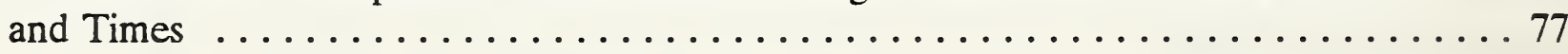

C. Tables of Resistances and Signals of Each Imager Detector Element at a Temperature of $105 \mathrm{~K}$ as a Function of Date and Time $\ldots \ldots \ldots \ldots \ldots \ldots \ldots \ldots \ldots \ldots$

D. Graphs of the Variation with Time of the Resistances and Signals of the Imager Detectors

\section{LIST OF FIGURES}

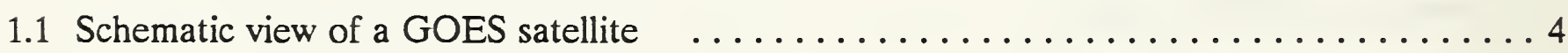

2.1 Principal components of a $\mathrm{HgCdTe}$ GOES detector element $\ldots \ldots \ldots \ldots \ldots \ldots \ldots$

3.1 Equivalent measurement circuit for detectors $\ldots \ldots \ldots \ldots \ldots \ldots \ldots \ldots \ldots \ldots$

4.1 Wafer map of the 11- and $12-\mu \mathrm{m}$ detectors showing the placement of

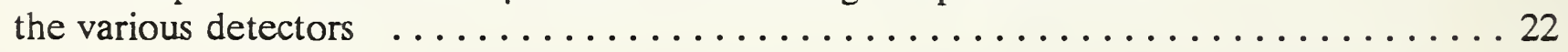

4.2 Degree of uniformity, at $77 \mathrm{~K}$, typically achievable in a 20 -element array of $55-\mu \mathrm{m}$ by $55-\mu \mathrm{m}$ active area detectors for an ambient

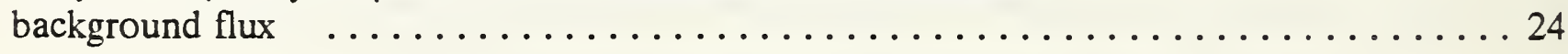

5.1 Histogram of the resistances of the 11- and $12-\mu \mathrm{m}$ detectors delivered to ITT

5.2 Histogram of the resistances of all $11-$ and $12-\mu \mathrm{m}$ detectors available for analysis 30 


\section{LIST OF FIGURES (cont'd).}

Page

5.3 Wafer map of the 11- and $12-\mu \mathrm{m}$ detectors showing the initial $105-\mathrm{K}$

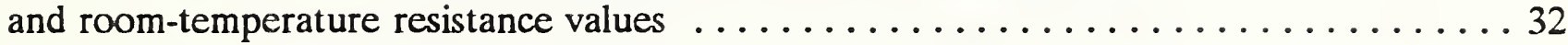

5.4 Cumulative dependence of the variance on the slope $\ldots \ldots \ldots \ldots \ldots \ldots \ldots$

6.1 Detector 44792-4: Examples of poor bonding on the package and the silicone rubber staking blobs

6.2 Detector 53238-4: Examples of initial nonsticking bonds to the indium $\ldots \ldots \ldots \ldots . \ldots 39$

6.3 Detector 53237-4: This sample is stated to have had 103 -h bake at $100{ }^{\circ} \mathrm{C} \ldots \ldots \ldots 41$

6.4 Detector 45839-4: This sample is reported to have seen the same

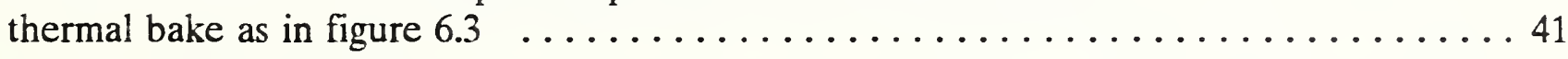

6.5 An overview of the metallization in Detector $12-111 \ldots \ldots \ldots \ldots \ldots \ldots \ldots$

6.6 Apparent separation of the $\mathrm{ZnS}$ and/or passivation film on Detector $12-111 \ldots \ldots \ldots 47$

6.7 Two elements of Detector 45839-4 are shown with the arrow pointing to several separation "bubbles" or "bulges" ....................... 47

6.8 The arrow points to a crack in the $\mathrm{ZnS}$ optical coating on Detector $12-111$.................................. 48

6.9 A top view of one electrical lead-through in Detector $12-111 \ldots \ldots \ldots \ldots \ldots \ldots$

6.10 An enlargement of the solder-gold wire interface revealing a crack is shown by the arrow

6.11 A further enlargement of the solder gold wire intersection $\ldots \ldots \ldots \ldots \ldots \ldots . \ldots 4$

6.12 Mercury profile in $\mathrm{HgCdTe}$ at $300 \mathrm{~K}$ as a function of position for times of $50,100,150$, and 250 days (sample width, $50 \mu \mathrm{m}) \ldots \ldots \ldots \ldots . \ldots . \ldots$.

6.13 Mercury profile in $\mathrm{HgCdTe}$ at $300 \mathrm{~K}$ as a function of position for times of $50,100,150$, and 250 days (sample width, $100 \mu \mathrm{m}$ ) $\ldots \ldots \ldots \ldots \ldots$

D.1 Resistance and signal of element $A$ of the $7-\mu \mathrm{m}$ detectors with aplanat lens as a function of time

D.2 Resistance and signal of element $B$ of the $7-\mu \mathrm{m}$ detectors with aplanat lens as function of time 


\section{LIST OF FIGURES (cont'd).}

D.3 Resistance and signal of element $A$ of the $11-\mu \mathrm{m}$ detectors with aplanat lens as a function of time

D.4 Resistance and signal of element B of the $11-\mu \mathrm{m}$ detectors with aplanat lens as a function of time

D.5 Resistance and signal of element $\mathrm{C}$ of the $11-\mu \mathrm{m}$ detectors with aplanat lens as a function of time

D.6 Resistance and signal of element $D$ of the $11-\mu \mathrm{m}$ detectors with aplanat lens as a function of time

D.7 Resistance and signal of element $A$ of the $12-\mu \mathrm{m}$ detectors with aplanat lens as a function of time

D.8 Resistance and signal of element B of the $12-\mu \mathrm{m}$ detectors with aplanat lens as a function of time

D.9 Resistance and signal of element $C$ of the $12-\mu \mathrm{m}$ detectors with aplanat lens as a function of time

D.10 Resistance and signal of element $\mathrm{D}$ of the $12-\mu \mathrm{m}$ detectors with aplanat lens as a function of time

D.11 Signals of elements of the $12-\mu \mathrm{m}$ detectors without aplanat lens as a function of time

\section{LIST OF TABLES}

1.1 Imager Channel Functions

2.1 Partial Listing of Spaceborne Infrared Sensor Programs Using Mercury-Cadmium-Telluride Detectors

4.1 Initial Status of Imager Detectors Delivered to ITT by Supplier 20

4.2 Sounder Detectors Delivered to ITT by Supplier $\ldots \ldots \ldots \ldots \ldots \ldots \ldots \ldots \ldots \ldots$

4.3 Vacuum Bake Data, Array Size: 55 by $55 \mu \mathrm{m} ; 20$ Elements; $77 \mathrm{~K}$ 25 


\title{
HgCdTe DETECTOR RELIABILITY STUDY FOR THE GOES PROGRAM
}

\author{
David G. Seiler, George G. Harman, Jeremiah R. Lowney, \\ Santos Mayo, and Walter S. Liggett, Jr. \\ National Institute of Standards and Technology \\ Gaithersburg, MD 20899
}

\section{EXECUTIVE SUMMARY}

This report summarizes the results of a special assessment carried out by the National Institute of Standards and Technology (NIST) at the request of the National Oceanic and Atmospheric Administration of the reliability of certain infrared detectors for the Geostationary Operational Environmental Satellite (GOES) system.

The NIST analysis and conclusions reached here rely on three sources of data or information: (1) the detector measurement database on GOES Detectors (compiled by ITT), (2) the $\mathrm{HgCdTe}$ Detector Degradation Task Force Meeting booklets, and (3) first-hand inspection by NIST staff of selected detectors provided to NIST.

An Interim Report submitted to NOAA and reprinted in appendix A shows signal reduction or instability for four GOES detectors. The data made available by ITT on detector resistances and signals have been further analyzed, and this analysis supports the conclusion that degradation or instability of some detector responses has occurred, even when the maximum estimated measurement uncertainty is included. The statistical analysis presented here, which was performed only for the $11-\mu \mathrm{m}$ detectors, has shown that it is very unlikely that the apparent decrease in signal with time can be attributed to measurement error.

The existing data available to NIST are not sufficient to identify uniquely the cause of degradation or unstable behavior present in a number of detectors. NIST's physical examination of several detectors by optical and scanning electron microscopy methods and an examination and analysis of the detector measurement database has yielded several possible mechanisms for the observed degradation. These mechanisms are related to the detector fabrication or processing steps and include:

- Poor indium electrical contacts produced by the indium-plated fabrication step. The indium-plated electrodes on the detectors are porous and have wormy structures, with individual grains often appearing not to be in contact with neighbors. Optical signals have been observed in the region of indium metallization and high contact resistance has been measured on many of the detectors. These contacts could be unstable over time because of ambient conditions, stresses, and interdiffusions, which can change both the resistance of and signals produced by these regions.

- Incomplete or poor passivation procedures which could cause variability of signal and resistance because the surface could be exposed to ambient conditions. 
- Excess mercury diffusion resulting from the ion-beam milling fabrication step. The ionmilling introduces a thin layer of excess mercury, which could diffuse into the bulk in about a year. The resulting increase in electron density could cause the signal to decrease primarily because of the sweepout effect.

- Delamination of the $\mathrm{ZnS}$ anti-reflection optical coating. Organics and other residual products could be trapped under the $\mathrm{ZnS}$ optical coating and prevent its molecular bonding to the $\mathrm{HgCdTe}$ or passivation layer.

The optical and scanning electron microscopy examination also identified several potential reliability problems which were probably not contributors to the observed degradation but may affect the service life of the detectors. These include:

- Poor wire bonding. NIST's bonding tests on a number of available detectors found that the range of pull forces and the number of rebonds, both to chip and package, were so large that the bonding operation was out of control and should be considered unreliable.

- Use of tin-lead solder to couple the fine gold wire (bonded to the detector) to the package terminal. Solder reacts rapidly with gold, dissolving it and/or converting it into a brittle intermetallic compound which could crack during temperature cycling. Tin-lead soldering is avoided in the microelectronics industry.

- Use of a silicone material to stake the bond wires to the edge of the $\mathrm{ZnS}$ substrate. The manufacturer does not recommend the use of the silicone material below $208 \mathrm{~K}$ because it undergoes a phase transition, becoming hard and brittle. Wire bonds have been observed to break at low temperatures when covered with silicone. Since the flight hardware detectors have an additional epoxy stake over the actual bonds on the indium, separation of or damage to the bonds could occur because of the differential temperature expansion.

In conclusion, there are significant technical questions which must be resolved before any of these detectors could be judged to be reliable. On the basis of the above observations, NIST cannot recommend the use of these detectors in a GOES satellite. 


\section{INTRODUCTION}

\section{A. Background}

The National Oceanic and Atmospheric Adminstration (NOAA) has the responsibility for producing, launching, and operating a multiple Geostationary Operational Environmental Satellite (GOES) system. The primary purpose of the GOES Program is the continuous and reliable collection of environmental data in support of weather forecasting and related services. The data obtained by the GOES satellites provide information needed for severe storm detection, monitoring, and tracking; wind measurements from cloud motion; sea surface thermal features; precipitation estimates; frost monitoring; rescue operations; and research. The geostationary orbit of these satellites allows continuous observation of a portion of the earth and its atmosphere. Since 1974, these GOES satellites have been used to collect and disseminate environmental data for the United States National Weather Service. At present, there is only one aging satellite, GOES H or GOES-7, in orbit. The United States National Weather Service now relies heavily on this aging satellite GOES-7 for crucial weather information.

New weather satellites are being produced by a program known as GOES-NEXT, for the next generation of Geostationary Operational Environmental Satellites. A series of five satellites, designated by the letters I-M, will be produced. There are significant differences between the GOES I-M series spacecraft and the earlier series. The GOES D-H satellites had a passive, spinstabilized, attitude control system. The GOES I-M series of satellites will use a three-axis attitude control system. Unlike the GOES D-H series, the GOES I-M satellites support separate imager and sounder instruments that operate independently and simultaneously performing imaging and sounding operations.

Figure 1.1 shows a schematic view of the GOES satellite as depicted by Space Systems/LORAL/ITT graphic artists [1.1]. This satellite performs a number of functions as illustrated including visible and infrared imaging (Imager) and atmospheric sounding (i.e. depth profiling of atmosphere) (Sounder) using various types of detectors.

The GOES sensors provide two-dimensional cloud and temperature imagery in both visible and infrared spectra, radiometric data providing the capability to determine the three-dimensional structure of atmospheric temperature and water-vapor distribution, and solar and near-space environmental data. Three different types of detectors are used in each of the Imager and Sounder systems: silicon ( $\mathrm{Si}$ ) photovoltaic detectors for visible radiation, indium antimonide (InSb) photovoltaic detectors for infrared radiation, and $\mathrm{HgCdTe}$ photoconductive detectors for various infrared radiation spectral regions. There are five channels for the Imager. Table 1.1 shows their specifications for detector type, wavelength range, and their purpose. Spectral separation in the Imager is done by fixed dichroic beam splitters, permitting simultaneous sampling of all five spectral channels.

The Sounder instrument has 19 channels. There are four Sounder bands containing Si detectors for the visible, InSb detectors for the shortwave infrared, and $\mathrm{HgCdTe}$ detectors for both the midwave and longwave infrared regions. These bands provide information on atmospheric temperature profiling. The visible spectrum and the three infrared bands are separated by dichroic beam splitters. The three infrared bands then pass through three concentric rings of a filter wheel where channel filters provide sequential sampling of the seven longwave, five 


\section{GOES SATELLITE ON-ORBIT CONFIGURATION}

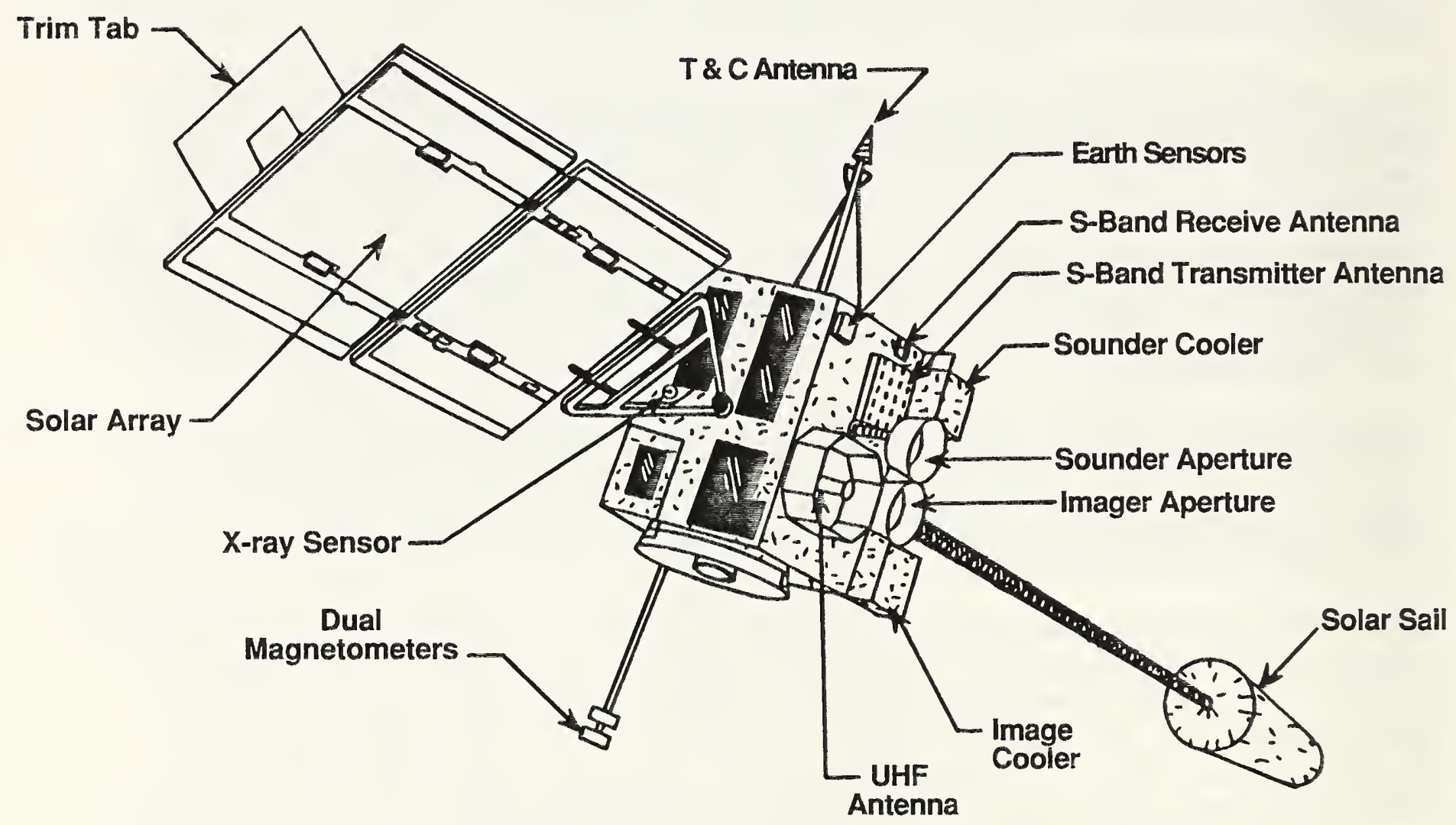

Figure 1.1 Schematic view of a GOES satellite [1.1]. 
Table 1.1 Imager Channel Functions.

Spectral Channels

1

2

3

4

5

Detector Type

$\mathrm{Si}$

$\operatorname{InSb}$

$\mathrm{HgCdTe}$

$\mathrm{HgCdTe}$

$\mathrm{HgCdTe}$

Wavelength $(\mu \mathrm{m})$

0.55 to 0.753 .80 to 4.00

6.50 to 7.0010 .20 to 11.20

11.50 to 12.50

Function

Cloud

Nighttime

Water

Surface

Sea Surface

Cover

Clouds

Vapor

Temperature Temperature \&

Water Vapor 
midwave, and six shortwave channels.

\section{B. Summary of HgCdTe Detector Degradation/Instability Problems}

In May 1990, HgCdTe detector degradation issues were first raised concerning the first satellite of the new GOES-NEXT series, the GOES I system, after the Imager Channel 5 was found by ITT to have a throughput problem. Subsequently, ITT tested Detector 12-103, a backup 12- $\mu \mathrm{m}$ detector, in order to determine its properties independent of any in the flight instrument. ITT measurements made on May 1, 1990, which were also subsequently confirmed by the supplier on May 3, indicated an apparent drop in signal of approximately $68 \%$. Remeasurements on other detectors during the past year by the supplier and ITT also suggest that other detectors were either unstable or had degraded.

In June 1990, a Detector Degradation Task Consultant Team was formed that consisted of members from ITT, Goddard Space Flight Center (GSFC), Space Systems/LORAL (SS/L), the supplier, Lockheed, Georgia Tech, and NIST. The goals were to: (1) determine the cause of the GOES HgCdTe photoconductive detector degradation/instability problems, (2) identify existing detectors that might become unstable, and (3) determine how to prevent future

degradation/instabilities. A final meeting of the Team was held on June 11, 1991, at ITT, and a final report of this Team is in the process of being written. Before that team issued its final report, NIST was requested to perform an independent assessment of detector reliability. This report summarizes the results of that assessment.

\section{Approach}

A definitive study on $\mathrm{HgCdTe}$ detector degradation phenomena, and related reliability concerns, would require analysis of data from accurate measurements on pertinent parameters to be able to predict detector performance on the basis of a physics-based understanding of observed changes of detector characteristics with time. The routine quality control data recorded for existing detectors do not include all the parameters NIST judges to be pertinent. In addition, there are serious concerns about the quality of the data which were recorded. NIST has been able to analyze the available detector database, especially data on detector resistances and output signal levels, to yield insights presented here on the trends that have occurred. NIST notes that degradation has been observed in some devices. This report extends an earlier analysis contained in an interim report previously submitted to NOAA. The interim report, reproduced here in appendix $\mathrm{A}$, showed that signal reduction/instability of selected detectors occurred even when the maximum amount of measurement uncertainty is taken into account. NIST believes that the patterns, or trends, in the available data presented here can provide insight into the cause of degradation.

It should be emphasized that the analysis in this report is based on data taken by others outside NIST. The nature of the problem, potential long-term degradation, made replicate studies impossible during this short study. NIST staff analyzed existing data, compared these data with existing knowledge about $\mathrm{HgCdTe}$ detectors, and conducted limited investigations of existing detectors.

Since little time-dependent data exist on the Sounder detectors, most of this report deals with the Imager detectors. Furthermore, on examining the Imager database, NIST found that the only detector parameters in the Imager database that provided useful information for analysis are the 
resistance and signal (the noise measurements were dominated by preamplifier noise, and so a quantitative measure of detector noise was not obtained).

Finally, NIST records some important observations obtained from visual and SEM examinations and analyses of the metallization and bonding on these types of $\mathrm{HgCdTe}$ detectors.

\section{Outline of Report}

The following items summarize the content of this report:

- Section 2 discusses the uses and design of photoconductive $\mathrm{HgCdTe}$ infrared detectors. Possible fabrication difficulties are discussed.

- Section 3 discusses the various measurement uncertainties that can affect the quality of the data upon which NIST's findings are based.

- Section 4 presents all of the data that NIST has obtained from ITT for analysis to determine whether the detectors have demonstrated degradation or instability. Comparable data on similar detectors are also presented.

- Section 5 analyzes the resistance and signal data for the $7-\mu \mathrm{m}, 11-\mu \mathrm{m}$, and $12-\mu \mathrm{m}$ detectors. Both a qualitative evaluation based on error criteria and a quantitative statistical analysis have been performed.

- Section 6 discusses the various methods that have been used both by NIST and other laboratories to diagnose the possible causes for the detector degradation or instability. These tests range from visual and SEM inspection to electrical characterization. Models have been constructed to interpret the data and suggest possible mechanisms for degradation.

- Section 7 gives the conclusions, and Section 8 discusses recommendations for work on future GOES detectors.

- Appendix A is the Interim Report to NOAA: "Signal Reduction/Instability Analysis of Four HgCdTe Detectors for the GOES Program."

- Appendix B contains tables of the room-temperature resistances of Imager detectors.

- Appendix $\mathrm{C}$ contains tables of resistances and signals of the Imager detector elements at $105 \mathrm{~K}$.

- Appendix D contains graphs of the data in appendix C. 


\section{TUTORIAL ON HgCdTe INFRARED DETECTORS}

This section discusses the uses and design of photoconductive $\mathrm{HgCdTe}$ infrared detectors. Possible fabrication difficulties are discussed.

The ternary intermetallic compound mercury cadmium telluride, $\mathrm{Hg}_{1-\mathrm{x}} \mathrm{Cd}_{\mathbf{x}} \mathrm{Te}$, is one of the most important materials used in infrared detectors. These infrared detectors are widely used for military applications and civilian purposes such as in satellites that need space-borne infrared sensors for remote temperature sensing. Interest also exists in using these detectors for evaluating home and industrial energy loss, medical thermography (i.e., breast cancer detection), astronomical research, spectrophotometers, laser light detection, remote controls for TV sets and VCRs, etc. Table 2.1 shows a partial listing of space programs that have used or presently use HgCdTe detectors. The first use of this type of detector in space occurred in 1972 on the Air Force Meteorological Satellite. Since that time, a variety of instruments using $\mathrm{HgCdTe}$ detectors has been flown by the National Aeronautics and Space Administration (NASA).

Infrared photoconductive detectors are devices that convert electromagnetic radiation to electric signals by direct conversion of incident photons into conducting electrons or holes. The signals can then be processed to obtain information from the intensity and wavelength distribution of the incident radiation. Figure 2.1 shows the principal elements of the HgCdTe GOES detectors [2.1].

There are a number of reasons why $\mathrm{Hg}_{1-\mathrm{x}} \mathrm{Cd}_{\mathrm{x}} \mathrm{Te}$ alloys are used. By varying the mole fraction $\mathrm{x}$, the energy gap can be continuously adjusted from below 0.04 to above $1.3 \mathrm{eV}$, covering the 1 - to $25-\mu \mathrm{m}$ infrared region. Tailor-made materials can thus be grown to respond to preselected wavelengths, providing one the opportunity to make a range of temperature measurements from orbit. Quantum efficiencies approaching $100 \%$ for 12 - to $16-\mu \mathrm{m}$-thick devices are possible. Long carrier-lifetime material can be produced even at relatively high processing temperatures. The material can also be made quite pure (approaching electrical levels of approximately $1 \times 10^{14}$ $\mathrm{cm}^{-3}$ carriers). In addition, the surfaces can be passivated by a number of approaches such as using $\mathrm{ZnS}$, native (anodic) oxides, sulphides, or fluorides.

Important factors that influence the responsivity, impedence, and noise of the photoconductive detectors are the energy gap, doping concentration, electron and hole mobilities, carrier lifetimes, passivation properties, the effects of ion millings, and the contacts. Effects associated with the device contacts and surfaces can cause gross distortions of the detector operating characteristics. The processing details for fabricating contacts to $\mathrm{HgCdTe}$ are based largely upon empiricism. A fundamental understanding is lacking. Formation of Schottky barriers causes voltage instabilities and problems with reproducibility and reliability.

An adequate passivation layer must (1) be a good insulator, (2) adhere sufficiently well to the $\mathrm{HgCdTe}$, (3) be time stable, (4) be stable against the atmosphere (unless a hermetic seal is used), (5) not be attacked by chemicals necessary for making the device, (6) be sufficiently nonporous that atmospheric gases cannot move through it and attack the $\mathrm{HgCdTe}$, and (7) produce an interface which is sufficiently inert electrically so that it does not degrade the operation of the detector. Inhomogeneity or nonuniformity in the relative concentrations of mercury and cadmium, doping concentration level, or defects throughout the wafers can cause problems. Production yields for the detectors are typically low, on the order of 5 to $10 \%$. 

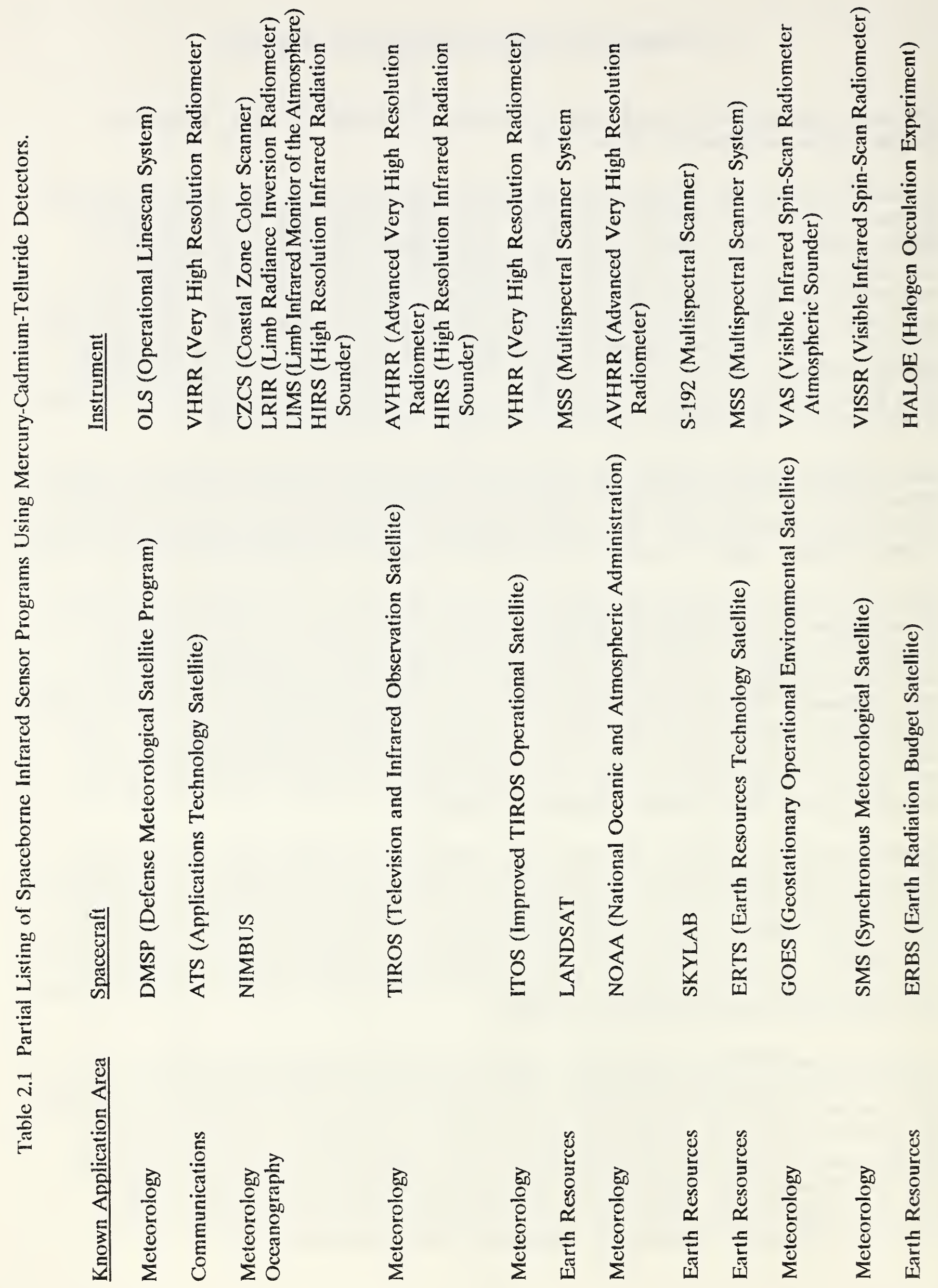


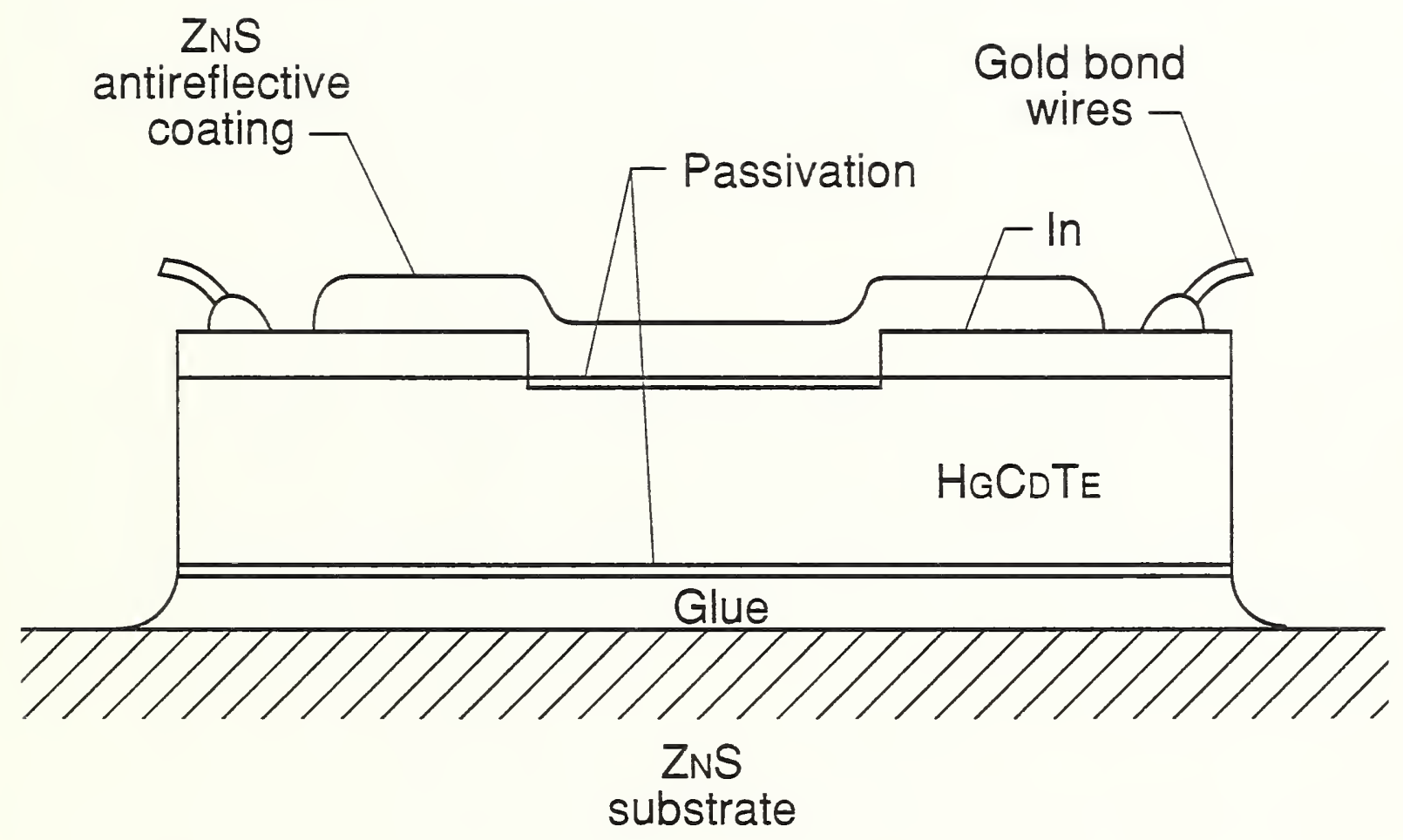

Figure 2.1 Principal components of a HgCdTe GOES detector element [2.1]. The 7- $\mu \mathrm{m}$-wavelength detectors have two elements; the $11-\mu \mathrm{m}$ - and $12-\mu \mathrm{m}$-wavelength detectors, four. 
In summary, there are many possible fabrication difficulties that can lead to reduced detector performance. These include both detector-specific effects as well as those related to contacts and packaging. 


\section{MEASUREMENT ISSUES}

This section discusses the various measurement uncertainties that can affect the quality of the data upon which NIST's findings are based.

\section{A. Overview}

For this study, a major parameter of concern is the detector output signal about which serious questions concerning measurement quality have been raised by NOAA. Two separate factors have been uncovered which prevent a rigorous assessment of degradation and the determination of confidence levels for the detectors: (1) the discovery in June of 1990 that undesirable reflections of blackbody radiation from a tube between the blackbody and detector may have been present when the detectors were measured and (2) measurements that indicate that the detectors produce optical signals from areas outside of the nominally active detector area. An analysis of the circuit used to measure detector signals shows that any decrease in the resistance of the responsive area of a detector must result in a corresponding decrease in the detector signal. Definitions of terms are given in section $\mathrm{E}$.

\section{B. Stray Reflections at the Supplier}

NIST finds that because experimental uncertainties were not evaluated and documented, rigorous comparisons among data taken from measurements made at different times and with different test setups are not possible. At the supplier, for example, the blackbody source was mounted vertically, and a mirror was used to produce a horizontal beam impinging on the detector mounted inside a cold dewar. The supplier used a light pipe arrangement that surrounds the beam. Light reflecting off the internal sides of this pipe onto the detector could produce artificially inflated signal levels because more light hit the detector than was available from the straight-through radiation. Because of the variability of the detector mountings, dewar placement, and test setup, the detectors tested could receive different amount of reflected radiation or "glint" on them. The supplier's staff estimate that some signals might be inflated by as much as 20 to $25 \%$ if there is a glint problem. Consequently, at any particular time, the flux impinging on the detectors could have been anywhere from 0 to approximately $25 \%$ higher than expected. This means the signal or responsitivity would also have been too high by a factor of as much as $25 \%$.

To remove the unwanted reflected light, the supplier later mounted several washers (which act as baffles) inside the tube to block possible reflections.

Most of the detector measurements are made with an aplanat lens mounted on the detector housing in front of the detector. The lens could collect more stray light than the bare detector, again inflating the signal. No measurements were made, however, which would document this effect, and no estimate of its magnitude can be made.

After the end of August 1990, the signal measurement imprecision was estimated by the supplier to be \pm 5 to $10 \%$. This improvement resulted from (1) removing the stray reflections by the baffles, (2) repeated measurement tests at the supplier, and (3) use of a common detector that was measured by ITT, Cincinnati Electronics (CE), and the supplier to determine consistency among measurements at ITT, CE, and the supplier. 


\section{ITT Measurements}

Prior to May 1990, detector measurements were carried out only at the supplier. During the period between May 1990 and February 1991, ITT established a detector measurements laboratory. Staff of ITT have estimated variability in the test setup. Detector temperature differences were expected to occur because the various dewars used have inherent temperature differences between the detector and cold finger (one dewar has a 3-K difference, another, 8-K). ITT staff have developed temperature correction factors to account for these differences.

A second source of uncertainty is uncontrolled background flux, which is a significant factor for the Sounder detector tests. For the Imagers, a holder controls the amount of background flux, and both ITT and the supplier use the same holder. A common holder was not used for the Sounder detectors.

\section{Optical Signals Measured from Sounder Contact Areas}

LIRIS (Loral Infrarer Imaging Systems) has recently reported results from experiments in which they masked the contact regions of Sounder detectors and found a drop in signal by more than $60 \%$ of the value obtained without the mask, indicating that these contact regions are optically active. This result suggests flaws in the metallization process which cause artificially high responsivities because the flaws permit excitation outside of the designed active area. These flaws have been seen in SEM micrographs, which show pinholes in the metal films.

\section{E. Definition of Key Detector Parameters and Related Concerns}

The following is a list of the terms that relate to the characterization of infrared detectors along with comments on measurement difficulties that may occur. The units for each parameter are given in parentheses.

Detector temperature, $\mathbf{T}(\mathrm{K})$ : The operating temperature of the detector. This parameter can be difficult to determine as it may not be the same as the temperature of the cold finger or the liquid in the dewar, to which it may be assumed equal.

Resistance, $\mathbf{R}_{\mathbf{d}}(\boldsymbol{\Omega})$ : The ratio of the dc voltage across the detector to the dc current through it. It is a function of temperature. This ratio can vary with applied current if the current-voltage characteristic is not linear.

Background temperature, $T_{B}(K)$ : The temperature of a uniform blackbody that would completely fill the detector field of view and give the total flux on the detector due to ambient radiation.

Responsive area, $\mathbf{A}_{\mathbf{d}}\left(\mathbf{c m}^{2}\right)$ : The geometric area of the active detector. This area does not include contacts or other peripheral regions of the detector, which could contribute signal if pinholes or other processing difficulties allow radiation to impinge on the $\mathrm{HgCdTe}$ outside the responsive area.

Detector solid angle, $\Omega$ (sr): The field of view from which the detector receives radiation. Comment: This parameter must be specified and controlled if measurements are made on different test stations. 
Bias voltage, $\mathbf{V}_{\mathbf{b}}(\mathrm{V})$ : The bias voltage that provides the current through the detector during operation. Comment: This voltage and the biasing circuit should be the same for measurements that are to be compared.

Signal frequency, $\mathbf{f}(\mathbf{H z})$ : The frequency of the optical signal falling on the detector, e.g., from a blackbody with a chopping frequency $\mathrm{f}$. This signal frequency is distinct from the optical frequency of the radiation itself.

Signal voltage (rms), $\mathbf{V}_{\mathbf{s}}$ (V): The component of the electrical output voltage that is coherent with the radiant power. It is a function of $f, T, A_{d}, V_{b}$, and the radiant flux. Comment: The signal voltage is subject to variations in the radiant flux falling on the detector as well as to instrumental variations from one test station to another and to variations in the inherent responsivity of the detector.

Noise voltage (rms), $V_{n}(V)$ : The component of the electrical output voltage that is incoherent with radiant power. It is a function of $A_{d}$ and $f$. The value is determined with signal power removed for a given bandwidth in frequency, $\Delta \mathrm{f}$. Comment: This noise should only be associated with the detector itself and not with the amplifier or other electronic components. Because of the need to amplify the noise voltage prior to measurement, a correction for amplifier noise is typically necessary.

Blackbody responsivity, $R_{b b}(V / W)$ : Ratio of $V_{s}$ to rms value of chopped power of blackbodyradiation falling on the active detector area. This ratio is a function of $f, T, A_{d}$, and $V_{b}$. Comment: The responsivity is more reliable than the signal voltage as a measure of detector sensitivity because it is normalized to the wattage from the blackbody falling on the active detector area. However, it is subject to measurement errors associated with the optical components of the test station between the blackbody and the detector itself. It should not depend on any electronic component, such as the amplifier, that comes after the detector in the measurement system.

Blackbody D-star, $\mathrm{D}^{*}\left(\mathrm{~cm} \mathrm{~Hz}^{1 / 2} / \mathrm{W}\right)$ : A normalization of blackbody responsivity to take into account detector area and noise bandwidth. For a given blackbody temperature $\left(T_{b b}\right)$, $T$, and $f$, $\mathrm{D}^{*}=\left(\mathrm{R}_{\mathrm{bb}} / N_{\mathrm{n}}\right)^{*}\left(\mathrm{~A}_{\mathrm{d}} \Delta \mathrm{f}\right)^{1 / 2}$. Comment: This relation holds for most detectors because many noise sources internal to a detector vary as $\left(\Delta f / A_{d}\right)^{1 / 2}$ and $R_{b b}$ varies as $1 / A_{d}$. For most detectors, this normalization implies that $V_{n} / R_{b b}$ is proportional to $\left(A_{d} \Delta f\right)^{1 / 2}$. However, this normalization is not valid for amplifier noise, which must not be included in the noise measurement. The quantity $\mathrm{D}^{*}$ is a figure of merit for a detector and can be compared with the background-limit value based on photon noise associated with a blackbody at temperature $T_{B}$.

Time constant, $\tau(s)$ : A measure of the detector's speed of response, $\tau=1 /\left(2 \pi f_{c}\right)$, where $f_{c}$ is the chopping frequency at which the responsivity has fallen to $(1 / 2)^{1 / 2}$ of its maximum value. This parameter is based on the responsivity dependence $R(f)=R(0) /\left(1+4 \pi^{2} f^{2} \tau^{2}\right)^{1 / 2}$, which holds for many detectors. Comment: An alternative and more accurate way to measure $\tau$ is from the signal decay after a short light pulse. This quantity determines the upper limit of $\mathrm{f}$ that can be used before the responsivity degrades significantly with chopping frequency.

Sweepout: A relatively high applied electric field across a detector which can cause the photoexcited minority carriers to be swept to a contact where they recombine. This effect causes 
the responsivity to reach a maximum value with increasing field because of a cancellation between the normal increase in responsivity due to field and the decrease in responsivity due to carrier drift. It only occurs in extrinsic material, because the ambipolar mobility is zero in intrinsic material.

Related Concerns: The detector data contained in this report are affected by other measurement uncertainties. The temperature of the detector was not always measured directly. A linear correction was employed to adjust the signal and resistance values for the approximately 8- $\mathrm{K}$ difference between the cold finger and detector. This difference was measured on at least one sample and is expected to be nearly the same for all the ITT measurements. The responsivities were not always determined. Thus, NIST has used the signal data instead, with the assumption that the radiation wattage falling on the detectors was always the same. The noise measurements could not be used because they contained a non-negligible amount of amplifier noise. The values for $D^{*}$ were thus not useful either. Time-constant measurements were not usually made, and thus they were not included in this analysis.

\section{F. Signal Measurement Circuit Analvsis}

The bias circuit for the detector measurements shown in figure 3.1 drives a constant current $\mathrm{I}_{\mathrm{B}}$ through the detector by placing a voltage source in series with a load resistor across the device. The load resistance must be much greater than the overall detector resistance $R_{t}$. including contact resistance, where

$$
R_{t}=R_{c}+\left[\frac{1}{R_{m}}+\frac{1}{R_{d}}+\frac{1}{R_{p}}\right]^{-1},
$$

and where $R_{c}$ is the contact resistance, $R_{m}$ is the resistance of the ion-milled region, $R_{d}$ is the bulk $\mathrm{HgCdTe}$ resistance, and $\mathrm{R}_{\mathrm{p}}$ is the resistance of the passivated regions of the detector.

$R_{\mathrm{d}}$ is the resistance of the bulk inner active detector region and will be considered to be constant. It can change if the physical sizes of the ion-milled or passivated surface-layer regions change. Dimensional changes are accounted for by adjusting the resistance values $R_{m}$ and $R_{p}$; as evident in eq (3.3b), this procedure leads to equivalent results because only the sum of the conductances matters.

$R_{m}$ may decrease in time as mercury interstitials annihilate mercury vacancies. It is generally comparable to or higher than the value of $R_{d} \cdot R_{p}$ is also comparable to or higher than $R_{d}$. $R_{p}$ can increase or decrease in time if the passivation layer changes. This could cause a change in $\Delta G_{\mathrm{d}}=\Delta\left(1 / \mathrm{R}_{\mathrm{d}}\right)$ for a given optical signal because a reduction of effective recombination lifetime, $\tau$, in the bulk of the detector may occur.

The equivalent bias circuit is given by a current source in series with the device, which provides the bias current $I_{B}$. The signal voltage $V_{S}$ is given by: 


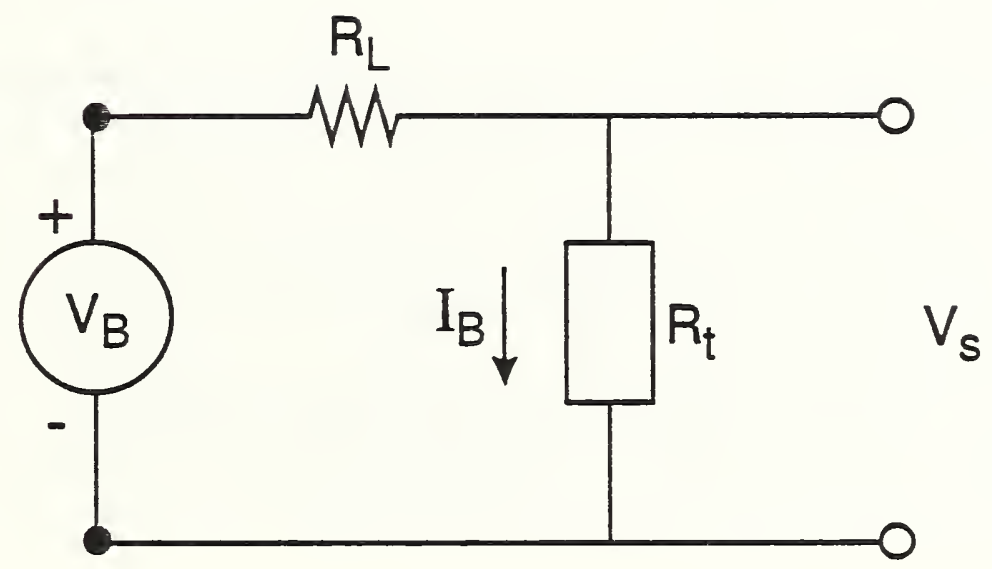

Figure 3.1 Equivalent measurement circuit for detectors. $V_{B}$ is the bias voltage; $I_{B}$, the bias current; $R_{L}$, the load resistance; $R_{t}$, the total detector resistance, and $V_{s}$, the signal voltage. 


$$
V_{s}=V_{s c}\left(R_{c}\right)+V_{s d}\left(R_{m}, R_{d} R_{p}\right)
$$

where $V_{s c}\left(R_{c}\right)$ is an unknown function of the photovoltaic and photoconductive responses of the contacts, which can depend on $R_{c}$ and $I_{B}$.

The actual detector signal $\mathrm{V}_{\mathrm{sd}}$ is given by:

$$
\begin{aligned}
V_{s d} & =I_{b}\left[\frac{1}{G_{d}+G_{m}+G_{p}}-\frac{1}{G_{d o}+G_{m o}+G_{p o}}\right] \\
& =-I_{B}\left[\frac{\Delta G_{d}+\Delta G_{m}+\Delta G_{p}}{\left(G_{d o}+G_{m o}+G_{p o}\right)^{2}}\right]
\end{aligned}
$$

where the subscript "o" denotes unilluminated and the quantity $G$ denotes conductances. The changes $\Delta G_{m}$ and $\Delta G_{p}$ are expected to be small because these regions have higher electron densities.

Thus, the percent signal decrease associated with a reduction in detector resistance is given by:

$$
\frac{V_{s 2}-V_{s I}}{V_{s I}}=\frac{\left(G_{d o}+G_{m o}+G_{p 0}\right)_{2}^{-2}-\left(G_{d o}+G_{m o}+G_{p o}\right)_{1}^{-2}}{\left(G_{d o}+G_{m o}+G_{p o}\right)_{1}^{-2}},
$$

where 1 and 2 designate two different times, if the contact-generated signal is neglected, $\tau$ is constant, and carrier sweepout is negligible. The quantity $\left(\mathrm{G}_{\mathrm{do}}+\mathrm{G}_{\mathrm{mo}}+\mathrm{G}_{\mathrm{po}}\right)$ can be determined from the total detector conductance $G_{\text {to }}$ and if $G_{c o}$ can be estimated, the conductance of the contacts:

$$
G_{t o}=\left[\frac{1}{G_{c o}}+\frac{1}{G_{d o}+G_{m o}+G_{p o}}\right]^{-1} .
$$

This model shows that any decrease in the resistance of the responsive area of a detector (i.e., excluding contacts) must result in a corresponding decrease of the signal.

\section{G. Summary of Measurement Issues Covered}

This section summarizes the various measurement issues such as stray reflections or "glint," temperature uncertainty, photosensitive contacts, and circuit effects. 


\section{SUMMARY OF AVAILABLE DATA}

This section presents the data that NIST has obtained from ITT for analysis to determine whether the detectors have demonstrated degradation or instability. Comparable data on similar detectors are also presented.

\section{A. GOES Detectors}

The GOES satellite uses a number of $\mathrm{HgCdTe}$ detectors, three in the Imager instrument and eight in the Sounder. The actual number of detectors developed was much larger because of the numerous prototypes and qualification units. Table 4.1 identifies the type of Imager detectors, and table 4.2 identifies the types of Sounder detectors produced for the GOES Program that have been delivered to ITT [4.1]. Both tables show the detector serial numbers, the type of detector, and whether the detector is in the Flight I instrument [designated by flight (FLT) I status under the Instrument column]. The designation EX FLT I (1) or (2) means that these detectors were previously designated as FLT I detectors, but were replaced (EX FLT I (1) was the first flight detector to be replaced, and EX FLT I (2), the second one to be replaced). The designation DPA means that those detectors could be used for destructive physical analysis (DPA) and QUAL implies a qualified unit.

Table 4.1 also summarizes the initial status of the Imager detector parameters measured at $105 \mathrm{~K}$. These parameter values are listed as supplied to NIST, i.e., with no uncertainty specified. All values listed are average values for either the two-element $(7-\mu \mathrm{m}$ series $)$ or the four-element (11- and $12-\mu \mathrm{m}$ series) arrays. All of the $11-$ and $12-\mu \mathrm{m}$ detectors came from the same wafer (P3948-33), except for 12-112 which was obtained from a separate wafer, P3968-37. The series number identifies the wavelength range for which the detector is optimized (see table 1.1). The location of each detector on HgCdTe wafer P3948-33 is specified by the wafer map shown in figure 4.1. This map is important because it shows if any problem detectors originated from the same wafer region or if other patterns might exist that would be helpful in analyzing the detector behavior.

\section{B. Measurement Results on Imager Detectors}

In order to establish whether degradation of the detectors has occurred or is occurring, sufficiently accurate measurements of detector parameters must have been made at various times and recorded in a database. ITT has maintained records of all the detector measurements taken on the detectors in such a database. NIST extracted from this database only the data for the resistances and the signals. Although the database contains no uncertainity estimates, these were considered by NIST to be the most reliable data. NIST has serious concerns about the noise measurements having been preamplifier limited, and thus they would be questionable to use in an analysis of the data. Since the detectivity involves the noise, it also is questionable to use. The detector signal is a more direct measurement than the responsivity, and values of the signal have always been recorded by ITT in their database. Consequently, NIST chose to analyze signals rather than responsivities.

Appendix B shows the reported resistances of each detector element at room temperature for all available detectors [4.1]. These resistances were determined with a low current ohmmeter. The detectors are identified by their serial numbers. Also shown are the individual cross-sectional 


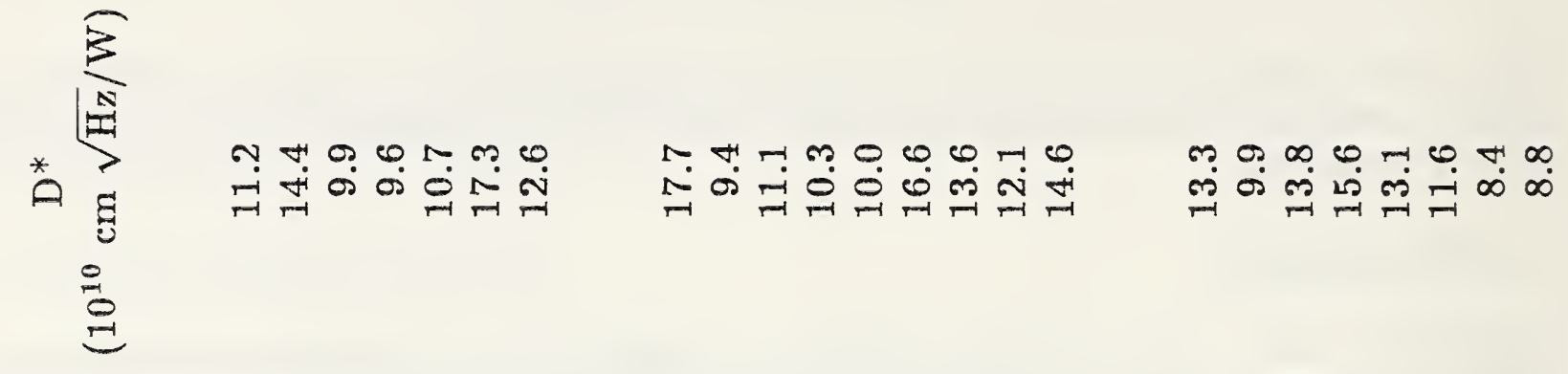

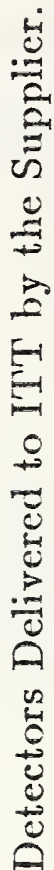

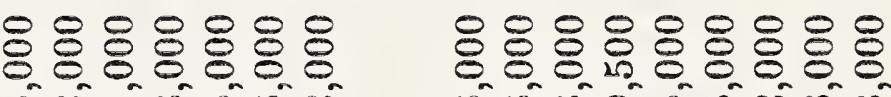

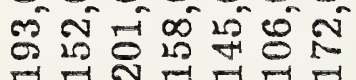

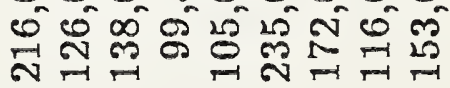

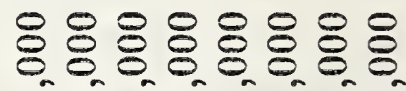

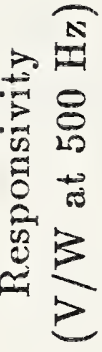
กิ่

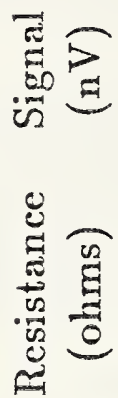

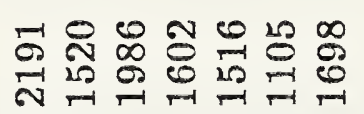

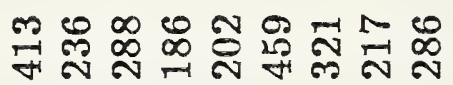

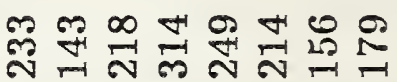

\#. ปี่

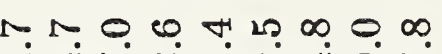
$0 . \forall \infty \forall, \forall n$

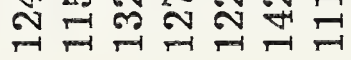
सं ऊँ 阔

苞

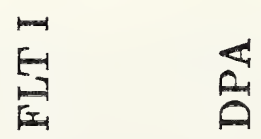

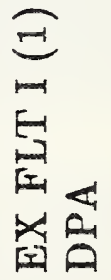

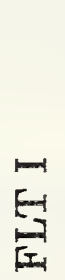

吾会

G

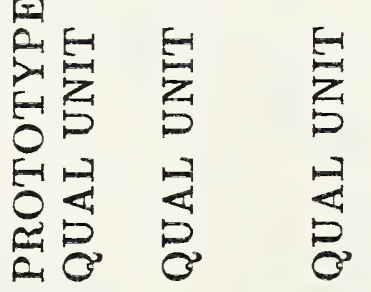

*

ㄱํㅇ จ ซํำ NN

HNanghen

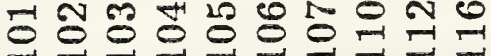

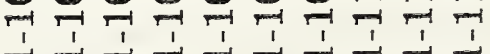

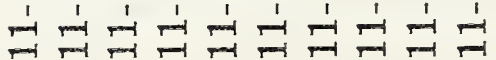

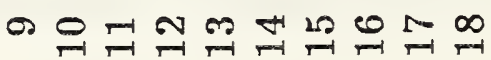



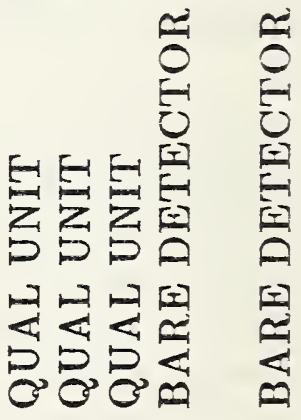

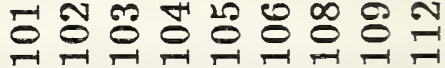

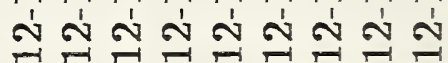
응ํำ 
Table 4.2 Sounder Detectors Delivered to ITT by the Supplier.

\begin{tabular}{|c|c|c|}
\hline Serial \# & Type & Instrument \\
\hline \multicolumn{3}{|l|}{ MW-1 } \\
\hline MW-2 & & FLT I \\
\hline MW-3 & & FLT I \\
\hline MW-4 & & FLT I \\
\hline MW-5 & PROTOTYPE & \\
\hline MW-6 & PROTOTYPE & \\
\hline MW-7 & PROTOTYPE & \\
\hline MW-9 & PROTOTYPE & \\
\hline MW-10 & PROTOTYPE & \\
\hline MW-11 & PROTOTYPE & \\
\hline MW-12 & PROTOTYPE & \\
\hline MW-13 & PROTOTYPE & \\
\hline \multicolumn{3}{|l|}{ MW-14 } \\
\hline MW-15 & PROTOTYPE & \\
\hline \multicolumn{3}{|l|}{ MW-16 } \\
\hline \multicolumn{3}{|l|}{ MW-20 } \\
\hline MW-22 & QUAL UNIT & DPA \\
\hline MW-23 & & FLT I \\
\hline MW-25 & & EX FLT I (1) \\
\hline MW-26 & QUAL UNIT & \\
\hline MW-35 & QUAL UNIT & \\
\hline LW-3 & PROTOTYPE & \\
\hline \multicolumn{3}{|l|}{ LW-4 } \\
\hline LW-5 & PROTOTYPE & \\
\hline LW-6 & & FLT I \\
\hline LW-8 & PROTOTYPE & \\
\hline LW-11 & PROTOTYPE & \\
\hline LW-13 & & FLT I \\
\hline \multicolumn{3}{|l|}{ LW-15 } \\
\hline LW-18 & PROTOTYPE & \\
\hline LW-19 & QUAL UNIT & DPA \\
\hline LW-20 & & FLT I \\
\hline LW-22 & & FLT I \\
\hline LW-23 & QUAL UNIT & \\
\hline LW-26 & QUAL UNIT & \\
\hline \multicolumn{3}{|l|}{ LW-27 } \\
\hline \multicolumn{3}{|l|}{ LW-30 } \\
\hline LW-40 & PROTOTYPE & \\
\hline LW-42 & PROTOTYPE & \\
\hline LW-44 & PROTOTYPE & \\
\hline LW-47 & PROTOTYPE & \\
\hline
\end{tabular}




\section{HgCdTe DETECTOR \\ Wafer Map (P3948-33)}

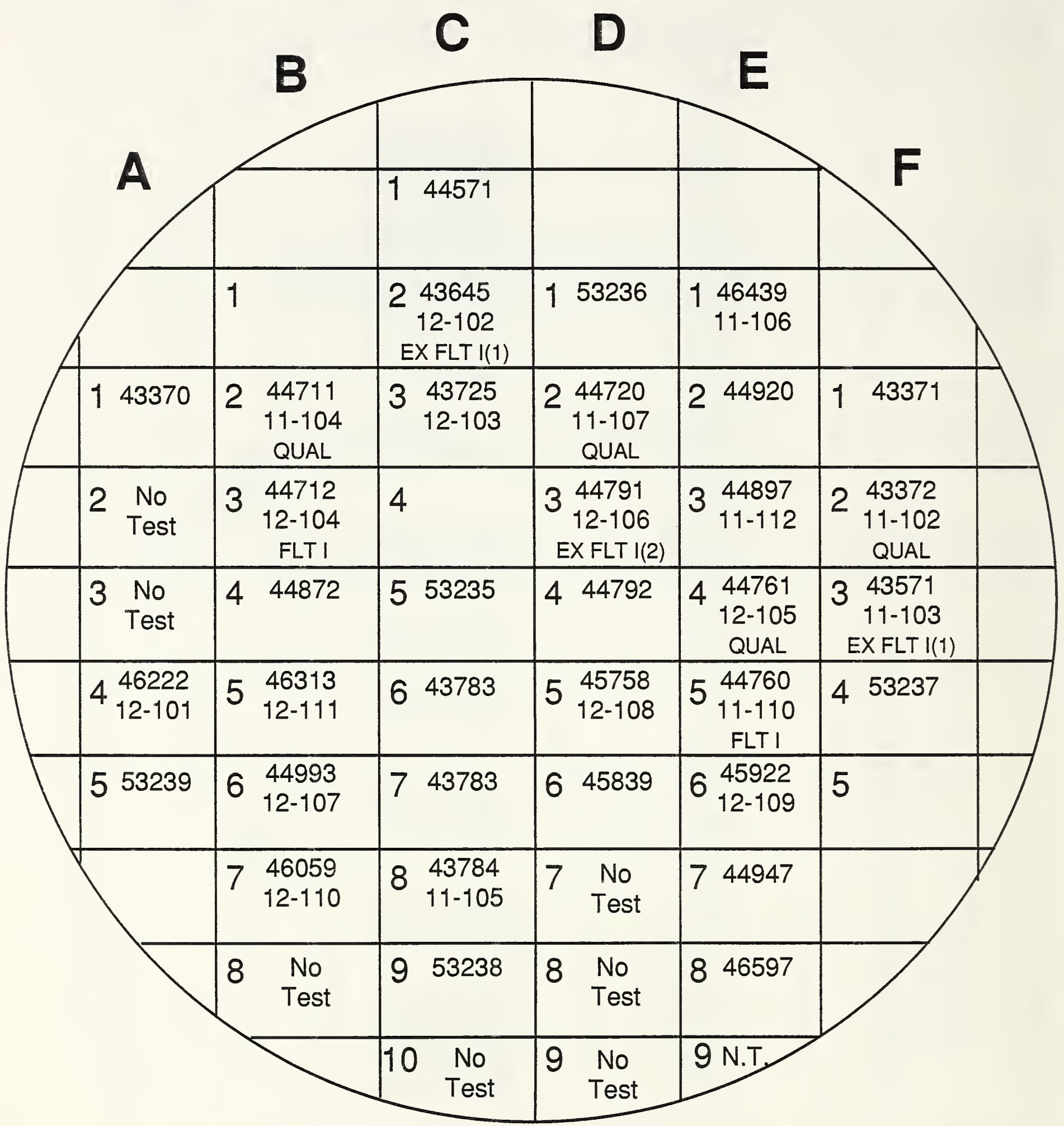

Figure 4.1 Wafer map of the $11-$ and $12-\mu \mathrm{m}$ detectors showing the placement of the various detectors. 
areas of the active regions of the detector elements as determined by scans of a blackbody light source. The dates and times of the room temperature resistance values are also shown. Typically, two or three measurements were made at room temperature and recorded over a period of about one year.

Appendix $\mathrm{C}$ shows the reported resistances and the signals of each detector element at a temperature of $105 \mathrm{~K}$ as a function of date and time [4.1]. The "*" in the left-hand column indicates that the resistance and signal measurements taken at ITT were corrected for the fact they were about 8 degrees above $105 \mathrm{~K}$, and so the results shown in appendix $\mathrm{C}$ are estimated values. Because of this temperature uncertainty, these ITT results are presumed by NIST to be less accurate than those of the supplier. The bias currents used for each element to obtain the recorded signal levels are also shown.

In the section on analysis of available data (sec. 5A), NIST uses the results given in appendices B and $C$ in analysis of the data.

\section{Published Data on Similar Types of Detectors}

Photoconductivity detector technology for the $\mathrm{HgCdTe}$ materials system has been extensively studied for over two decades, largely driven by defense applications. Military specifications on detector performance and reliability have been met. In this section, NIST summarizes published results on the uniformity and bake stability of $0.1-\mathrm{eV} \mathrm{HgCdTe}$ photoconductivity detectors having a spectral cut-off wavelength of $12.5 \mu \mathrm{m}$ at $77 \mathrm{~K}$ [4.2].

Figure 4.2 shows, at $77 \mathrm{~K}$, the degree of uniformity typically achievable in a 20-element array of detectors having an active area of $55-\mu \mathrm{m}$ by $55-\mu \mathrm{m}$ for an ambient background flux [4.2].

Variations in detector resistances are around \pm 5 to $10 \%$, while the detectivities vary by $\pm 25 \%$. This degree of uniformity also seems to be achievable as shown by some recent data [4.3]. Cryoprobe performance data for the ten best four-element arrays for the longwave Sounder at $102 \mathrm{~K}$ showed:

$$
\begin{aligned}
& \text { resistance }=40.1 \Omega \pm 16.3 \% \text { standard deviation } \\
& \text { responsivity }=20.9 \mathrm{kV} / \mathrm{W} \pm 25.8 \% \text { standard deviation } \\
& \text { detectivity }=9.1 \times 10^{9} \mathrm{~cm} \mathrm{~Hz} \mathrm{~Hz} \mathrm{~Hz}^{1 / 2} \mathrm{~W}^{-1} \pm 21.4 \% \text { standard deviation. }
\end{aligned}
$$

Published vacuum bakeability of $0.1-\mathrm{eV} \mathrm{HgCdTe}$ devices is summarized in table 4.3 [4.2]. The resistance, responsivity at a bias voltage of $0.15 \mathrm{~V}$, and $\mathrm{D}^{*}$ values are listed and compared for various bake-out conditions for three separate 20-element arrays having detector active areas of 55 by $55 \mu \mathrm{m}$. The degree of $1 / \mathrm{f}$ noise present is indicated by the $\mathrm{D}^{*}$ measurements at chopping frequencies of $400 \mathrm{~Hz}, 1 \mathrm{kHz}$, and $4 \mathrm{kHz}$. The initial device data taken immediately after fabrication are shown in the first column, the second column shows results of measurements taken after a period of baking at $368 \mathrm{~K}$ for three days, and the third column after a further seven days' baking at $398 \mathrm{~K}$. Slight increases in resistances are observed, along with a slight increase in $1 / \mathrm{f}$ noise indicated by a decrease in $\mathrm{D}^{*}$ measured at $400 \mathrm{~Hz}$. Thus, there is little or no change in the vital detector parameters.

In summary, NIST has considered the various measurement uncertainties and chosen to examine the resistances and signals (normalized to constant current) of the $7-\mu \mathrm{m}, 11-\mu \mathrm{m}$, and $12-\mu \mathrm{m}$ detectors because NIST believes these data are the most consistent and trustworthy. NIST notes that room-temperature resistance values are very useful as well. 


\section{Array Uniformity}
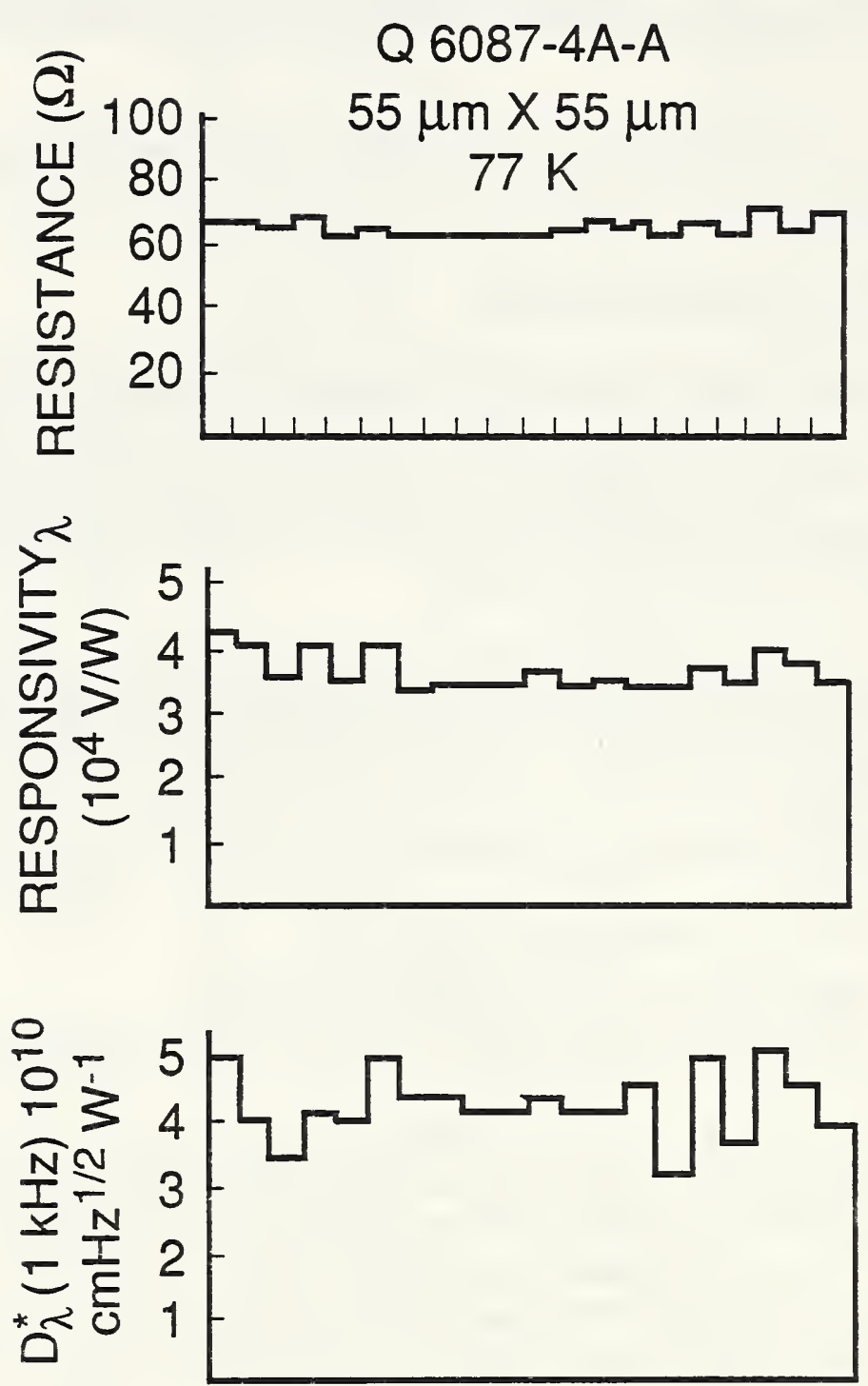

Figure 4.2 Degree of uniformity, at $77 \mathrm{~K}$, typically achievable in a 20 -element array of $55-\mu \mathrm{m}$ by $55-\mu \mathrm{m}$ active area detectors for an ambient background flux [4.2]. 
Table 4.3 Vacuum Bake Data, Array Size: 55 by $55 \mu \mathrm{m} ; 20$ Elements; $77 \mathrm{~K}$.<smiles>C=[14C][14CH2]O</smiles>

Resistance $(\Omega)$

Responsivity $(0.15 \mathrm{~V})(\mathrm{V} / \mathrm{W})$

$D_{b b}^{*}(400 \mathrm{~Hz}) \mathrm{cm} \mathrm{Hz}^{1 / 2} \mathrm{~W}^{-1}$

$D_{b b}^{*}(1 \mathrm{kHz})$

$D_{b b}^{*}(4 \mathrm{kHz})$

Q 2015-2B-B

Resistance $(\Omega)$

Responsivity $(0.15 \mathrm{~V})(\mathrm{V} / \mathrm{W})$

$D_{b b}^{*}(400 \mathrm{~Hz}) \mathrm{cm} \mathrm{Hz}^{1 / 2} \mathrm{~W}^{-1}$

$D_{b b}^{*}(1 \mathrm{kHz})$

$D_{b b}^{*}(4 \mathrm{kHz})$

Q 2015-2B-A

Resistance $(\Omega)$

Responsivity $(0.15 \mathrm{~V})(\mathrm{V} / \mathrm{W})$

$D_{b b}^{*}(400 \mathrm{~Hz}) \mathrm{cm} \mathrm{Hz}^{1 / 2} \mathrm{~W}^{-1}$

$D_{b b}^{*}(1 \mathrm{kHz})$

$D_{b b}^{*}(4 \mathrm{kHz})$
$368 \mathrm{~K}$

Initial

60

$2.4 \times 10^{4}$

$2.3 \times 10^{10}$

$2.5 \times 10^{10}$

$2.8 \times 10^{10}$

67

$3.0 \times 10^{4}$

$2.8 \times 10^{10}$

$3.3 \times 10^{10}$

$3.5 \times 10^{10}$

48

$2.4 \times 10^{4}$

$2.7 \times 10^{10}$

$2.8 \times 10^{10}$

$2.8 \times 10^{10}$
3 days

63

$2.2 \times 10^{4}$

$1.7 \times 10^{10}$

$2.2 \times 10^{10}$

$2.7 \times 10^{10}$

3 days

77

$2.6 \times 10^{4}$

$2.3 \times 10^{10}$

$2.7 \times 10^{10}$

$2.8 \times 10^{10}$

2 days

49

$2.2 \times 10^{4}$

$2.3 \times 10^{10}$

$2.7 \times 10^{10}$

$2.8 \times 10^{10}$
$398 \mathrm{~K}$

7 days

65

$2.4 \times 10^{4}$

$1.7 \times 10^{10}$

$2.3 \times 10^{10}$

$2.5 \times 10^{10}$

76

$2.5 \times 10^{4}$

$2.0 \times 10^{10}$

$2.5 \times 10^{10}$

$3.0 \times 10^{10}$ 


\section{ANALYSIS OF AVAILABLE DATA}

This section analyzes the resistance and signal data for the $7-\mu \mathrm{m}, 11-\mu \mathrm{m}$, and $12-\mu \mathrm{m}$ detectors. Both a qualitative evaluation based on error criteria and a quantitative statistical analysis have been performed.

\section{A. Qualitative Evaluation}

Before discussing the evaluation of the data, NIST had to establish the criteria for error. The data were measured outside of NIST, and thus NIST had to rely to a degree on the uncertainties specified by those who did the measurements. The resistance measurements were mostly made by the supplier, and their estimate of the uncertainty was $\pm 5 \%$. Similarly, their estimate for signal repeatability was $\pm 10 \%$. NIST has used these estimates to evaluate the variations observed in the data. There is the further complication that prior to September 1990 , there could have been greater optical signals illuminating the detector because of reflections from the wall of the tube connecting the blackbody with the detector. This so-called glint problem was removed with a series of baffles in the tube after that date. Thus, signals could be higher by up to $25 \%$ prior to September 1990 when compared with signals measured after that date.

The figures shown in appendix $\mathrm{D}$ display the resistance and signal as a function time: at the time the detectors were first measured and then at subsequent times until the present. The signal values have been normalized to a constant current of $1 \mathrm{~mA}$. NIST has compared corresponding elements of different detectors because an element in a given location on one detector should have experienced similar processing as corresponding elements in other detectors. NIST has only considered the overall trends in the data and, except for specific comments below, does not discuss the occassional jumps in the data. This analysis is similar to that performed in appendix $A$, an interim report that showed detector degradation or instability for selected detectors.

The $7-\mu \mathrm{m}$ detectors were generally stable, both in resistance and signal. Close examination of the data for the $7-\mu \mathrm{m}$ detectors shows a possible gradual increase in resistance with time for some of the detectors, although it is comparable to the measurement error and thus may not be significant. The signals have remained relatively stable. Any decrease in signal with time may be explained on the basis of random error or the glint problem.

The resistance values of the $11-\mu \mathrm{m}$ detectors have remained relatively stable except for that of Detector $11-105$, which decreased by about $26 \%$ for element $A$. This detector element had a large resistance initially, $102 \Omega$, which subsequently decreased to $73 \Omega$. Similar percentage decreases are observed for the other elements as well, although their resistances are generally smaller. A signal decrease of $54 \%$ occurred for element $A$, with similar decreases for the other elements. Note that the percentage decrease in signal is approximately twice the percentage decrease of the resistance, which could imply that the resistance of optically active regions is accounting for the decrease in overall detector resistances (eq (3.4)) if no glint effect has occurred. The other detectors have remained relatively stable in signal except for some low values measured at ITT. It is possible that these low values may have been associated with undocumented measurement uncertainties during the establishment of their test setup. The overall signal level is more than an order of magnitude lower for the $11-\mu \mathrm{m}$ detectors than for the $7-\mu \mathrm{m}$ detectors, and the spread in signal level among the detectors is much greater. For the $7-\mu \mathrm{m}$ detectors, the average signal level is about $25 \mathrm{mV} / \mathrm{A}$ with a maximum spread of about $\pm 32 \%$; for 
the $11-\mu \mathrm{m}$ detectors, the average signal level is about $1.5 \mathrm{mV} / \mathrm{A}$ with a maximum spread of $\pm 65 \%$.

The resistances of the $12-\mu \mathrm{m}$ detectors decrease with time except for those with the lowest values, 12-109 and 12-102, which are relatively stable. The signal levels of Detectors 12-104, 12-105, and 12-109 were not measured for a long enough period of time for any assessment to be made.

Detector 12-102 appears to have suffered a decrease in signal over almost two years that is a little greater than can be accounted for by random error or glint. Element A decreased by $42 \%$, element $\mathrm{B}$ by $39 \%$, element $\mathrm{C}$ by $35 \%$, and element $\mathrm{D}$ by $35 \%$. Detector $12-103$ decreased sharply in signal in less than a year by $74 \%$ for element $A, 73 \%$ for element $B, 73 \%$ for element $\mathrm{C}$, and $72 \%$ for element $\mathrm{D}$. There are no subsequent measurements made after this marked decrease was discovered, and the detector was subjected to destructive testing. This large decrease is much greater than expected from the 10 to $20 \%$ decrease observed in the resistance values for these elements. NIST cannot assess whether 12-106 was stable in signal because the last point, which shows a signal decrease, may have been too low due to undocumented measurement errors.

Note that the $12-\mu \mathrm{m}$ detectors generally have even lower signal levels than the $11-\mu \mathrm{m}$ ones, but show much less variability in signal level from detector to detector. Detectors 12-108 and 12-112 were never provided with an aplanat lens. Detector $12-108$ shows a signal decrease of $48 \%$ for element A, $48 \%$ for element B, $51 \%$ for element $C$, and $55 \%$ for element $\mathrm{D}$, which is greater than could be accounted for by random error or glint. Detector 12-112 shows a large signal instability, $-66 \%$ to $+15 \%$ for element $\mathrm{A}$, for which NIST has no explanation. The other elements show nearly identical variations. This instability is not seen in the resistance, which shows a continual drop in value from 95 to $82 \Omega$ for element $A$ and similar drops for the other elements. The resistance variations and signal variations do not appear to be correlated for the $12-\mu \mathrm{m}$ detectors.

\section{Room-Temperature Resistance}

The comparison of the resistances of the detectors at room temperature with theoretical calculations of the resistance of the active-area region of the detectors suggests that the contact resistance is probably large in many of the $11-\mu \mathrm{m}$ and $12-\mu \mathrm{m}$ detectors. At room temperature, the detectors are all intrinsic with intrinsic carrier density, $\mathrm{n}_{\mathrm{j}}$, equal to $2.8,2.4$, and $1.8 \times 10^{16}$ $\mathrm{cm}^{-3}$ for $\mathrm{x}=0.200,0.207$, and 0.220 , respectively. The corresponding room temperature mobilities are 1.0, 0.9 , and $0.8 \times 10^{4} \mathrm{~cm}^{2} / \mathrm{Vs}$, which are dominated by phonon scattering. Thus, the theoretical resistance values of the bulk active region of the detectors are 26 and $34 \Omega$ for $\mathrm{x}=0.200$ and 0.207 , respectively. It is not possible to compute the value for the 7 - $\mu \mathrm{m}$ detectors because they have extended contacts. The ion-milled and passivation layers do not contribute significantly to the detector resistance at room temperature because they have a much larger resistance. Therefore, the detector resistance should be approximately equal to $34 \Omega$ for the $11-\mu \mathrm{m}$ detectors and $26 \Omega$ for the $12-\mu \mathrm{m}$ detectors. Much larger measured values are presumably due to contact resistance.

The histograms of the resistances of the $11-$ and $12-\mu \mathrm{m}$ detectors shown in figures 5.1 and 5.2 show that many detectors have values that are much larger than the theoretical values. Because the theoretical values correspond well with the lowest measured values, it is assumed that these detectors have low contact resistance. A high contact resistance is significant because it can contribute to excess noise and optically active contact areas. 


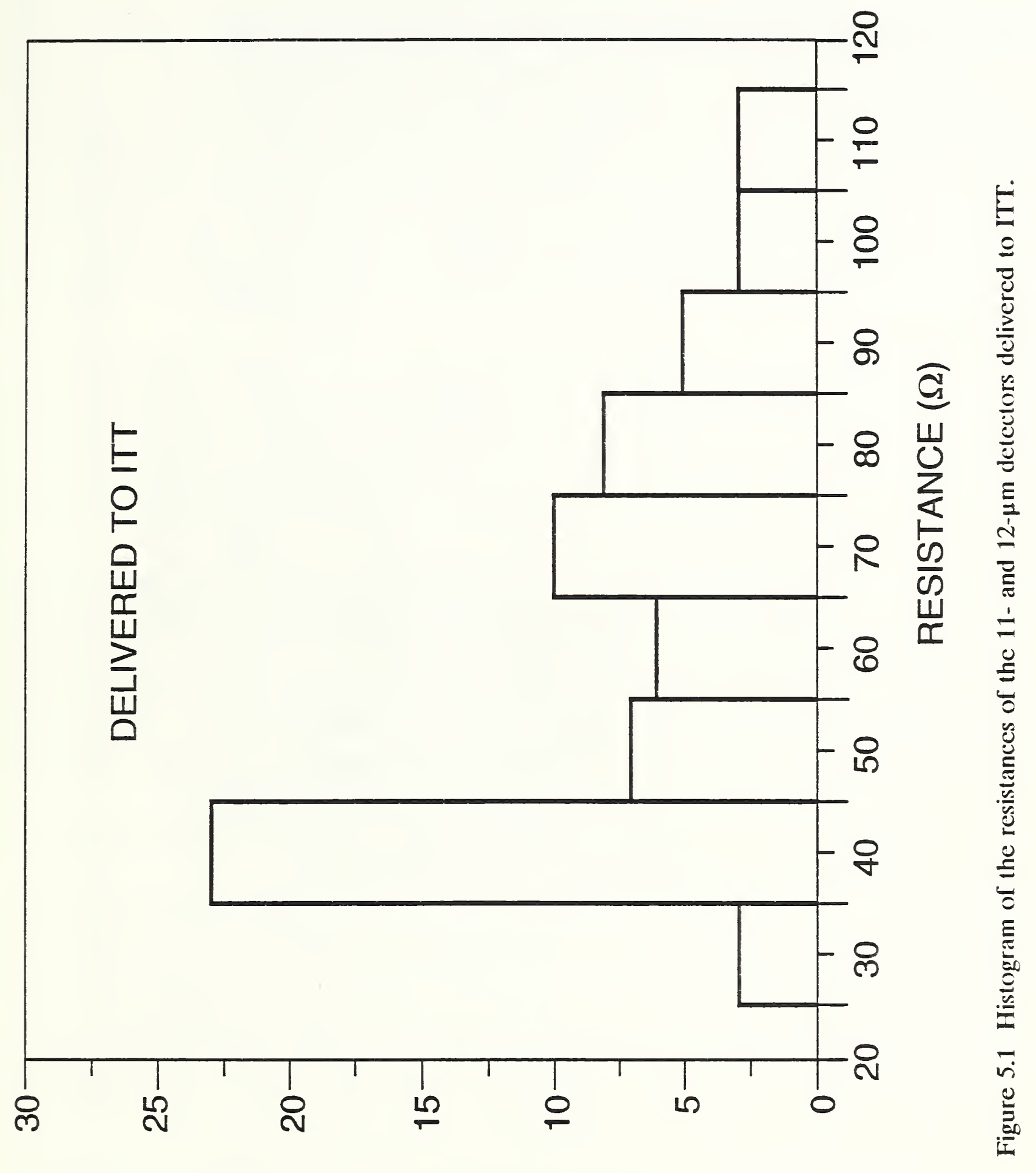

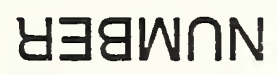




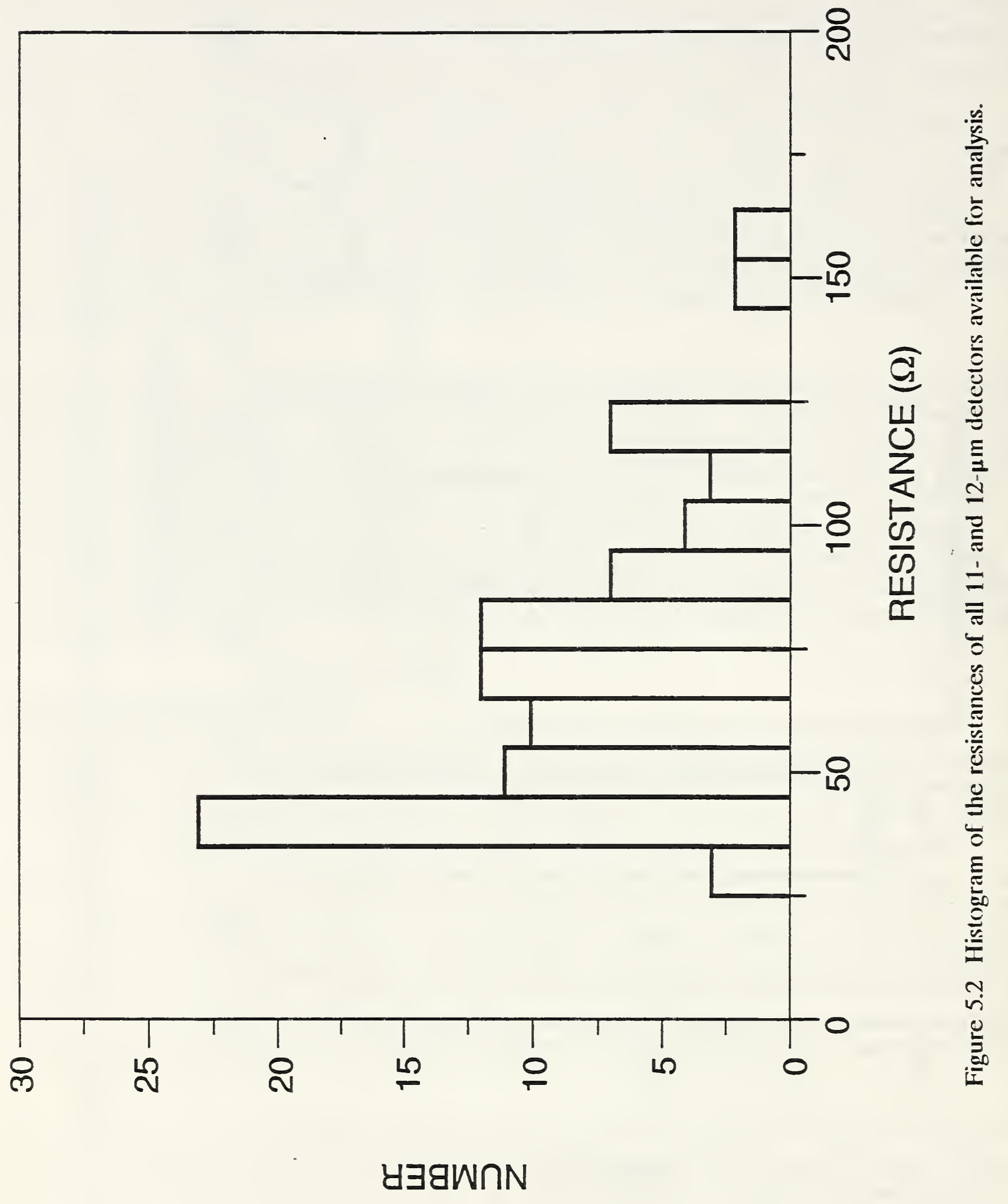


Current-voltage measurements of Detector 12-111, which was never given an aplanat lens, were made at NIST: The dependence of current on voltage for elements $B$ and $D$ were shown to be linear to within a few percent from 0 to $\pm 1 \mathrm{~mA}$ at both 300 and $77 \mathrm{~K}$. This detector has roomtemperature values of resistance of $57 \Omega$ for $B$ and $72 \Omega$ for $D( \pm 5 \%)$, which are very high. Therefore, the contact resistance is probably high for this detector. Subsequent visual and SEM inspection has shown the contacts to have many voids, a condition consistent with high contact resistance. The values measured at NIST in September 1991 were a little less than those measured by the manufacturer on June 9,1989 : B was $58 \Omega$; D was $78 \Omega$. Thus, the contact resistance may have decreased in the two years between measurements, but without knowing the uncertainty of the original measurements, one cannot draw an unambiguous conclusion. The data measured by the manufacturer at $105 \mathrm{~K}$ and by NIST at $77 \mathrm{~K}$ showed that the low-temperature resistance values were high as well: $\mathrm{B}$ was $94 \Omega$ at $77 \mathrm{~K}$ and $94 \Omega$ at $105 \mathrm{~K}$; D was $107 \Omega$ at $77 \mathrm{~K}$ and $118 \Omega$ at $105 \mathrm{~K}$. Thus, there is a correlation between relatively high values of resistance at 300 and $105 \mathrm{~K}$. This correlation is also evident in all the $11-$ and $12-\mu \mathrm{m}$ detectors for which room temperature and $105-\mathrm{K}$ data exist.

It is interesting to inspect the wafer map that shows the locations of the $11-$ and $12-\mu \mathrm{m}$ detectors. The initial resistances of the detectors at 300 and $105 \mathrm{~K}$ are given in figure 5.3. The 105-K values are the top numbers. It is seen that large values at room temperature correlate with large values at $105 \mathrm{~K}$, and NIST expects the larger values to be associated with poor contact metallization. The values for detectors near the perimeter of the wafer are mostly lower than those in the interior, which may suggest better metallization near the perimeter.

NIST compared the resistance of Detector 12-102 measured (1) at room temperature initially at the supplier and (2) on September 18, 1991, at ITT with values measured (3) at $105^{\circ} \mathrm{K}$ initially at the supplier and (4) on June 12,1991. The room-temperature values ITT measured on September 19, 1991, are: A, 20.0; B, 18.7; C, 20.1; and D, 28.1 $\Omega$. Elements A, B, and C have decreased by about $1 \Omega$, while $D$ decreased by about $3 \Omega$ between the initial and final measurements. At $105 \mathrm{~K}$, elements $\mathrm{A}, \mathrm{B}$, and $\mathrm{C}$ also decreased by about $1 \Omega$, while element $\mathrm{D}$ decreased by about $3 \Omega$, in agreement with the room-temperature data. Thus, it appears that the decrease in resistance is a fixed amount and contact related at both temperatures.

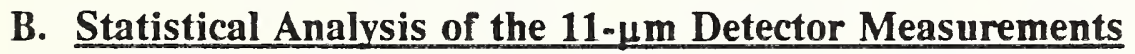

This section presents an analysis of the $11-\mu \mathrm{m}$ measurements that characterizes the measurement error and shows that the apparent degradation cannot all be attributed to measurement error. The analysis consists of three steps. The first step is demonstration that fitting a particular model of the change of signal with time does give residuals with probability properties that appear constant and reasonably attributable to measurement error. The second step is a search for evidence of a difference caused by an August 1990 change in measurement procedure that was instituted to correct the glint problem. The third step is computation of confidence intervals for the rates of decrease of the signals for the various detectors.

The analysis is performed on a subset of the measurements chosen to eliminate differences in error properties caused by differences in detector wavelength, differences in the mounting of the detector, and differences in the company that made the measurements. The subset consists of the post-aplanat measurements made by the supplier on $11-\mu \mathrm{m}$ detectors. The $11-\mu \mathrm{m}$ detectors are the largest group of detectors, and the post-aplanat mounting provides the longest observation times. The measurement considered is the voltage-normalized signal measurement, which is 


\section{Wafer Map of Detector Resistances (ohms) at $\mathrm{T}=105 \mathrm{~K}$ and $\mathrm{T}=300 \mathrm{~K}$ for Wafer P3948-33 (105 $\mathrm{K}$ values are top numbers)}

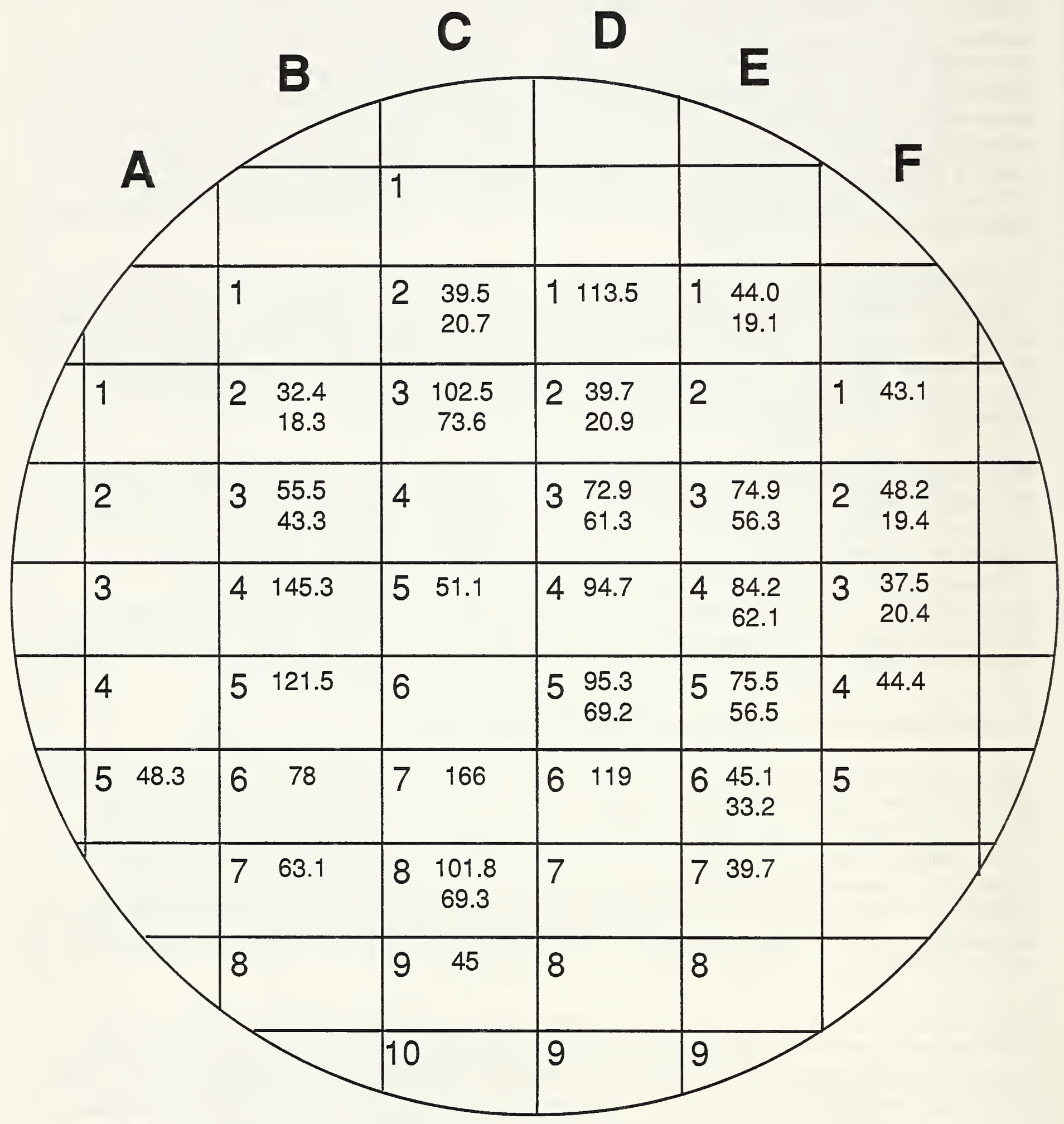

Figure 5.3 Wafer map of the 11 - and $12-\mu \mathrm{m}$ detectors showing the initial $105-\mathrm{K}$ and roomtemperature resistance values. Values were not available for all chips identified in figure 4.1. 
obtained by dividing the measured signal difference by the product of the current setting and the measured resistance.

Characterization of the measurement error requires separation of the error from the on-going changes in the performance of the detectors. To achieve this separation, NIST models the signal $\mathrm{y}_{\mathrm{ji}}$ observed for element $\mathrm{j}$ at time $\mathrm{t}_{\mathrm{ji}}$ by:

$$
\log \left(\mathrm{y}_{\mathrm{ji}}\right)=\alpha_{\mathrm{j}}+\beta_{\mathrm{j}} \mathrm{t}_{\mathrm{ji}}+\epsilon_{\mathrm{ji}}
$$

where $\alpha_{\mathrm{j}}$ and $\beta_{\mathrm{j}}$ describe the physical behavior of element $\mathrm{j}$ and $\epsilon_{\mathrm{ji}}$ is the measurement error. The values of $\alpha_{j}$ and $\beta_{j}$ are different for each of the four elements in each of nine detectors.

Unfortunately, this model has no basis in physical theory. For this reason, the first step is to check the fit of this model to the measurements. If replicate measurements that would provide a model-independent characterization of the measurement error were available, this checking would be easy. Since this is not the case, proceed as follows: From measurements on each element, NIST estimates $\beta_{\mathrm{j}}$ and $\sigma^{2}$, the variance of the measurement error. Let these estimates be given by $b_{j}$ and $s_{j}^{2}$, respectively, and let the degrees of freedom for the variance estimate from element $j$ be $v_{j}$. ( $v_{j}$ is 2 less than the number of measurements on element $j$.) If $\varepsilon_{\mathrm{ji}}$ reflects measurement error alone, then $\sigma^{2}$ will not depend on $\mathrm{j}$, and the variation in $\mathrm{s}_{\mathrm{j}}{ }^{2}$ will be due only to the randomness of the error. Moreover, if the error is normally distributed, $b_{j}$ is independent of $s_{j}{ }^{2}$. We sort the sequence $\left\{v_{j} s_{j}^{2}\right\}$ in order of increasing $b_{j} . \quad\left(v_{j} s_{j}^{2}\right.$ is the sum of squared residuals for element j.) Let the sorted sequence be denoted $\left\{v_{(j)} s_{(j)}\right\}$ and the corresponding sorted sequence of $v_{j}$ 's be $\left\{v_{(j)}\right\}$. To check the model, we plot the cumulative sum of squares

$\Sigma_{j=1}^{k} v_{(j)} s_{(j)}^{2}$ versus the cumulative degrees of freedom $\Sigma_{j=1}^{k} v_{(j)}$. Each point on the plot corresponds to a value of $\mathrm{k}$, which increases as more elements are included in the sums. If $\varepsilon_{\mathrm{ji}}$ reflects measurement error alone, then this plot will be straight except for deviations due to the randomness. Curvature indicates a dependence of the error properties on the element.

The plot of cumulative sums, which is shown in figure 5.4, does exhibit curvature. But this curvature is due to five elements. The first four points are the contributions of the four elements of Detector 11-105, the detector that shows the largest decrease in signal with time. The gap between the fourth and fifth points is due to element $D$ of Detector 11-103. The last two measurements on this element were made close together in time and yet are quite different. This suggests that one of these measurements is an outlier. One outlier in 148 measurements is not bad performance. The rest of the curve is quite straight. The slope of this straight part, which is roughly 0.0009 , gives a value for the measurement error variance based on all but the five elements mentioned above. In terms of the signal measurements $\mathrm{y}_{\mathrm{ji}}$, the corresponding standard deviation is $3 \%$.

A change in the measurement procedure was made in August 1990 to alleviate the glint problem. This change and the problem that led to this change suggest that the observed decreases in signal might be due to a bias in the measurement procedure. NIST checked on this possibility by comparing the decrease in signal level before the change with the overall decrease. The measurements on Detectors 11-102, 11-105, 11-107, and 11-112 are useful for this purpose because these sets of measurements have the property that more than one measurement was made before August 1990 and exactly one measurement was made afterward. Let $b_{\mathrm{p}}$ be the slope estimated from the period previous to August 1990 , let $t_{P}$ and $z_{P}$ be the means of the $t_{j i}$ and the 


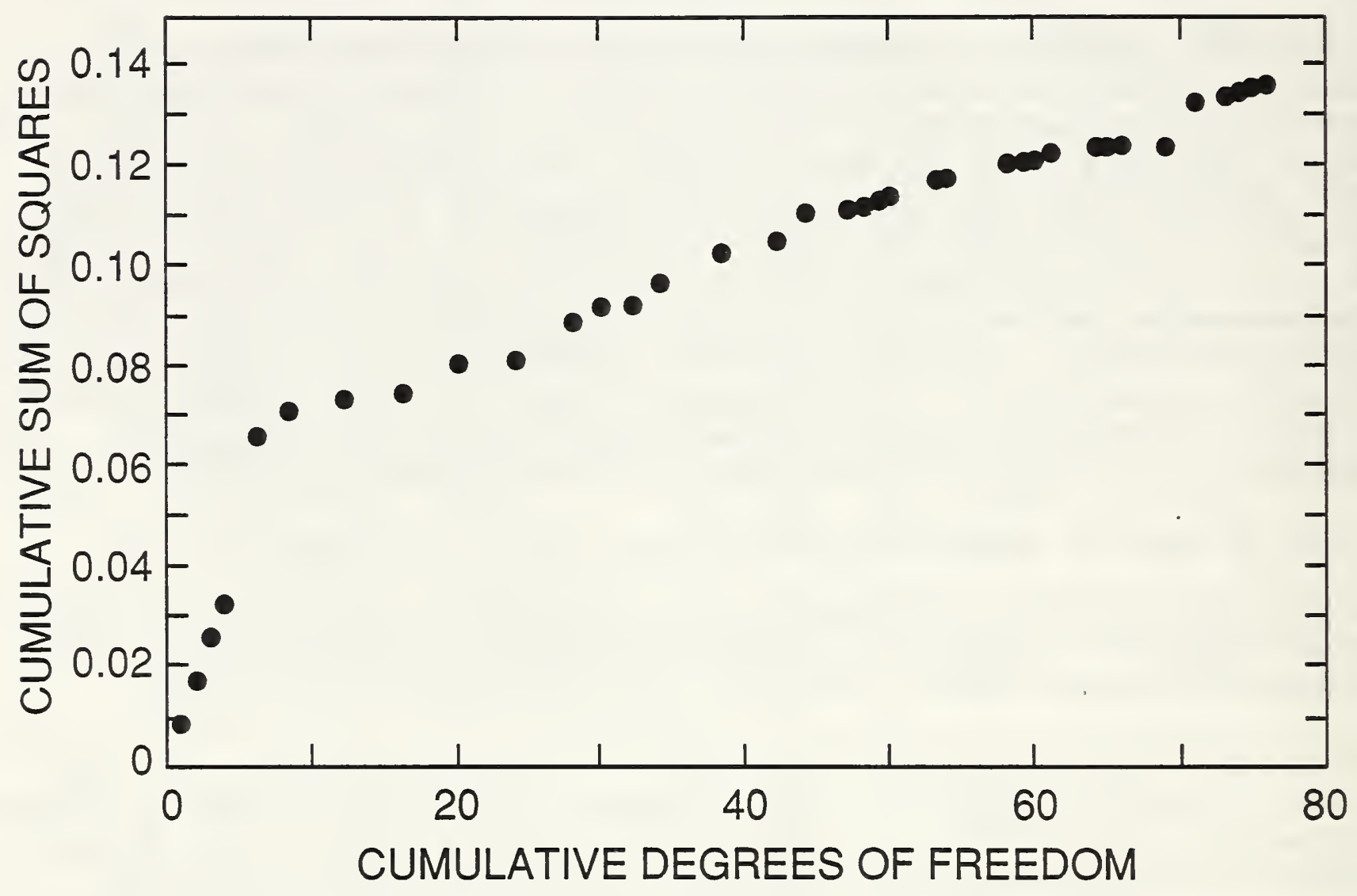

Figure 5.4 Cumulative dependence of the variance on the slope. 
$\log \left(y_{j i}\right)$ for the previous period, and let $t_{A}$ and $z_{A}\left[=\log \left(y_{j i}\right)\right]$ be the signal and time for the measurement after August 1990. Consider the following difference in slopes:

$$
b_{P}-\left(z_{P}-z_{A}\right) /\left(t_{P}-t_{A}\right)
$$

This difference has variance

$$
\sigma^{2}\left[1 /\left(\Sigma_{P}\left(t_{i}-t_{P}\right)^{2}+\left(1+1 / N_{P}\right) /\left(t_{A}-t_{A}\right)^{2}\right],\right.
$$

where $\Sigma_{P}$ is the sum over the previous period and $N_{P}$ is the number of measurements in the previous period. Take 0.03 as the value of $\sigma$.

Dividing the difference in slopes by the square root of the variance, the following values were obtained for the 16 elements considered: $11-102: 0.3,-0.1,-0.7,-1.9 ; 11-105: 2.5,3.1,3.1,3.1$; 11-107: $1.7,-1.1,0.3,-0.6 ; 11-112: 0.1,-1.2,0.4,0.1$. Only the elements of Detector $11-105$ have values that are suspiciously large, that is, have differences greater than two standard deviations. Note that the subset of the measurements analyzed here contains only three measurements for each of the elements of Detector 11-105. NIST concludes that there is little evidence of bias associated with the change of measurement procedure. Moreover, the decrease in signal in Detectors 11-102 and 11-107 was apparent before the final measurement on these detectors.

Having decided on the appropriateness of the above model, NIST estimates for each detector the rate of decrease of the signal averaged over the elements. NIST fit the above model to (1/4) $\Sigma$ $\log \left(y_{\mathrm{ji}}\right)$. The slope estimates and their standard deviations are

$\begin{array}{ll}11-102 & -2.1(0.6) \\ 11-103 & -1.9(0.9) \\ 11-104 & -0.4(2.7) \\ 11-105 & -7.3(0.6) \\ 11-106 & -1.7(1.6) \\ 11-107 & -2.9(0.7) \\ 11-110 & 0.9(1.9) \\ 11-112 & -0.5(0.7) \\ 11-116 & -0.4(0.8)\end{array}$

in terms of decrease of $\log \left(\mathrm{y}_{\mathrm{ji}}\right)$ per 10,000 days. Detectors 11-102,11-105, and 11-107 give signals that are decreasing. Moreover, a test of the hypothesis that the slopes for all the detectors are equal leads to the conclusion that the slopes are not all equal.

In summary, NIST has shown from the qualitative analysis that detectors $(11-105,12-102,12-103$, 12-108, and 12-112) have shown signal decrease or instability with time. The quantitative statistical analysis, which was performed only for the $11-\mu \mathrm{m}$ detectors, has shown that any measurement bias due to stray reflections or "glint" is not apparent and that Detector 11-105 and to a lesser degree Detectors 11-102 and 11-107 showed a decrease in signal with time. 



\section{CRITICAL ANALYSIS TO DETERMINE AND UNDERSTAND STABILITY/DEGRADATION ISSUES}

This section discusses the various methods that have been used both by NIST and other laboratories to diagnose the possible causes for the detector degradation or instability. These tests range from visual and scanning-electron-microscope (SEM) inspection to electrical characterization. Models have been constructed to interpret the data and suggest possible mechanisms for degradation.

\section{A. Detector Assembly--Workmanship Reliability Assessment Wire Pull Tests, and Proposed Mechanisms to Explain the Degradation}

NIST staff inspected several $12-\mu \mathrm{m}$ GOES infrared detectors because they were available. This inspection included visual examination, optical photomicrography, wire bond pull tests, and SEM examination. Even though these detectors were not flight hardware, it was important to examine them further since their characteristics had been extensively studied. As is discussed below, the present study questions the validity of some of the temperature data reported for these detectors. In addition, it discovered several potential failure and degradation mechanisms.

Later, after this study on non-flight units was complete, one additional detector (12-111) was received for evaluation. Although it was mounted in a flight hardware package, it had not received its germanium aplanat lens and was therefore open for examination. Data, SEM photographs, and an evaluation of this device also are given in this section.

\section{Part 1: Non-Flight Hardware Detectors.}

Five "process-reject" detectors that were packaged in flatpacks (not flight packages) were visually examined and photographed. There were many examples of poor workmanship and equally poor choices of materials, which is fully discussed below. Since these were not flight hardware, NIST cannot say whether similar defects are also in the flight hardware. But if so, then there is cause for concern.

\section{1). Wire Bonding}

A. General Comments: The surface of the indium metallization was not smooth. It had a wormy or grainy texture with individual worms often appearing not to contact their neighbors. The detector-to-package bond on this indium was an ultrasonic gold wedge bond. The bonding tool had a perpendicular groove in it, which is common for gold wedge bonding. Most of the bonds to indium on the chip appeared to be normal, but several were overbonded to the point that the heel area was too thin, as was evident in some of the pull tests. Two out of the four packages had initial failed bonds (non-sticks) and then rebonds on the indium chip metallization. (Detector 53237-4 had one such as-made failure, and 53238-4 had two, one of which was rebonded with a gold ball bond instead of a wedge bond. This rebonding may have been done later during testing.) The latter device would have failed the class B and S rebond criteria (MIL STD 883, Method 2010.10) for the detector indium-metallization alone. All of the devices would have failed if the package post rebonds were included, as required in Method 2010.10.

Wire bonds to the gold-plated post of the package were of poor quality. In many cases, the gold bondability was so poor that the gold was manually scratched (scored) to enhance bondability. This appears to have been done during initial detector packaging to attach the detector-to- 
package wire bonds. Even then, several rebond attempts were necessary to achieve a weld (for both the chip-connecting wedge bond and ball bonds) used for connection outside the package during testing, and possibly added after manufacture for that purpose. Photomicrographs from 44792-4 (poor package post bonding and silicone rubber globs, see fig. 6.1) and 53238-4 (two nonstick bonds on indium, see fig. 6.2) are examples of such poor bonding. It appears that the chip-to-post wedge bond was made with a different bonder for the chip and for the package post, implying a large amount of operator-dependent handling. These bonds were poorly made. The flatpack bonding post is too close to the high wall of the package for anything but capillary-type ball bonding, or reverse wedge bonding with great care. This package was a poor choice when wedge bonding is chosen for the chip interconnection.

B. Pull Test Results: Pull tests were performed on some of the bonds from three out of the four available samples (53237-4, 44792-4 and 45839-4). Tests were performed on a Unitek MicropullIV instrument, ${ }^{1}$ calibrated prior to the test. Because of the unusual wire dress, all bonds were nondestructively pulled to 1-gf to straighten the loops and reveal any potential silicone rubber (SR) interference with the test. In most cases, the SR lifted readily from the substrate (see sec. 3 below) or it was manually removed. The bonds were pulled near the center of the span as specified in MIL STD 883, Method 2011.7. The strength after thermal stress for gold 25.4- $\mu \mathrm{m}$ (1-mil) wires is specified to be $2.5 \mathrm{gf}$, minimum. A number of the bonds failed this test as seen in the data below, and based on the pull test data alone, two out of three of these units would be rejects under class $\mathrm{S}$ specified conditions.

$\begin{array}{lcl}\text { Sample \# } & \text { Bond \# } & \text { Pull force }(g f) \\ 53237-4 & 1 & 2.4 \\ & 2 & 6.4 \\ & 3 & 6.3 \\ & 4 & 0.1\end{array}$

Bonds from the other opposite of the chip

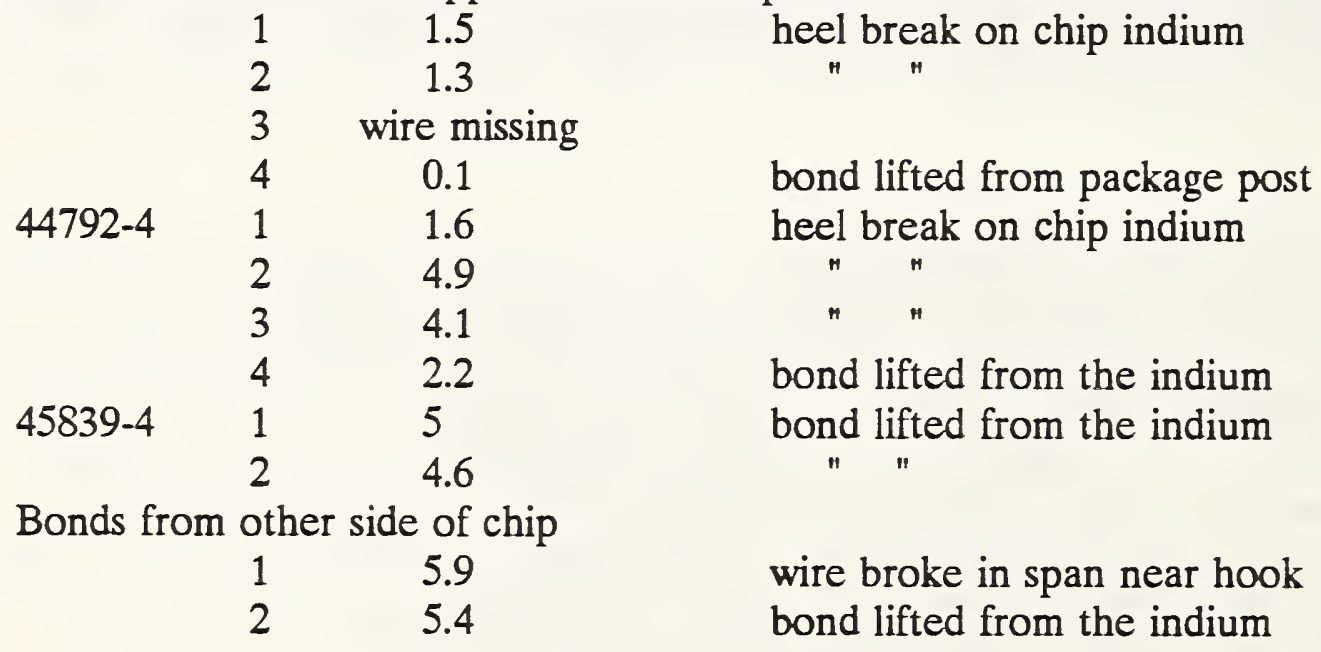

Sample 53237-4 showed the most evidence of poor bonding (lifts and rebonds on the indium, etc);

\footnotetext{
${ }^{1}$ Certain commercial equipment, instruments, or materials are identified in this report in order to adequately specify the experimental procedure. Such identification does not imply recommendation or endorsement by the National Institute of Standards and Technology, nor does it imply that the materials or equipment identified are necessarily the best available for the purpose.
} 


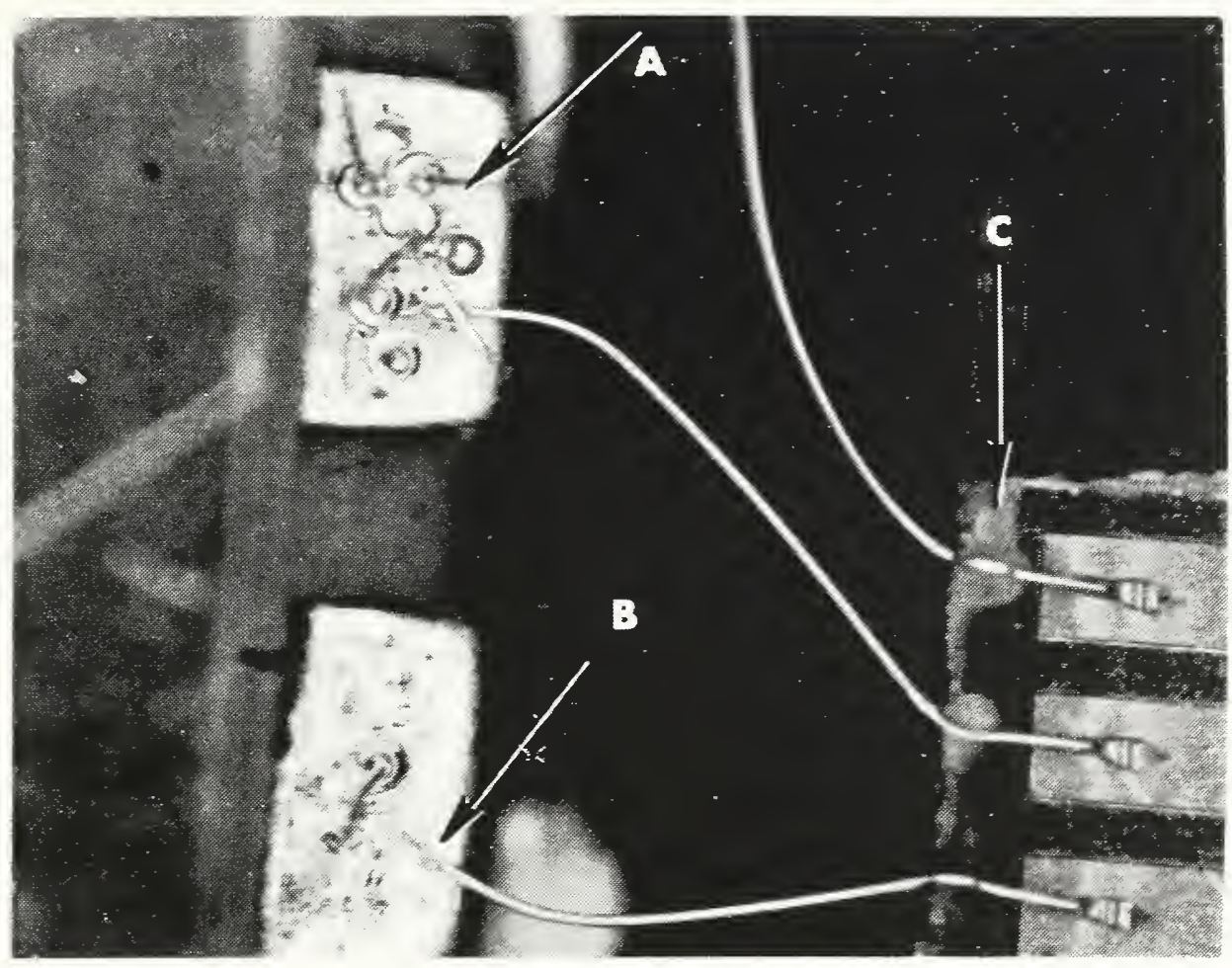

Figure 6.1 Detector 44792-4: Examples of poor bonding on the package and the silicone rubber staking blobs. (A) shows generally poor and multiple bonds on the package post. (B) shows a poorly placed (too near the edge and poorly deformed) package-to-chip bond. (C) The arrow points to the silicone rubber bond-staking blobs. Both this and figure 6.2 are optical photomicrographs taken at $50 \mathrm{X}$.

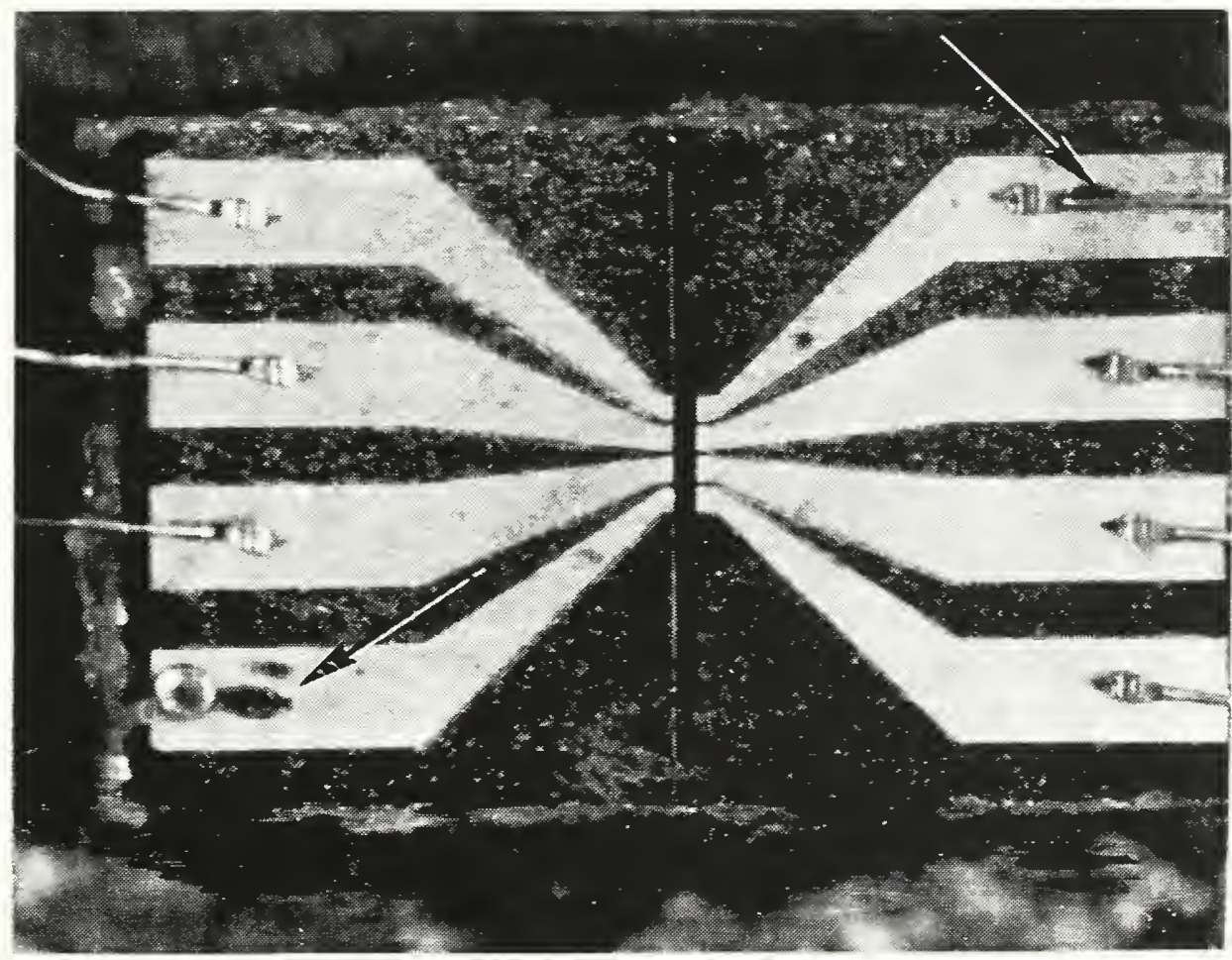

Figure 6.2 Detector 53238-4: Examples of initial nonsticking bonds to the indium. The liftoff is indicated by the arrows (dark patches where the indium was lifted up by the failed bond). Rebonding is apparent nearby. This photograph gives an overview of one of the $\mathrm{HgCdTe}$ detector chips. The light colored stripes are indium metallization. These converge onto the $\mathrm{HgCdTe}$ detectors in the center. 
it had been the humidity test sample and could not be pull tested.

C. Comments: Only a few wires were pulled, so a statistical analysis of the data is not useful; however, some comments are appropriate. a) The range of pull forces and the number of rebonds, both to chip and package, are so large that NIST concludes the bonding operation was clearly out of control. It was reported by the manufacturer that, unlike the case for soldering, NASA did not require bonding operator certification. b) Gold-to-gold bonds improve with time and temperature, thus several weak bonds on the package posts cannot be attributed to the earlier $100{ }^{\circ} \mathrm{C}$ temperature testing, but rather to initially poor bonding. c) Bonds to $53237-4$ showed Au-In intermetallic formation, indicating that the sample had experienced a higher temperature stress than all of the other samples (no other sample showed similar phenomena). Nevertheless, two of the intermetallic bonds were the strongest tested. This is not unexpected since intermetallics are stronger than gold or indium. Weakness would only occur if Kirkendall or similar voids were present.

NIST finds that based on these data, the temperature stress cannot be blamed for weakening any bonds. They were poor as-made. The fact that some bonds to the chip were strong suggests that either a thin layer of intermetallic exists under the bond or that all of the indium was pushed aside and bonding took place directly to the HgCdTe. Such direct bonding is known to occur to silicon and other similar materials.

\section{2). Gold Indium Intermetallics around Several Bonds}

NIST was informed that the heat-treated samples received either 103 - or 60 -h bakes. However, only one sample (53237-4, baked for $103 \mathrm{~h}$ ) showed significant Au-In intermetallic formation around the bond area. SEM photographs were made of these bonds, and one is shown in figure 6.3. For comparison, sample $45839-4$ (also listed as having $103 \mathrm{~h}$ of bake) was examined, and two of its bonds are shown in figure 6.4. It shows only minimal intermetallic growth. From these figures, it is apparent that sample 53237-4 has seen much more thermal stress than all other bonds examined. NIST was unable to determine where or when the additional thermal stress was applied. In any case, the large amount of intermetallic calls into question any thermal-induced degradation data that were reported. For example, if $103 \mathrm{~h}$ is enough to generate such intermetallics, then sample $45839-4$ did not see that full temperature exposure, and the electrical degradation data taken from it are not representative. This question should be further investigated.

\section{3). Silicone RTV}

A silicone RTV was used to stake the bond wires to the edge of the ZnS substrate, apparently to facilitate a wire bend. Upon examination, several of these "blobs" had cracked out part of the substrate they were attached to, presumably at the low testing temperature (about $100 \mathrm{~K}$ ). In a conversation with staff from Dow Corning, NIST learned that Dow Corning does not recommend the use of this silicone material below $-65^{\circ} \mathrm{C}(208 \mathrm{~K})$ because it undergoes a transition, becoming hard and brittle. The use of such a material in this application implies a lack of knowledge of its low-temperature properties. Also, wire bonds have been observed to break at low temperatures when covered with silicone. NIST was told that the flight hardware detectors have an additional epoxy stake over the actual bonds on the indium. If so, then this could separate or damage the bonds due to differential temperature expansion the same way the silicone damaged the $\mathrm{ZnS}$ substrate. 


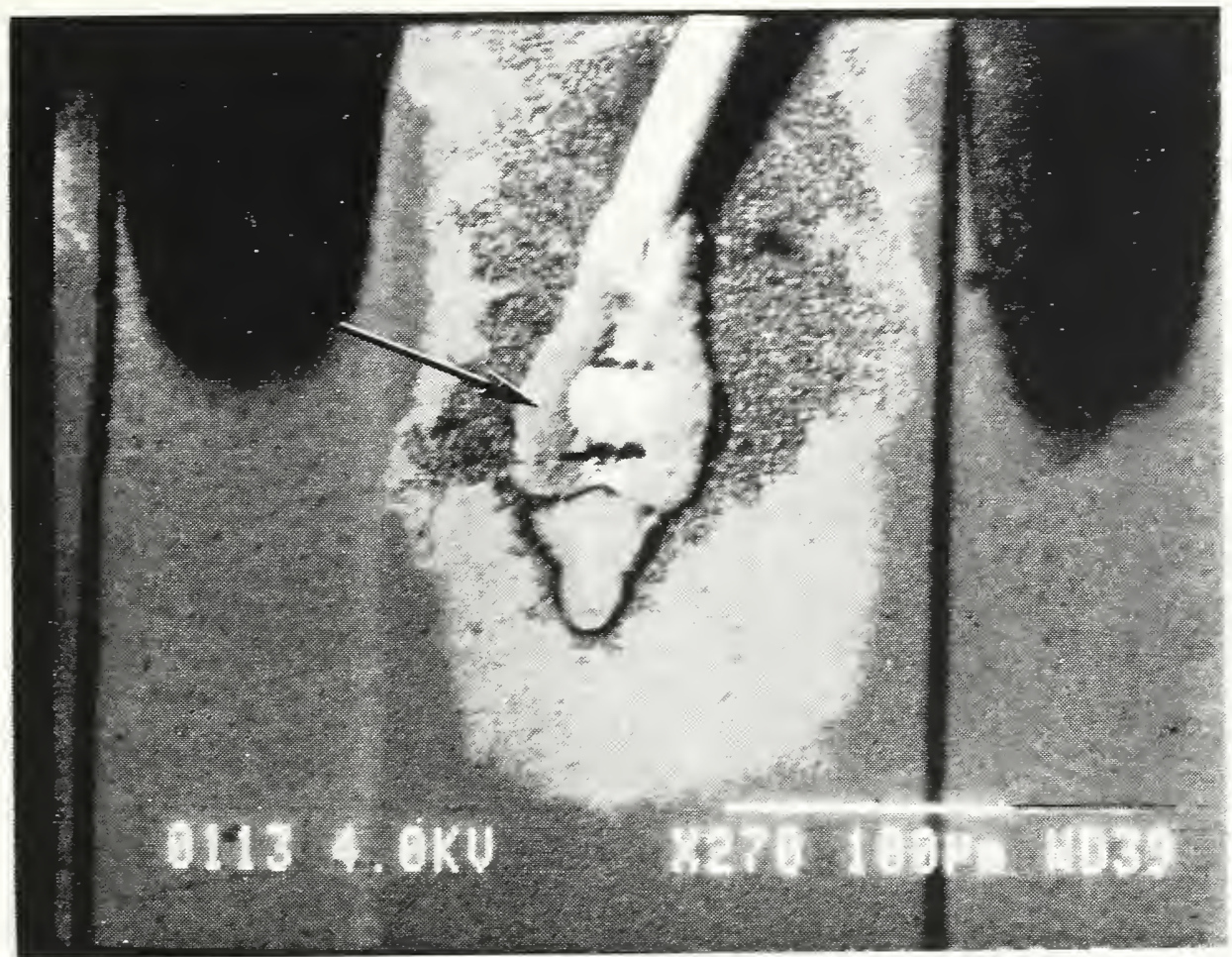

Figure 6.3 Detector 53237-4: This sample is stated to have had 103 -h bake at $100^{\circ} \mathrm{C}$. (See above about the nonspecified temperature.) The arrow points to the thick rim of Au-In intermetallic growth around the bond. The darkened area on the indium metallization results from indium depletion as the indium diffused into the gold bond. This and figure 6.4 are SEM photographs with scale indicated by white markers.

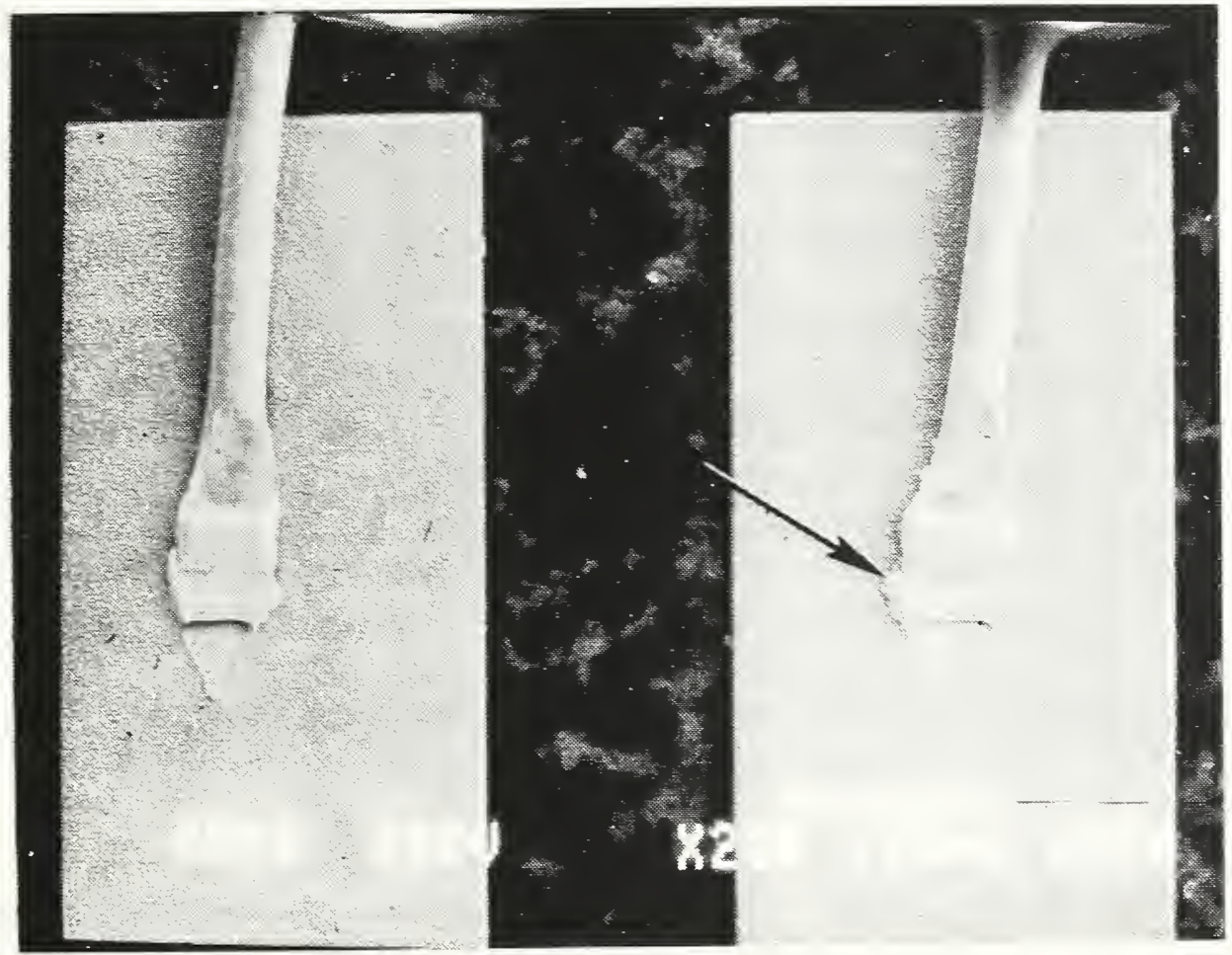

Figure 6.4 Detector 45839-4: This sample is reported to have seen the same thermal bake as in figure 6.3. Two gold wire bonds are shown on indium metallization stripes. Only a minor amount of intermetallic compound is seen, and the largest part of it is indicated by the arrow. Note: all other samples (except fig. 6.3) revealed less intermetallic formation than this sample. 


\section{4). ZnS Optical Coating}

From observation, NIST concludes that the $\mathrm{ZnS}$ optical coating is applied as a final or near-final assembly step, after bonding (optical fringes of it often appear over the bonds) and possibly after the silicone staking. If so, then any cleaning procedure that was used should be specified. If no cleaning (argon plasma or other) was used, then there is a significant possibility that organics and other residual products from all preceding steps (the e-beam cutting, die bond epoxy curing, the silicone curing, and general handling) will be trapped under the $\mathrm{ZnS}$ optical coating and prevent its molecular bonding to the $\mathrm{HgCdTe}$ or oxide, if it was passivated earlier. This would predispose the $\mathrm{ZnS}$ film to delaminate from the $\mathrm{HgCdTe}$ or from any passivation layer, if such a layer were applied separately. One type of stress that might cause a poorly adhering layer to separate would occur during changing temperatures as the sample is cooled for the various low-temperature electrical and optical tests.

\section{5). Soldering of Fine Gold Wires}

It was reported to NIST that the $25.4-\mu \mathrm{m}$ (1-mil) gold wires in the actual flight detectors were ultrasonically bonded to the indium and later soldered to the kovar posts on the package with a normal tin-lead solder. If this report is correct, it raises a serious concern about reliability. Solder reacts rapidly with gold, dissolving it and/or converting it into brittle intermetallic compound which could crack during temperature cycling. The use of indium-lead solder is preferable to tin-lead, but if heated to too high a temperature or for too long during soldering, then indium solder can also produce similar effects. Hand soldering, if it were used, is an operator-dependent process that introduces unknown variables (such as iron temperature, contact time, and cooling rate) which may affect reliability. One does not normally solder such fine gold wire; rather ultrasonic bonding is used. If manual soldering were performed, then all soassembled flight detectors should be disqualified unless an appropriate screen can be devised, and none is apparent. If an automated soldering process were used, then the same questions should be asked before assessing its reliability.

\section{Part 2: Examination of a "Flight-Type" Detector (12-111).}

On September 5, 1991, NIST received one detector mounted in a flight package, but without the germanium lens, for examination and measurement. The unit was first examined optically, up to a magnification of $140 \mathrm{X}$, then measured electrically at room and at liquid nitrogen temperatures. (Four such temperature cycles were involved in these measurements.) Finally, the samples were examined in an SEM. The general packaging workmanship was better than on the units reported above. However, some of the same materials reliability problems were observed. For example, the fine gold wires bonded to the indium on one end were tin-lead-soldered to the package terminals on the other, leading to serious reliability concerns. There was no rebonding to the detector's indium metallization, and the bonds were not overdeformed. The ZnS substrates are apparently scribed on the wafer for break-and-separation, leaving the edges quite rough and irregular, but this should not be a reliability hazard. There was no epoxy applied over the wire bond sites on the indium, as NIST had been told were on all flight detectors. This unit is thus not fully equivalent to actual flight hardware.

\section{1). "Wormy" Indium Metallization}

The indium metallization had a "wormy," "grainy," appearance (this was noted above as well as in other investigations) [6.1]. In many cases, it appeared that individual indium worms were attached to the $\mathrm{HgCdTe}$ but were not in contact with their neighbor indium worms or grains. Numerous photographs were taken. However, later attempts to prove this lack of contact through examination in the SEM at very high magnification were difficult because of the $>1-\mu \mathrm{m}$ thick 
$\mathrm{ZnS}$ film. By adjusting the voltage, reasonable, if not sharp, SEM photographs were taken in various areas of the four individual detectors, but at several points the beam (operating at relatively high voltage) damaged the sample. Examples of this unusual metallization are shown in figures $6.5 \mathrm{a}$ to $6.5 \mathrm{~d}$, where it is clear that many indium grains do not touch their neighbors and, therefore, offer no conductivity in the horizontal direction.

NIST carried out discussions about electroplating indium to III-V and II-VI semiconductors with staff from the Indium Corporation of America. They reported that the III-V semiconductor compounds are easily indium plated. Indium tends to plate in a dendritic structure. If the plating current density is high (about $215.3 \mathrm{~A} / \mathrm{m}^{2}$ ), then there is a tendency to grow wormy or grainy appearing films with new material growing rapidly on top of existing peaks, leaving unplated or lightly plated valleys. They recommend slow plating rates (about $53.8 \mathrm{~A} / \mathrm{m}^{2}$ ) for uniform films. They also said that Te-based materials develop tenacious oxides and are hard to electroplate uniformly, so a vapor deposition of indium is recommended. From information provided by the detector manufacturer, NIST calculates that the plating current density is approximately 17.2 $\mathrm{A} / \mathrm{m}^{2}$. This does not appear high enough to cause the observed worms. One explanation might be that the surface condition is not conducive to plating (e.g., some tellurium oxide on the surface), and another could be that the plating did not take place at the specified current density and the time was shortened to give the same film thickness. Another could be that the electrical contact to the wafer rim is nonuniform, causing some areas to be plated at a higher rate. One would expect that the center of the wafer would receive less current density than the rim. However, if there were a significant difference, then there would be large variations in plating thickness across a wafer. NIST cannot verify this latter possibility with the number of specimens available.

As a result of these observations and the statements that optical detection has been observed over the indium metallization, NIST proposed a model that may offer an explanation for some of the observed detector degradation. If the horizontal conductivity is dominated by tiny (essentially pressure-type) contact areas at specific points on the indium worms, then the indium film will have a high resistivity. Furthermore, these interface areas may be subject to oxidation or chemical attack (by plating bath residue or oxidation). The standard thermodynamic heat of formation $\Delta \mathrm{Hf}^{\circ}$ in calories per mole of indium oxide from its elements (indium and oxygen) at $25^{\circ} \mathrm{C}\left(\Delta \mathrm{Hf}^{\circ}=\right.$ -220 ) is so negative that indium will reduce most materials and find oxygen somewhere. For example, it could reduce passivating coatings of tellurium oxide $\left(\Delta \mathrm{Hf}^{\circ}=-77\right)$ (also, Cd oxide $=-60$ and $\mathrm{Hg}$ oxide $=-21$ ). Any indium oxide films that form will be semiconductors rather than metal conductors and have a high resistance. The oxide could form under the worms as well as at horizontal points of contact. These high-resistance interfaces will be put under stress during various temperature excursions. Thus, the contact resistance of the indium could change over time. Different indium metallization runs, even on the same detector chip, often have different worm or grain densities, and this could explain the varying resistance from unit to unit.

The area under the wire bond is assumed to be a mechanically strong, electrically stable contact to the $\mathrm{HgCdTe}$ (as discussed above). When the indium film offers a sufficiently high horizontal resistance, then some of the bias field will appear in a shunt path in the underlying $\mathrm{HgCdTe}$ film. The field will no longer be shorted out from the wire bond to the detector area by the indium. Any light that falls in the voids between indium grains will generate carriers that will be swept out by the fringing field and thus be detected. Without such electric fields in the underlying $\mathrm{HgCdTe}$, there could be no photosignals originating from the indium "covered" contact region. Thus, such optical sensitivity is a direct test of both the porosity and the resistivity of the film. One might speculate that a high-resistivity film would result in a high $1 / \mathrm{f}$ noise, but this has not been proven. 


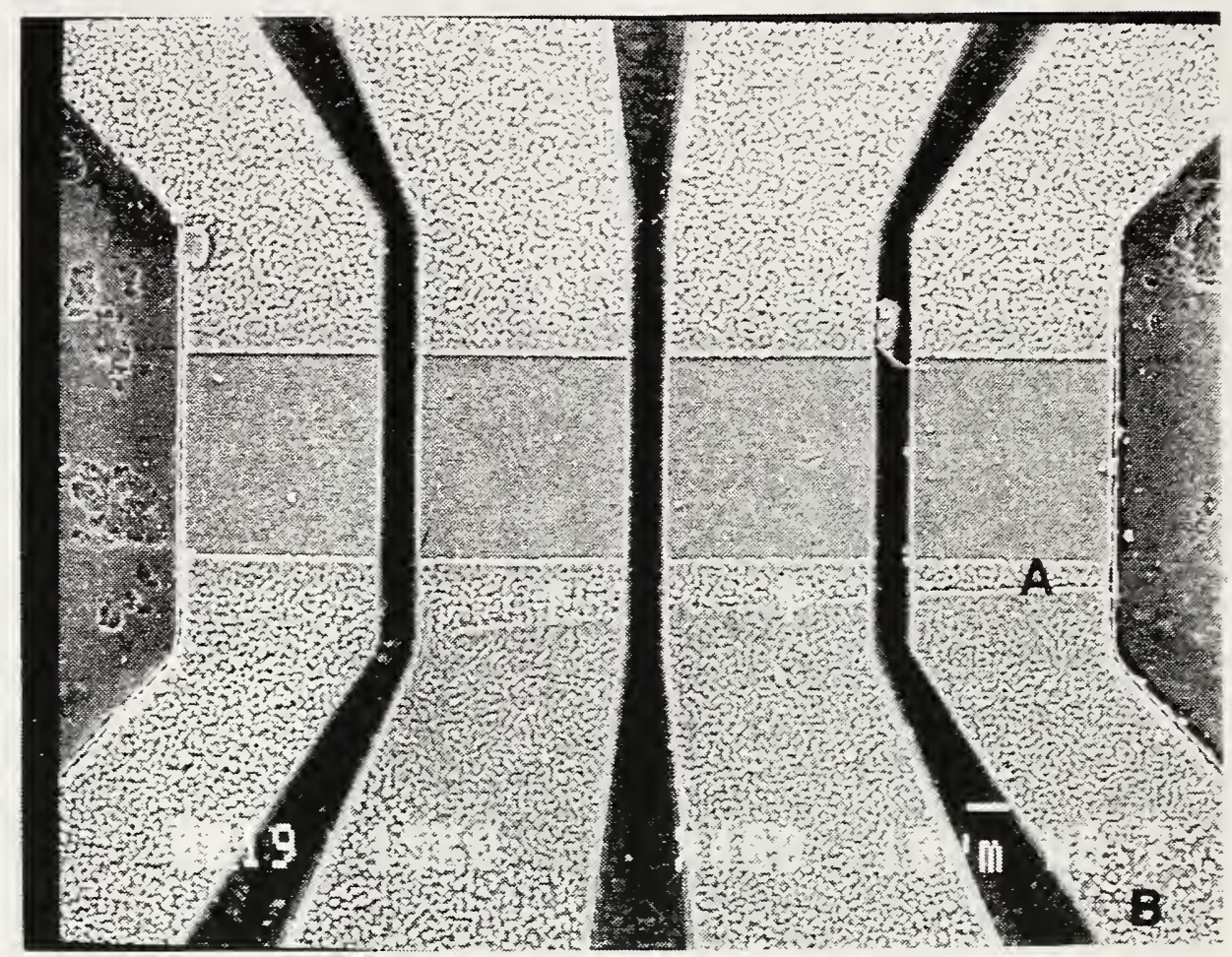

(a)

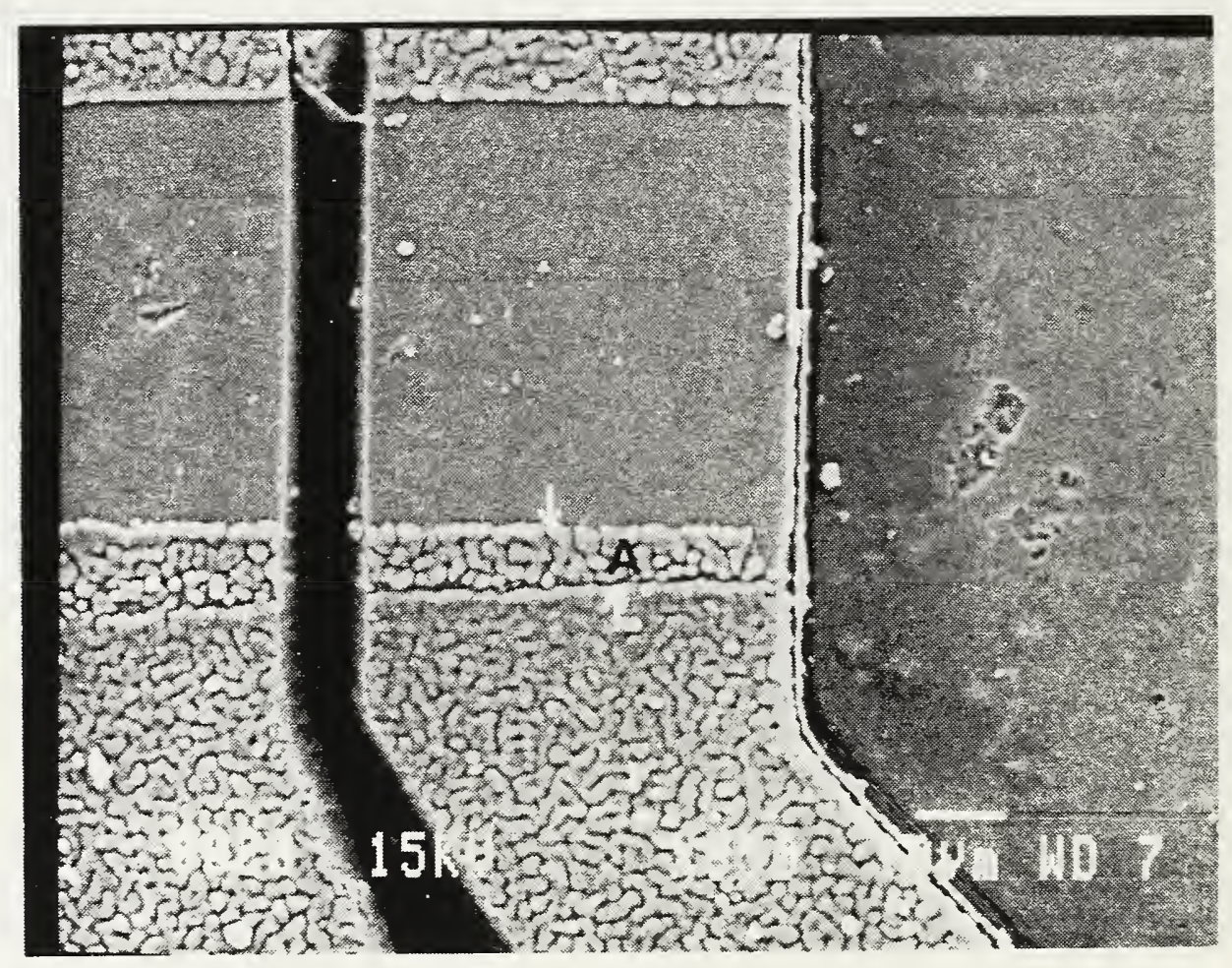

(b)

Figure 6.5 An overview of the metallization in Detector 12-111. (A) is an unusual indium plating that shows some separation from one part of the indium film to the main part. (B) is an area with large spacing between indium grains where horizontal electrical conductivity could not occur. Figures $6.5 \mathrm{c}$ and $6.5 \mathrm{~d}$ are closeups of this area. 


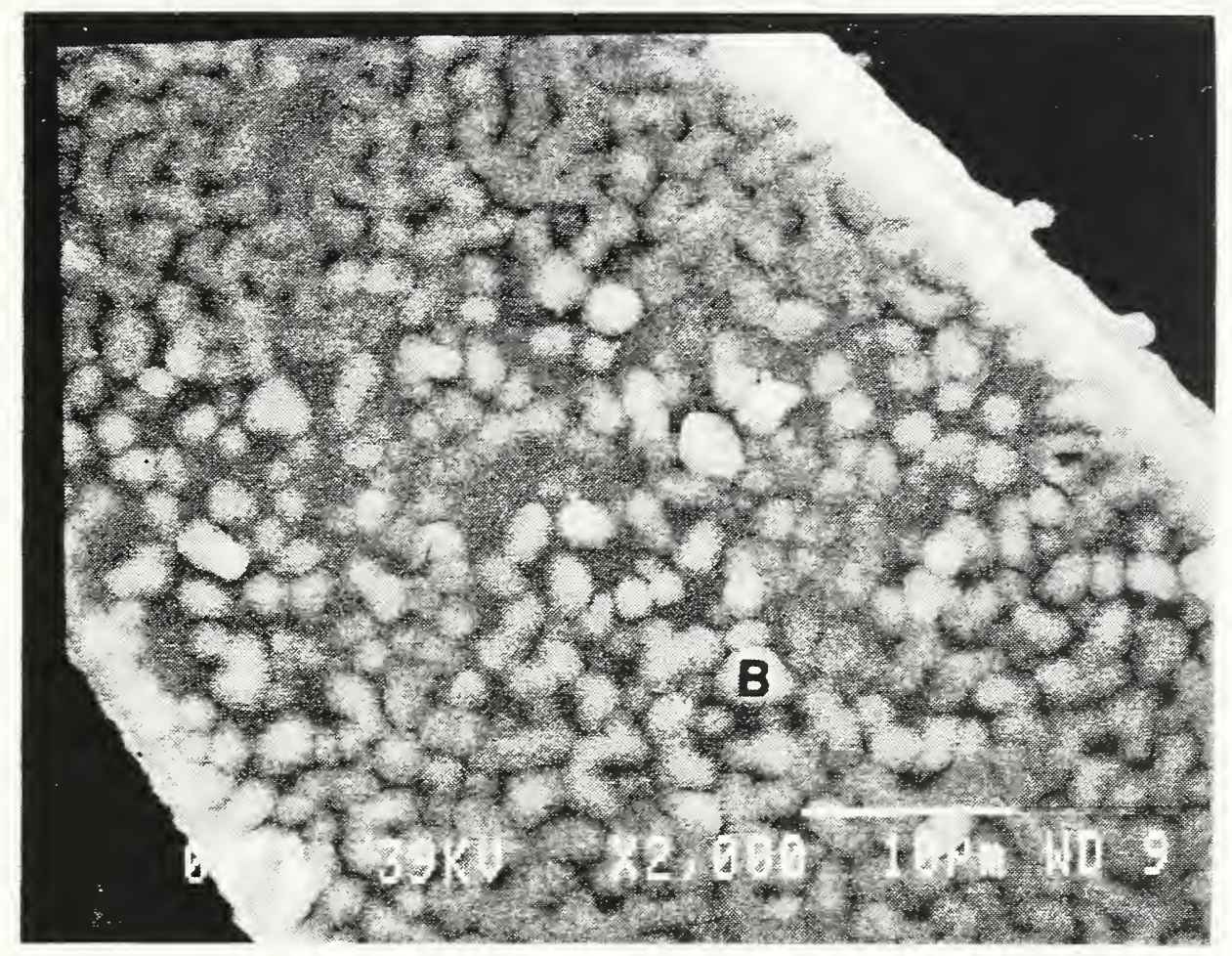

(c)

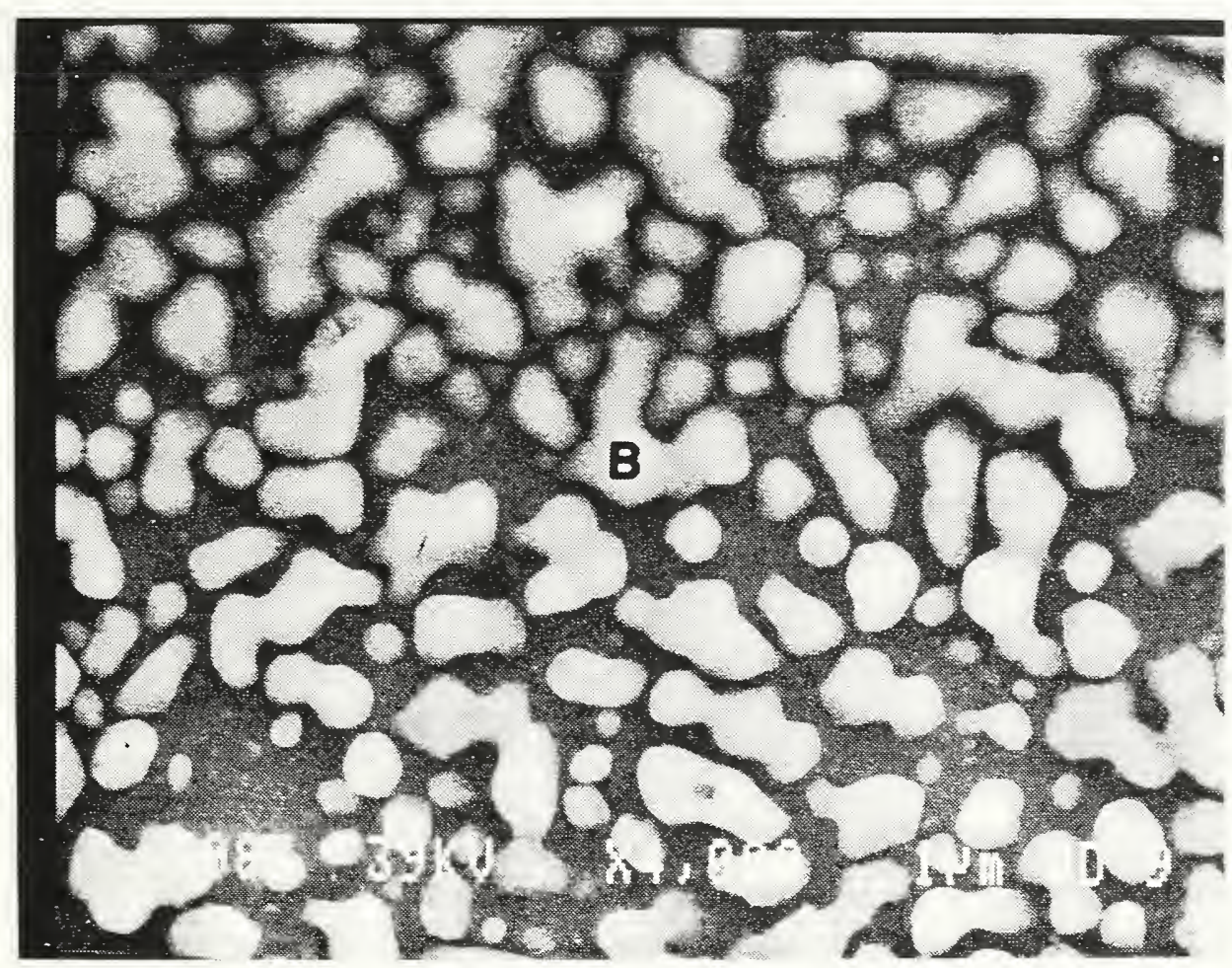

(d) 


\section{2). Delamination of the $\mathrm{ZnS}$ Optical and Passivation Coating}

When Detector 12-111 was examined with a high-power Nomarski microscope, NIST found irregular interference patterns on the $\mathrm{HgCdTe}$ detector surface, often appearing to correspond to bulges. The only apparent explanation is that some of the surface passivation and/or $\mathrm{ZnS}$ optical coating on the detector elements had separated from the $\mathrm{HgCdTe}$ (fig. 6.6). Careful reexamination of the earlier detectors revealed that some separation had also occurred on Detector 45839-4 (fig. 6.7) and to a lesser extent in 53237-4. Nomarski microscopy also revealed more pits and voids on the HgCdTe surface than was evident from the SEM photograph, as shown in figure 6.6. In addition, a crack in the $\mathrm{ZnS}$ optical film was revealed, on the left (fig. 6.8). Re-examination of a special detector assembly containing two detectors from flight wafers also revealed optical film coloration which is either an unusual separation or an uneven passivation film deposition.

The observed separations could result in some direct loss of detector sensitivity because the signal must pass through two additional surfaces (the loss would depend upon the film's separation distance). The separation of the $\mathrm{ZnS}$ and the passivation layer could also result in slow, timedependent degradation of the detection sensitivity due to ambient gas attack (such as oxygen or water vapor) on the less protected HgCdTe surface. The polymer die attach, the "glue" under the $\mathrm{HgCdTe}$ material, and especially the silicone rubber all absorb water vapor which can be released inside the package after hermetic sealing and during storage at room temperature. Also, the germanium lens is sealed on the detector package by a polymer (epoxy), and water vapor permeates such material at room temperature in a few weeks, depending on the path length and any "fill" in the epoxy. NIST notes that no passivation/ZnS delamination was observed on the humidity test sample 53238-4, so it would not be expected to degrade by this mechanism, and indeed it did not.

The comments on ZnS coatings above in Part 1, section 4, suggest some possible causes of this delamination. A manufacturing process that results in separation-prone passivation coatings on samples from several different wafers must be considered out of control.

\section{3). Bond Wires Soldered to the Kovar Package Pins}

The flight package contains eight kovar pin-type lead-throughs (LT) to bring out the electrical connections to the chip. The wire bonded on one end to the indium metallization is siliconerubber staked to the edge of the $\mathrm{ZnS}$ substrate, bent, wrapped around the appropriate LT, and then soldered. X-ray microanalysis revealed that a high tin-content solder was used. See Part 1, section 5, above for a discussion of potential soldering problems. SEM examination of the wireto-solder interface was difficult because of the high package walls in proximity to the LTs, limiting the electron-beam angle. (NIST looked essentially straight down from the top and could only see problems that occurred on the top side of the solder-wire interface. Thus, there may have been several unseen cracks.) Nevertheless, one wire was found to have developed gold-tin intermetallics and brittle cracking along the top of the wire-solder interface. Standard SEM microscopy as well as X-ray microanalysis were performed in this interface area. See figures 6.9 to 6.11 for an overview of the top of the solder-coated LT, the solder-wire interface area, and a closeup of the crack area, respectively. Temperature cycling the device can flex wires and propagate such cracks.

It would be speculation to say that this particular cracked wire would or would not fail in a given number of temperature cycles of a given temperature difference. If there is ductile gold below the crack, then it may take many cycles before failure, but if there is brittle intermetallic below, 


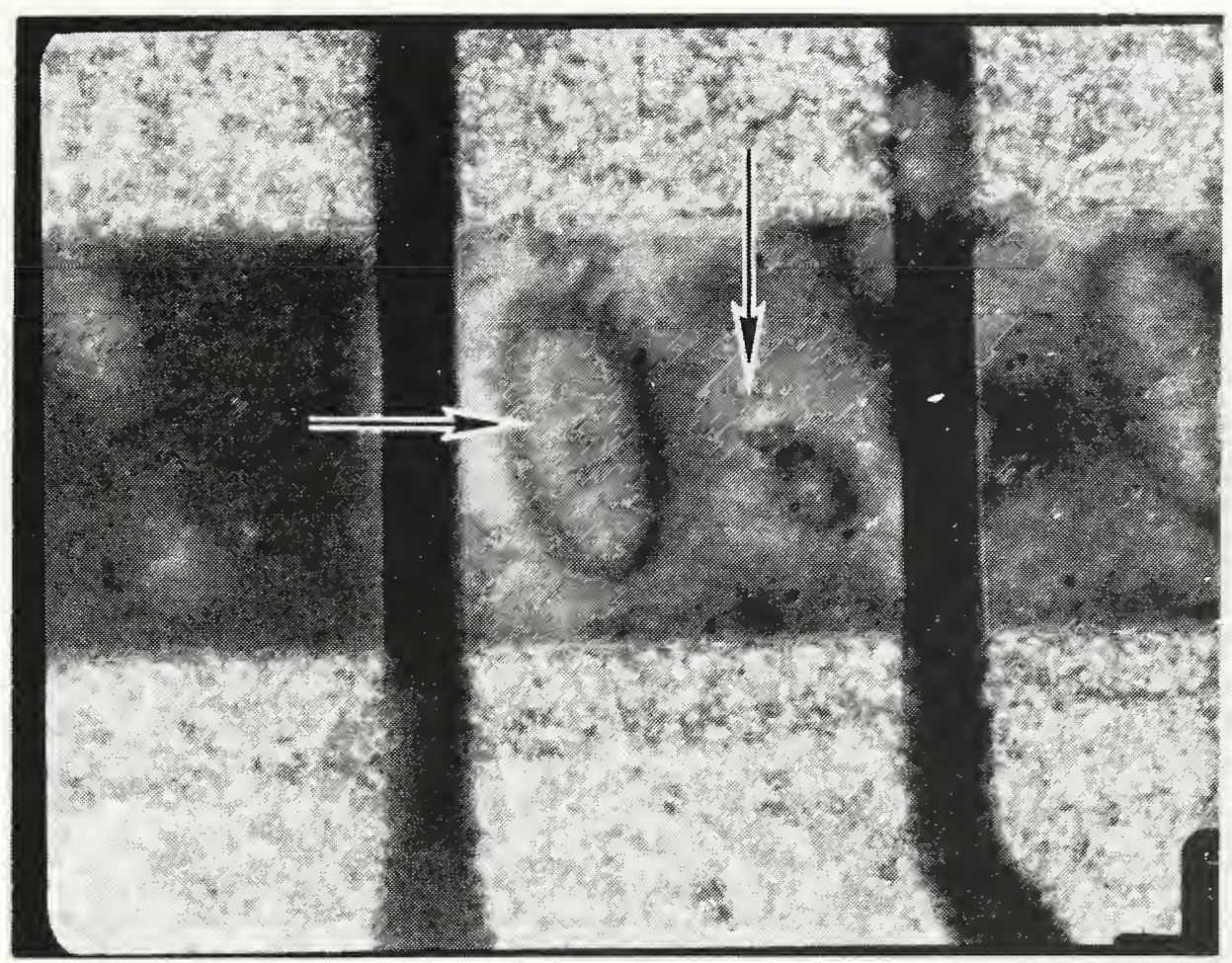

Figure 6.6 Apparent separation of the $\mathrm{ZnS}$ and/or passivation film on Detector 12-111. Three out of four elements showed major separation. The horizontal arrow points to one of the "bulges," as revealed by Nomarski microscopy. The vertical arrow reveals one of the large pits in the surface of the $\mathrm{HgCdTe}$.

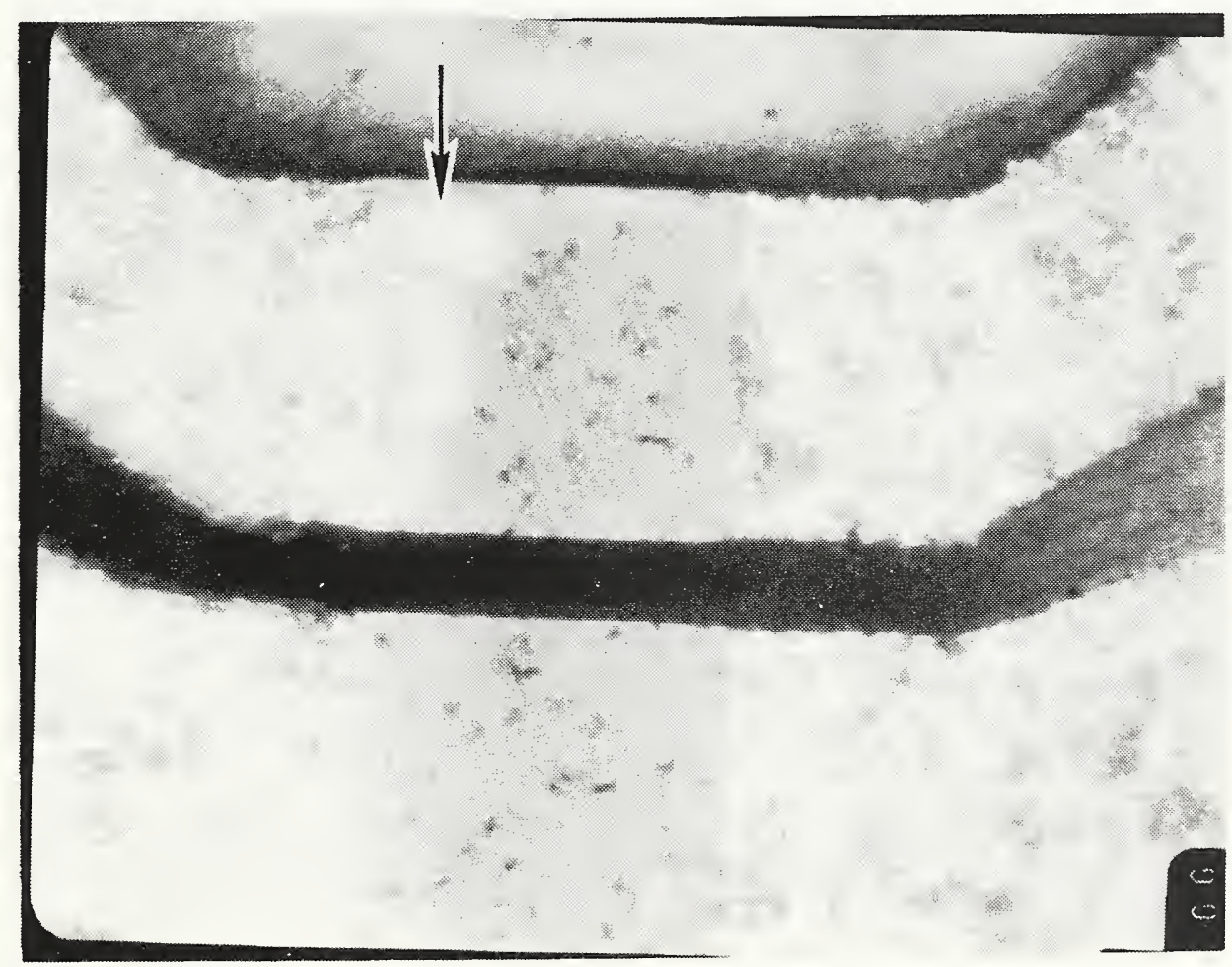

Figure 6.7 Two elements of Detector 45839-4 are shown with the arrow pointing to several separation "bubbles" or "bulges." 


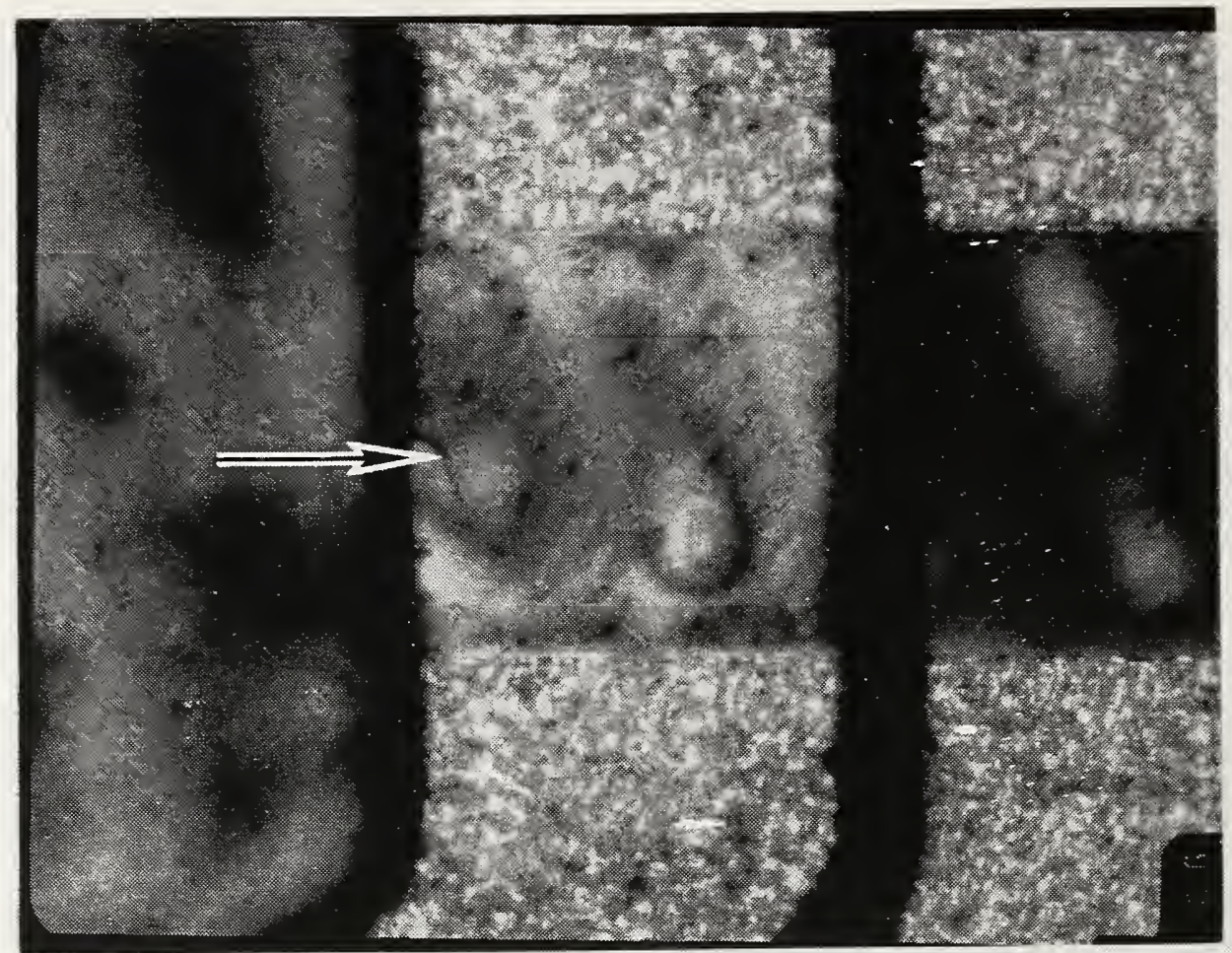

Figure 6.8 The arrow points to a crack in the $\mathrm{ZnS}$ optical coating on Detector 12-111. Several separation bubbles or bulges are evident. This is the same detector as in figure 6.6 but the photograph is of elements to the left of it.

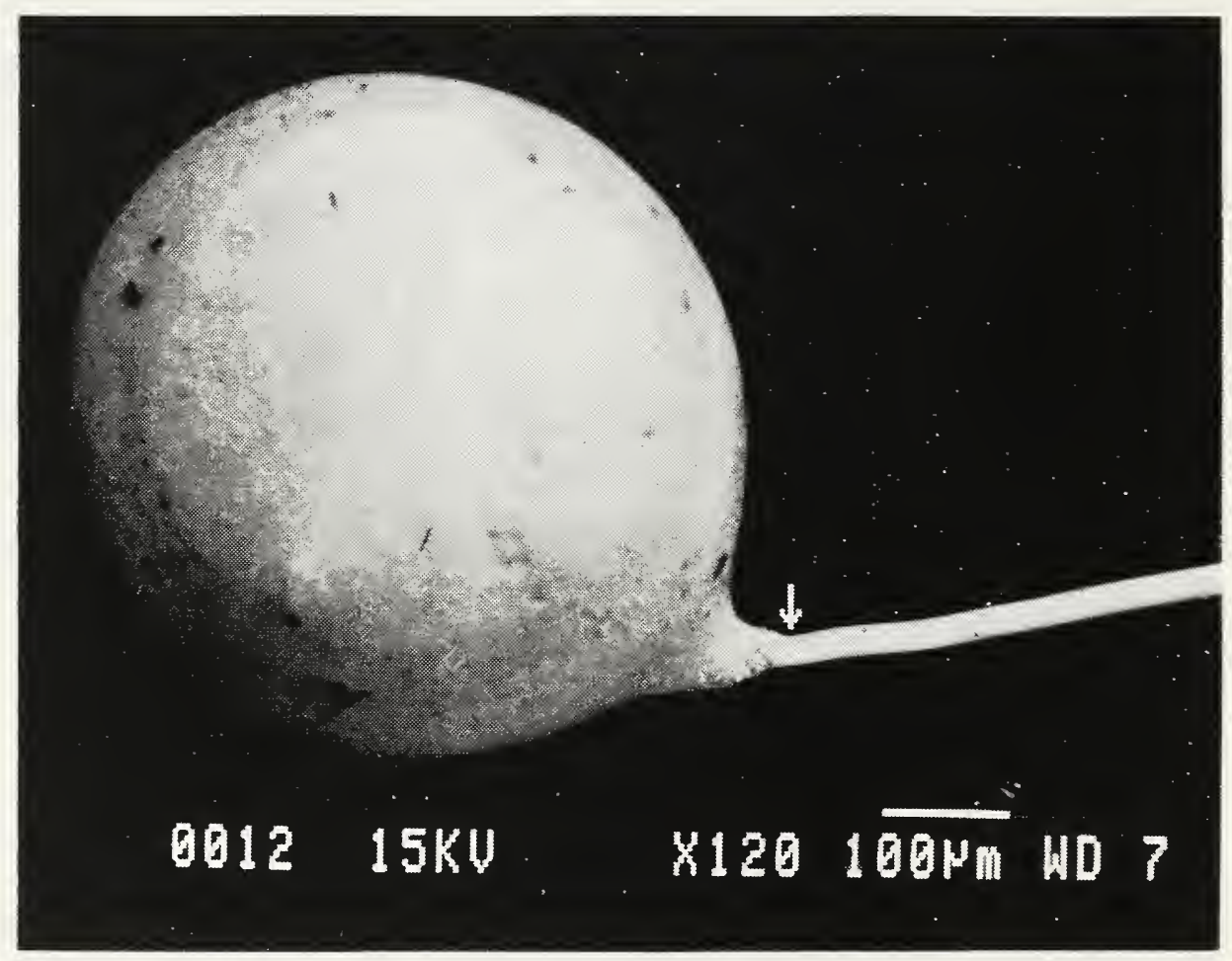

Figure 6.9 A top view of one electrical lead-through in Detector 12-111. The round shape is a high tin content soft solder. The $25-\mu \mathrm{m}$-diameter gold interconnection wire (from a detector element) is shown going off to the right. An arrow points to the interface of the gold wire and the solder, and the next two figures show closeups of that area. 


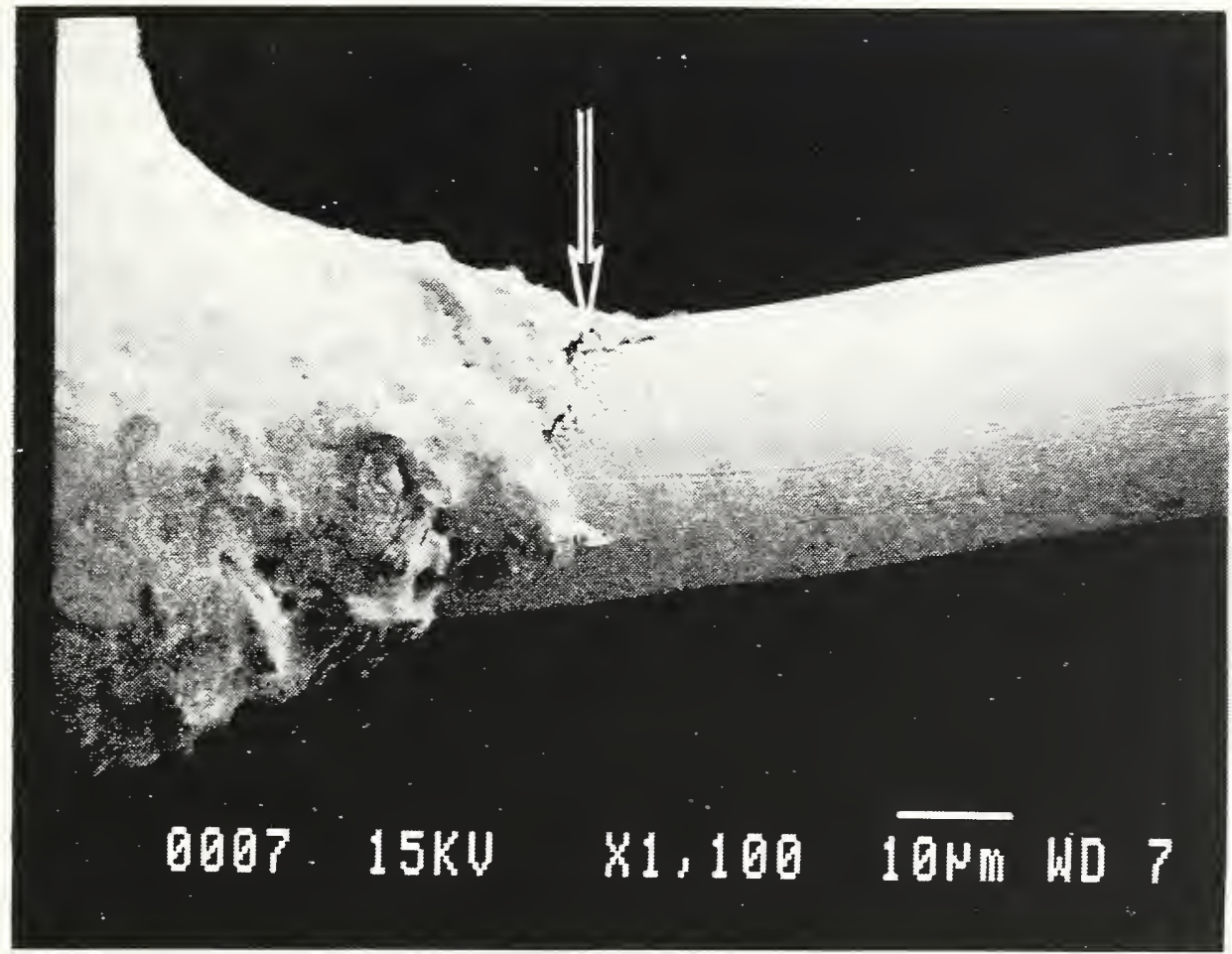

Figure 6.10 An enlargement of the solder-gold wire interface revealing a crack is shown by the arrow.

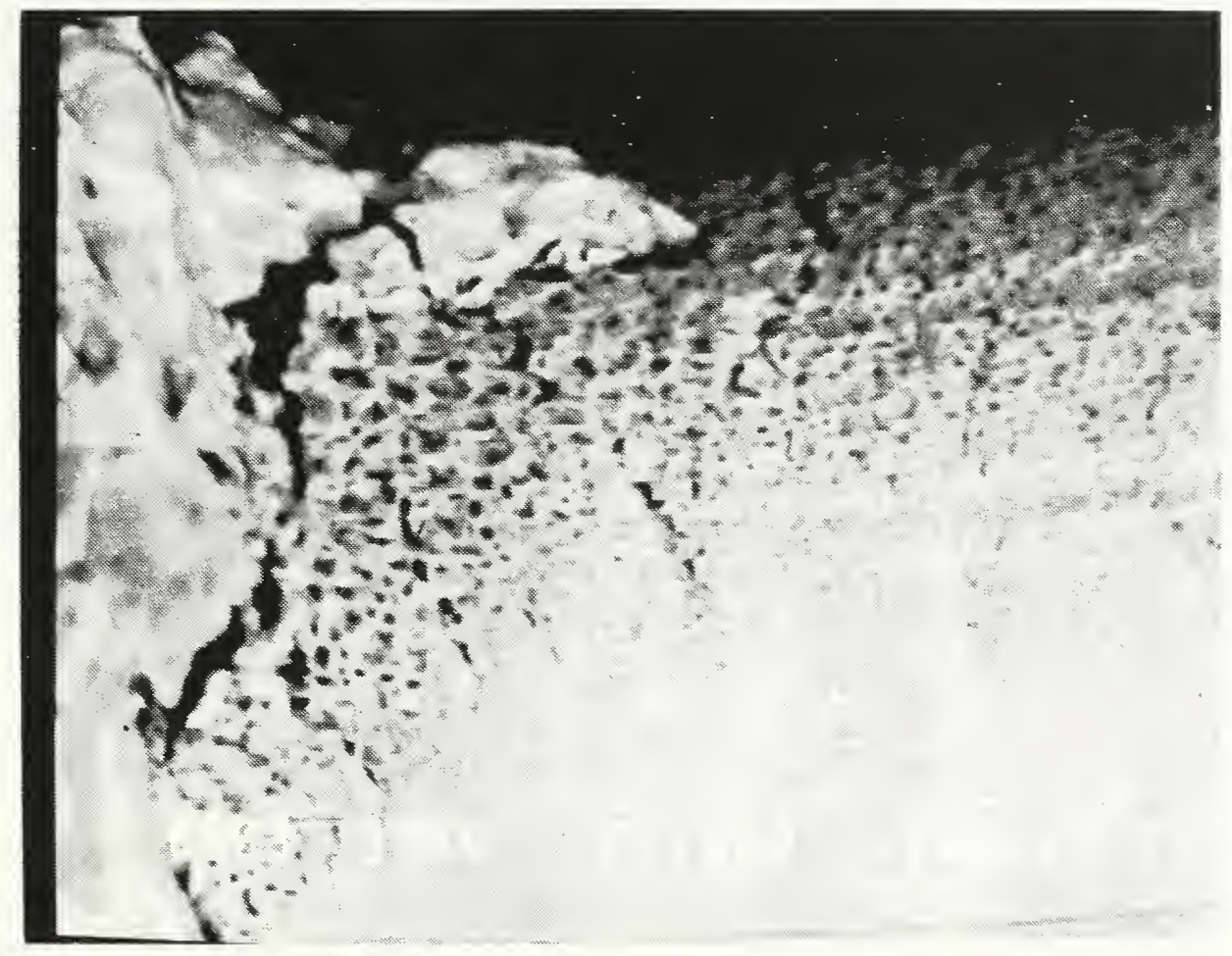

Figure 6.11 A further enlargement of the solder gold wire intersection. A large crack is evident as well as several smaller cracks. The dimpled surface is the result of tin diffusing out along the gold wire and forming gold-tin intermetallics. 
then only a few. However, considering that the GOES satellite contains 42 detectors (best available estimate) having 84 soldered fine gold wire leads, some may be partially dissolved in the solder or contain significant intermetallics and cracks, while others may be little affected. The microelectronics industry does not solder fine gold wires, thus there is not enough reliability information available (on fine gold wires with $\mathrm{Au}-\mathrm{Sn}$ intermetallics) to establish a safe temperature-cycling screen. In addition, such a screen (if applied) may also cause $\mathrm{ZnS}$ film separation damage to the HgCdTe device. Thus, there is no apparent safe screening method for the soldered gold wire problem.

\section{B. A Brief Summary of Some Diagnostic Tests Performed by Other Laboratories}

The following sections give results of a number of diagnostic measurements as presented by ITT on May 2, 1991, at the HgCdTe Detector Degradation Task Force Meeting in Fort Wayne, Indiana [2.1]. These include accelerated lifetime, humidity, carrier lifetime, and Auger electron spectroscopy tests, and blackbody spot scanning.

\section{1). Accelerated Lifetime Testing}

Three detectors were used in an accelerated life test that was supposed to determine if exposure to high temperatures $\left(100^{\circ} \mathrm{C}\right)$ could induce the degradation phenomena. The following detector parameters were monitored as the detectors were vacuum baked for extended periods of time: resistance, responsivity, noise, and carrier lifetime.

The results of the tests showed that: (1) the vacuum bake caused the resistances to increase with time (whereas the 11- and $12-\mu \mathrm{m}$ detector resistances generally decrease with time); (2) the responsivity varied significantly with time, sometimes increasing and other times decreasing. The responsivity of the detector was still changing after a 90 - to 100 -h bake at $100{ }^{\circ} \mathrm{C}$ with no apparent stabilization; and (3) the effective carrier lifetime and noise also varied with time during the vacuum bake. Unfortunately, even though the detectors' responsivities were affected by the vacuum baking, the observed GOES degradation phenomena of a great responsivity change accompanied by a resistance decrease were not seen.

\section{2). Humidity Testing}

One detector (53238) was exposed to a high humidity environment to see if moisture could induce the degradation phenomena. The test consisted of (1) an initial baseline measurement of signal, noise, and resistance; (2) measurements after 24 -h exposure to $93 \%$ humidity at $30^{\circ} \mathrm{C}$; (3) measurements after a three-day exposure to $93 \%$ humidity at $30^{\circ} \mathrm{C}$; and (4) measurements after a full military standard humidity exposure.

The results of these tests showed that the resistance did not change, the noise oscillated slightly, and the signal varied less than $20 \%$ during this severe humidity exposure. The high humidity test thus did not reproduce the degradation phenomena.

\section{3). Carrier Lifetime Tests}

The purpose of these carrier lifetime tests was to determine if the degradation could be explained by variations in minority carrier lifetime. There is a direct relationship between responsivity and lifetime, and thus the decrease in responsivity might be due to a drop in lifetime. ITT built up a test apparatus illuminating samples with 100 -ns-wide light pulses from a laser diode operating at a wavelength of $5 \mu \mathrm{m}$. Measurements on four samples gave values of 300 to $400 \mathrm{~ns}$, which some detector experts thought were too low. Unfortunately, the effective carrier lifetime did not vary 
significantly between good and bad samples, and so the degradation was not shown to be related to a carrier lifetime effect.

No bias dependence was observed and so minority carrier sweepout effects are thought to be negligible.

\section{4). Auger Electron Spectroscopy Measurements}

When electrons of energies 1 to $5 \mathrm{keV}$ penetrate into a material, they excite atoms which lose energy by the emission of Auger electrons. These electrons provide a means for elemental identification since they leave the atoms with discrete energies characteristic of a specific atom. The Auger electrons are highly absorbed so that only those in the outermost monolayers ( 1 to 3 $\mu \mathrm{m})$ of the solid can escape and be collected and counted. The distribution of particular elements into a bulk sample can be measured by using sputter etching with an inert gas to remove surface atoms while monitoring the Auger signal.

Auger studies done on Detector 12-103 showed the presence of indium in the active area plus indium nodules scattered about. A control sample studied showed similar indium nodules, but no indium in the active area.

\section{5). Blackbody Spot Scans}

Blackbody spot scans provide a nondestructive measure of the uniformity of the detector signal response. Raster scans over the whole detector assembly, including the active area and the contacts, provide indications of the relative signal responses from each region. Blackbody spot scans were done on two detectors (53239 and 53236). No measurable optical responses were found at distances beyond about $50.8 \mu \mathrm{m}$ from the active area of each element in the metallization regions.

\section{6). Electron-Beam-Induced Current Measurements}

Electron-beam-induced current (EBIC) measurements have been made on several samples. This measurement technique has been shown to be useful as a high-resolution spot scan on the detector devices although specific results have not been published. ITT has identified it as a technique that will be pursued in the future.

\section{7). Scanning Electron Microscope Studies}

Scanning electron microscope (SEM) studies have shown that ITT's indium contact metallization is noncontinuous or porous. It is granular in nature, exhibiting voids which exist down to the $\mathrm{HgCdTe}$ layer.

\section{Possible Degradation Mechanisms}

The detectors used in the GOES program are especially vulnerable to degradation because they have small active areas and are thus greatly affected by edge effects induced by ion-beam milling, passivation treatments, and metallization procedures. First, consider the design and operation of the 11 - or $12-\mu \mathrm{m}$ detectors. The $7-\mu \mathrm{m}$ detectors cannot be modeled as easily because of their extended contacts.

As seen in figure 2.1, the top and bottom surfaces are passivated, so that one can expect that there should be a high density of electrons near these surfaces in accumulation layers. From a study by Nemirovsky and Kidron [6.2], one can estimate a surface electron density of about $6 \times$ 
$10^{11} \mathrm{~cm}^{-2}$ and a surface mobility of about $3 \times 10^{4} \mathrm{~cm}^{2} / \mathrm{Vs}$ at $77 \mathrm{~K}$, which is nearly seven times smaller than the bulk mobility. This gives a surface conductance of about $3 \times 10^{-3} \mathrm{mho} / \mathrm{square}$ at $77 \mathrm{~K}$, which NIST takes to be the same at $105 \mathrm{~K}$, the operating temperature of the detector. Thus, the estimate for the resistance of the two passivated regions is about $170 \Omega$ for both 11 and $12-\mu \mathrm{m}$ detectors.

The two sidewalls of the detector are ion-beam milled. Since a wet chemical etch was not used, this processing could introduce two $1-\mu \mathrm{m}$-thick layers with an electron density of at least $4 \times 10^{15}$ $\mathrm{cm}^{-3}$, according to measurements made by Bahir and Finkman [6.3]. If one assumes a bulk mobility of approximately $1.2 \times 10^{5} \mathrm{~cm}^{2} / \mathrm{Vs}$ at $105 \mathrm{~K}$ for the $12-\mu \mathrm{m}$ detectors, these regions have a resistance of $380 \Omega$; for the $11-\mu \mathrm{m}$ detectors, the corresponding mobility is $1.0 \times 10^{5} \mathrm{~cm}^{2} / \mathrm{Vs}$ and the combined resistance is $460 \Omega$ [6.4]. However, the diffusion coefficient $\mathrm{D}_{\mathrm{Hg}}$ of mercury into $\mathrm{HgCdTe}$ is large at room temperature [6.5], and thus the excess mercury contained in these ion-beam-milled regions could diffuse appreciably into the bulk of the detector during times of direct interest. With a lower-bound value of $1 \times 10^{13} \mathrm{~cm}^{2} / \mathrm{s}$ for $D_{\mathrm{Hg}}$ at $300 \mathrm{~K}$, NIST obtains the diffusion profiles observed in figures 6.12 and 6.13 as a function of time. A Gaussian solution of the diffusion equation is used for each layer:

$$
C(x, t)=\frac{S}{\left(\pi D_{H g} t\right)^{1 / 2}} e^{-x^{2}} / 4 D_{H g} t,
$$

where $\mathrm{C}$ is the density as a function of position $\mathrm{x}$ and time $\mathrm{t}$ and $\mathrm{S}_{\mathrm{i}}$ is the initial density per square centimeter.

The solution is valid for times such that the density at the opposite edge due to diffusion is negligible. NIST used the criterion $\mathrm{t}_{\text {max }}=-\mathrm{L}^{2} /\left(16 \mathrm{D}_{\mathrm{Hg}} \ln (0.5)\right)$ to establish the maximum time for which eq (6.1) is valid where $L$ is the width of the detector. Note that the entire detector bulk could have an increase in $\mathrm{Hg}$ density in less than a year comparable to the $2 \times 10^{14} \mathrm{~cm}^{-3}$ background doping. If this is only a redistribution of mercury, the detector resistance would not change appreciably. However, the signal could still degrade because of the increase in the doping density which could result in an increased sweepout effect.

The carrier density in the bulk of the detector varies with the cadmium fraction $\mathrm{x}$. The intrinsic carrier density $n_{i}$ is estimated to be $5.2 \times 10^{14} \mathrm{~cm}^{-3}$ for $\mathrm{x}=0.200,3.0 \times 10^{14} \mathrm{~cm}^{-3}$ for $\mathrm{x}=0.207$, and $1.1 \times 10^{14} \mathrm{~cm}^{-3}$ for $\mathrm{x}=0.220$ at $105 \mathrm{~K}$, which correspond to the $12-, 11$, and $7-\mu \mathrm{m}$ detectors, respectively. The carrier density $\mathrm{n}$ is computed from $\mathrm{n}=0.5\left(\mathrm{~N}_{\mathrm{D}}+\left(\mathrm{N}_{\mathrm{D}}{ }^{2}+4 \mathrm{n}_{\mathrm{i}}^{2}\right)^{1 / 2}\right)$, where $\mathrm{N}_{\mathrm{D}}$ is $2.4 \times 10^{14} \mathrm{~cm}^{-3}$ according to the wafer supplier's data sheet. If one uses a bulk mobility of about $1.2 \times 10^{5} \mathrm{~cm}^{2} / \mathrm{Vs}$ for $\mathrm{x}=0.200$ and $1.0 \times 10^{5}$ for $\mathrm{x}=0.207$, the bulk resistivity is $94 \Omega$ for $\mathrm{x}=0.200$ and $166 \Omega$ for $\mathrm{x}=0.207$. This result is based on the assumption that the electrons that supply the passivated regions do not come from the bulk of the detector, but result from mercury introduced by the passivation. If insufficient electrons are introduced, the surface charge associated with the passivation can cause electrons to leave the bulk and accumulate at the surfaces. The carriers within the bulk will become polarized with more electrons near the surface and more holes near the center. The resistance of the detector would increase because the surface mobility is less. Thus, one obtains the total detector resistance, excluding contact resistance, to be $52 \Omega$ for $\mathrm{t}=0.200$ and $71 \Omega$ for $\mathrm{x}=0.207$.

An effect that can significantly reduce the responsivity of a detector is minority-carrier sweepout 


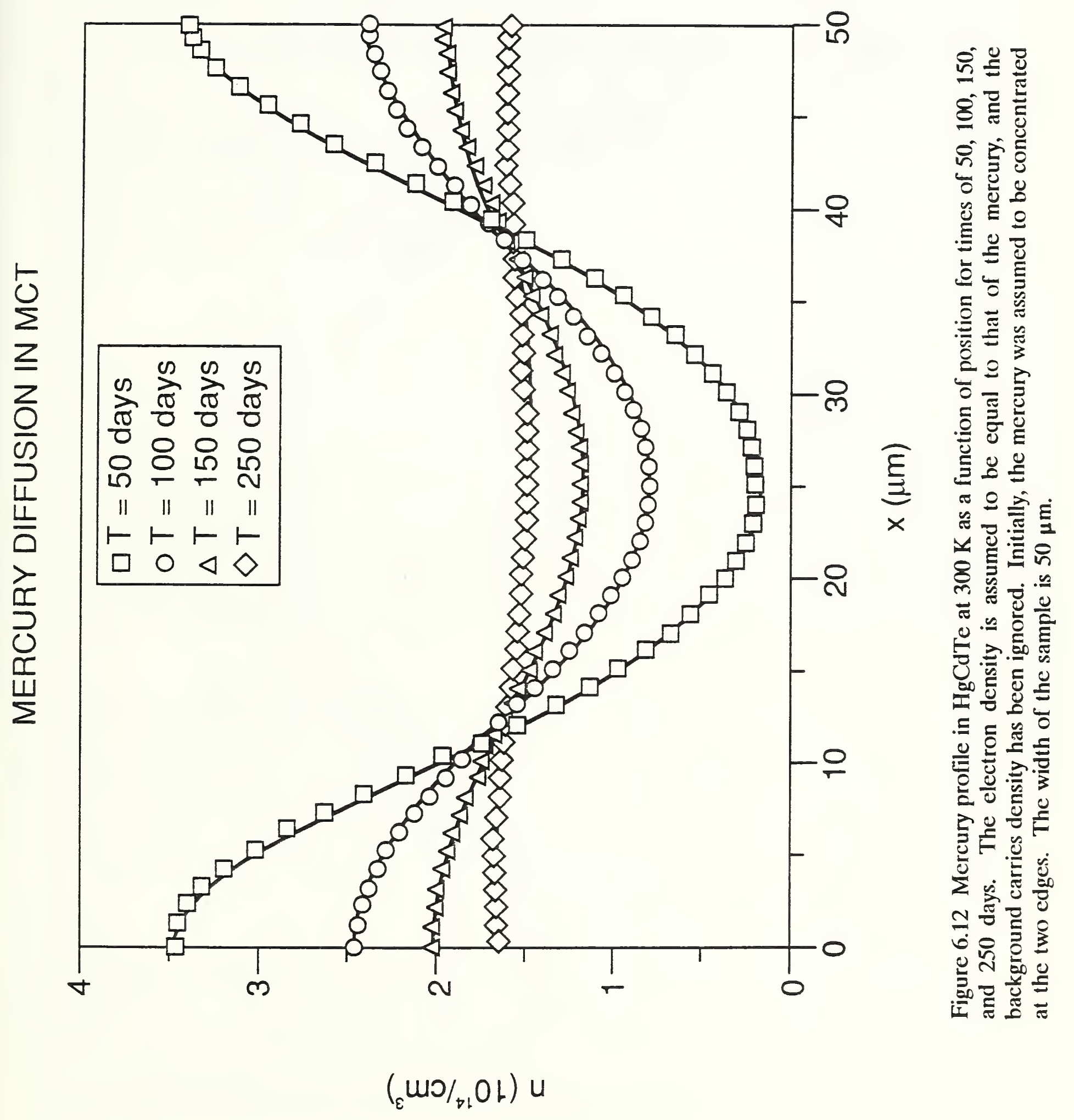




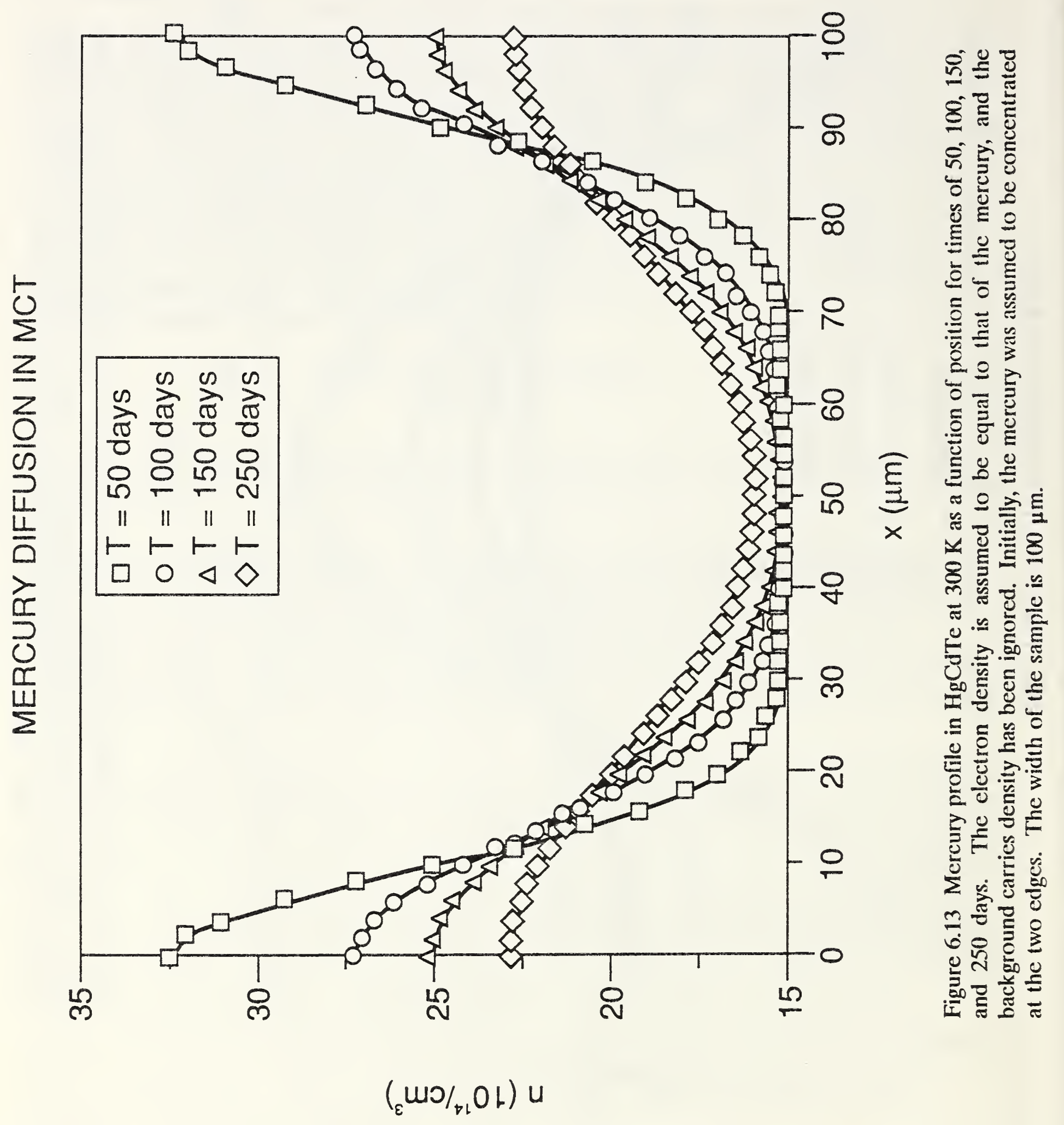


[6.6]. When a sufficiently large field is applied across the detector, minority carriers can drift to a contact and recombine. Since the responsivity increases linearly with field at low field and the transit time varies inversely with field, the responsivity reaches a maximum with field and saturates. If the bulk of the detector is intrinsic, there is no sweepout because the ambipolar drift mobility $\mu_{0}$ is zero. However, if there is an imbalance between electron and hole densities, this effect can occur. As an example, consider for the $12-\mu \mathrm{m}$ detectors $\mathrm{n}_{\mathrm{O}} \approx 6 \times 10^{14} \mathrm{~cm}^{-3}, \mathrm{n}_{\mathrm{o}}$ $p_{0} \approx 2 \times 10^{14} \mathrm{~cm}^{-3}$, and $\mu_{0} \approx \mu_{\mathrm{h}} / 3=330 \mathrm{~cm}^{2} / \mathrm{Vs}$ at $105 \mathrm{~K}$ A hole will drift a length $1=$ $\mu_{\mathrm{O}} \mathrm{E} \tau$ before recombining at the contact. For $\mathrm{E}=20 \mathrm{~V} / \mathrm{cm}$ and $\tau=300 \mathrm{~ns}, 1=20 \mu \mathrm{m}$, which is comparable to a diffusion length. Thus, carriers near one of the contacts could have a reduced lifetime, and the responsivity would be reduced near this contact. Therefore, not only can the responsivity be less because of an increase of carriers in the bulk, but also because of minoritycarrier sweepout. The situation is less important in the $7-\mu \mathrm{m}$ detectors because $p_{0}$ is less than $n_{0}$ and $\left|\mu_{0}\right| \propto \mu_{n}$. Extended contacts have been used to reduce this effect on the $7-\mu \mathrm{m}$ detectors.

It is a very complicated issue to determine the nature of a signal decrease with time. Mercury may slowly diffuse into the bulk from both the passivated and ion-milled regions. This could cause a decrease in the bulk resistance and possibly a much larger decrease in the signal because of sweepout. However, it would be necessary to study the behavior of the detector in detail to determine the true cause of the signal decrease. It is important to note that extended contacts have been used on the $7-\mu \mathrm{m}$ band detectors in order to reduce the sweepout effect, but not on the 11- and 12- $\mu \mathrm{m}$ detectors, presumably because these were sufficiently intrinsic. However, the $11-\mu \mathrm{m}$ and $12-\mu \mathrm{m}$ detectors are about half the length and width of the $7-\mu \mathrm{m}$ ones and therefore are even more susceptible to sweepout if they become less intrinsic. Variations in surface charge density with time would thus have a major impact on these detectors by changing the internal balance between electron and hole densities. This may cause the striking instability in Detector $12-112$.

Another issue that can affect device performance is the quality of the contacts to the device. The contact resistance should be low relative to the detector resistance and constant. The contacts should not be photosensitive because this could lead to unspecified signal properties. Recently reported measurements on two Sounder detectors, LW-30 and LW-48, showed significant signal associated with the contact region. The contact signal was nearly the same magnitude as the detector signal. It is expected that the contact signal is from pinholes in the metallization that have been seen in SEM photographs. The contribution to the total signal by the contacts adds a worriesome unknown because it is not clear how this signal is modeled and whether it is stable.

A further issue to be discussed is the efficiency of the aplanat lens. NIST has computed the ratio of the signal after the installation of an aplanat lens to that before for the $7-\mu \mathrm{m}, 11-\mu \mathrm{m}$, and $12-\mu \mathrm{m}$ detectors. The $7-\mu \mathrm{m}$ detectors have an average ratio of 10.1 with a standard deviation of 0.428 . The $11-\mu \mathrm{m}$ detectors have an average ratio of only 6.88 with a standard deviation of 1.69 . The $12-\mu \mathrm{m}$ detectors have a similar average ratio of 5.27 with a standard deviation of 1.55 . This shows that the aplanat lens is less effective for the 11 - and $12-\mu \mathrm{m}$ detectors, probably because of their smaller size and the difficulty in optimally positioning the aplanat.

NIST notes that Detector 11-105, which showed signal degradation, has a ratio of 10.1 , which is very high for the $11-\mu \mathrm{m}$ detectors. Detector $12-103$ has a ratio of 8.2 , and $12-102$ has one of 5.8 , 
which are high for the $12-\mu \mathrm{m}$ detectors. These detectors also showed signal degradation. Thus, it is possible that thermal cycling or aging caused the lenses to shift somewhat and reduce their effectiveness with a concomitant decrease in the signal.

In summary, NIST has shown that the metallization of inspected detectors contains numerous voids, which could lead to photosensitivity of the contacts as well as high contact resistance. Signals from the contact areas could change with time and thus contribute to the degradation or instability of the detectors. NIST has also shown that a significant amount of mercury could diffuse into the detectors from the ion-milled regions in about a year and cause the signal to decrease. Other problems with the fabrication and packaging were found as well. 


\section{CONCLUSIONS}

The primary conclusion that can be drawn from a review of the available data on the $7-\mu \mathrm{m}, 11$ $\mu \mathrm{m}$, and $12-\mu \mathrm{m}$ detectors is that one cannot have confidence that the $11-\mu \mathrm{m}$ and $12-\mu \mathrm{m}$ detectors will perform satisfactorily over time during the mission. Several companion detectors to those presently in the flight system have shown decreases in signal over time that cannot be accounted for on the basis of experimental uncertainty. A statistical analysis performed on the $11-\mu \mathrm{m}$ detectors showed that three of the nine detectors had decreased in signal over time. It also showed that no measurement bias due to reflections from the tube between the blackbody source and the detector, which was removed in September 1990 by a series of baffles, existed. The 7- $\mu \mathrm{m}$ detectors, on the other hand, did not show any appreciable signal decrease with time.

The causes of the signal decrease cannot be determined uniquely because no obvious correlations could be drawn from the available data. However, possible causes for the signal decrease have been considered. The ion-milling process introduces a thin layer of excess mercury, which could diffuse into the bulk in about a year. The resulting increase in electron density could cause the signal to decrease primarily because of the sweepout effect. Variability in the passivation process could cause variability in signal, and sensitivity of the surface to ambient conditions could cause the signal to vary with time.

The quality of the contacts has also been shown to be questionable and may contribute to signal decrease and instability. Many $11-$ and $12-\mu \mathrm{m}$ detectors had unexpectedly high values of resistance both at 105 and $300 \mathrm{~K}$, which can be attributed to contact resistance. Measurements have also shown that the contact areas are photosensitive, which is probably due to voids in the metallization. Since these areas can contribute to the overall signal, some of the signal decrease and instability can be attributed to them. There is no way to model these regions because of their unknown physical properties, but they are worrisome with regard to detector reliability.

The detectors studied by the Degradation Task Force Team were examined by optical and SEM microscopy and also mechanically tested. In addition, one detector mounted in a flight package was also examined. The assembly techniques were extremely poor. The large variations in wire bond strengths indicated that the operation was not in control and is considered to be unreliable. Further, the choice of materials (e.g., silicone rubber, epoxies, and solder) is extremely poor and can lead to degradation or actual failures. The indium-plated electrodes on the detectors are porous and have grainy or wormy structures, with individual grains often appearing not to be in contact with their neighbors. A degradation model based on this observation is proposed that explains other observed anomalies such as light sensitivity over the electrode areas. When examined with Nomarski microscopy, several detectors showed evidence of the $\mathrm{ZnS}$ optical coating delaminating from the detector, and this offered another possible degradation mechanism. This delamination is attributed to poor or uncontrolled detector manufacturing and processing steps. The detector in the flight package revealed an additional reliability problem not observed in the devices studied by the Degradation Task Force. This and all flight detectors use tin-lead solder to couple the fine gold wire (bonded to the detector) to the package terminal. Tin can dissolve and/or form brittle intermetallics with the fine gold wire. Such usage is avoided in the microelectronics industry. SEM examination of the wire-to-solder joints revealed both intermetallics and cracks in the wire which can be an additional reliability problem. 
NIST suggests the following explanation for some of the observed degradation. It is based upon the wormy nature of the indium metallization, the optical signals observed in the region of the indium metallization, and the high contact resistance measured on many of the detectors. If the conductivity of the indium metallization is dominated by tiny (essentially pressure-type) contact areas at specific points on the indium worms, then the indium film will have a high resistivity. These interface areas may be subject to oxidation or chemical attack. High-resistance interfaces will be put under stress during various temperature excursions, and thus the contact resistance of the indium could change over time. When the indium film offers a sufficiently high resistance, then some of the bias field will appear in a shunt path in the underlying $\mathrm{HgCdTe}$ film. The field will no longer be shorted out from the wire bond to the detector area by the indium. Any light that falls in the voids between the indium grains will generate carriers that will be detected. Without such electric fields in the underlying $\mathrm{HgCdTe}$, there could be no photosignals originating from the indium "covered" contact region. Such optical sensitivity is a direct test of both the porosity and the resistivity of the film. Thus, on the basis of this model, a decrease in resistance (attributed to a decrease in contact resistance) would be related to a decrease in signal (the part generated by the indium voids), as observed in the data.

On the basis of the above observations, NIST feels that use of these detectors would be an unnecessary risk for the GOES mission. 


\section{RECOMMENDATIONS FOR FUTURE WORK ON NEW DETECTORS FOR THE GOES PROGRAM}

NIST recommends that the reliability of any detectors used in the GOES system be evaluated as rigorously as possible prior to launch. The tools and information to implement this recommendation need to be developed. A carefully planned series of experiments needs to be carried out to determine the characteristics of the detectors and their variation in time. It is not clear that accelerated life tests can furnish accurate information regarding the stability of these detectors, and thus NIST recommends that tests designed to assess the quality of the detectors should be performed.

NIST specifically recommends:

1. Monitoring the resistance of the detectors at both room and low temperature over time. Any appreciable changes should raise suspicions. The current-voltage characteristics should also be investigated as a function of temperature. Any nonlinearities are a sign of poor processing.

2. Hall-effect measurements on typical passivated detector material to determine the properties of the passivation process. The two-layer model of Petriz [8.1] can be used to determine the surface mobility and surface charge density if the bulk properties are known. It is also worth considering high-magnetic-field measurements of the magnetoresistance, i.e., the Shubnikov-de Haas effect, which has been shown to be sensitive to the properties of the upper and lower passivation regions [8.2].

3. Visual and SEM inspection of the processing and packaging. Defective techniques and workmanship can be identified, which could lead to failure prior or during the mission.

4. A program should be worked out to ensure manufacturing quality and overall system performance. This includes documenting the procedures for fabrication and assembly as well as the procedures for calibration and testing. A program should be developed and put in place to retest the various detectors and their associated optics during the time between manufacture and deployment. This program is essential to ensure that launched devices are performing and operating in a known manner and that they will return reliable information on a long-term basis. A program could also be developed to ensure an in-flight calibration strategy for the detector systems while the mission is ongoing to ensure reference to a stable calibration base. 


\section{REFERENCES}

1.1 Reproduction from the NASA/LORAL/ITT Briefing to the GOES Assessment Team on August 26, 1991 at Fort Wayne, Indiana, p. C2.

2.1 Reproduction from May 2, $1991 \mathrm{HgCdTe}$ Detector Degradation Task Force Meeting Booklet, p. 76.

4.1 Private communication of these results obtained from ITT.

4.2 M.A. Kinch, S.R. Borrello, and A. Simmons, Infrared Physics, $0.1 \mathrm{eV} \mathrm{HgCdTe}$ Photoconductive Detector Performance, Infrared Physics 17, 127 (1977).

4.3 Data presented at the June 12, 1991 GOES Detector Manufacturing Readiness Review at ITT.

6.1 May 2, $1991 \mathrm{HgCdTe}$ Detector Degradation Task Force Meeting Booklet, pp. 53, 54, and 57.

6.2 Y. Nemirovsky and I. Kidron, The Interface between $\mathrm{Hg}_{1-\mathrm{x}} \mathrm{Cd}_{\mathrm{x}} \mathrm{Te}$ and its Native Oxide., Solid-State Electronics 22, 831-837 (1979).

6.3 G. Bahir and E. Finkman, Ion Beam Milling Effect on Electrical Properties of $\mathrm{Hg}_{1-\mathrm{x}} \mathrm{Cd}_{\mathrm{x}} \mathrm{Te}$, J. Vac. Sci. Technol. A7, 348-353 (1989).

6.4 R. Dornhaus and G. Nimtz, The Properties and Applications of the $\mathrm{Hg}_{1-\mathrm{x}} \mathrm{Cd}_{\mathrm{x}} \mathrm{Te}$ Alloy System, Springer Tracts in Modern Physics 98 (Springer-Verlag, New York, 1983).

6.5 H.M. Nitz, O. Ganschow, U. Kaiser, L. Wiedmann, and A. Benninghoven, Quasisimultaneous SIMS, AES, XPS, and TDMS Study of Preferential Sputtering Diffusion, and Mercury Evaporation in $\mathrm{Cd}_{x} \mathrm{Hg}_{1-\mathrm{x}} \mathrm{Te}$, Surf. Sci. 104, 365 (1981).

6.6 R.M. Bouky and V.J. Mazurezyk, (HgCd)Te Photoconductive Detectors, in Semiconductors and Semimetals, Vol. 18, R.K. Willerdeon and A.C. Beer, Eds. (Academic Press, New York, 1981).

8.1 A. Many, Y. Goldstein, and M. B. Grover, Semiconductor Surfaces (Wiley, New York, 1965), pp. 295-299.

8.2 J. Singleton, F. Nasir, and R. J. Nicholas, High-Magnetic Field Characterization of (Hg,Cd)Te Detectors, SPIE, Vol. 659, pp. 99-108, 1986. 


\section{Appendix A}

Interim Report Submitted Earlier to NOAA:

Signal Reduction/Instability Analysis of Four HgCdTe Detectors for the GOES Program 


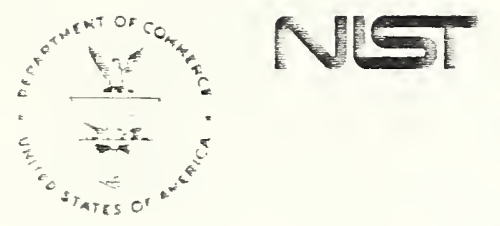

August 5, 1991

(Revised October 3, 1991)

\section{MEMORANDUM FOR Thomas McGunigal GOES Program Manager NOAA/NESDIS}

From: David G. Seiler

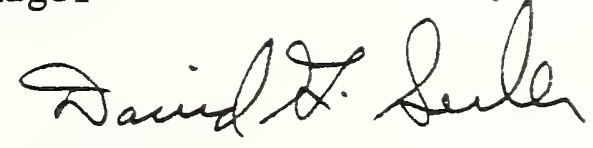

Semiconductor Electronics Division

Subject: Signal Reduction/Instability Analysis of Four HgCdTe Detectors for the GOES Program

\section{INTRODUCTION}

- At the request of NOAA, NIST is examining the data taken by the companies that manufactured and tested the mercury cadmium telluride (HgCdTe) detectors for the GOES Program.

- This is an interim report which shows that, for at least some of the detectors, the measured reduction in signal cannot be fully accounted for by the measurement uncertainties reported to NIST by those who performed the measurements. NIST has been reviewing all of the detector data for a more comprehensive analysis and report that subsequently will be submitted to NOAA. This report will include reviews of data on seven channel-3 (7 micrometers wavelength), nine channel-4 (11 micrometers), and eight channel-5 (12 micrometers) detectors.

- We present here the data and analysis in graphical and tabular form covering four selected detectors: 11-105, 12-102, 12-108, 12-112.

- On the basis of statements made by the manufacturer of the detectors, NIST has used upper and lower bounds for measurement uncertainty and repeatability of $\pm 10 \%$, excluding the effects of the glint problem identified below. 
- One of the most difficult uncertainties in establishing the magnitude of the degradation has been the so called "glint" problem. This arose because early signal measurements at the supplier (before September 1990) could have involved unwanted reflections of blackbody radiation from the sidewalls of a tube placed between the blackbody and the detector. These unwanted reflections could have enhanced the signal by as much as $25 \%$ (according to staff at the supplier). The supplier reported that this problem was corrected in August of 1990 by putting baffles in the tube. Thus, signal measurements before September 1990 may be systematically high by as much as $25 \%$ and the systematic error can range from 0 to $25 \%$. To account for this possible effect, the observed signal levels subject to this problem must be multiplied by, at most, a factor of 0.8 .

- This possible systematic error of 0 to $25 \%$ in the initial signal measurements cannot be simply subtracted from the percent degradation value. Rather the effect of this glint on the amount of degradation must be calculated from the ratio of the signals.

- The reduction in the signal from a detector measured under similar conditions is presented in two equivalent ways. The first is a ratio of signal levels, with the level measured at a later time as the numerator and the level measured at a prior time as the denominator. The second is a percent reduction in signal level as defined by the difference between the measurements earlier and later divided by the signal level at the earlier time, all multiplied by 100 . 


\section{DATA AND ANALYSIS}

\section{Detector $11-105(43784-4)$}

- This detector was fabricated from wafer 非3948-33 and is from location C8 on the wafer map supplied by the manufacturer.

- The following average parameters were calculated from the four elements of this detector from data obtained from the Aerospace/Communications Division of ITT, the Program data base manager. All measurements discussed in this report were made by the supplier, except as indicated; all measurements were made with the detectors held at $105 \mathrm{~K}$ except as noted:

\begin{tabular}{|c|c|c|c|c|}
\hline Date & Time (days) & $\begin{array}{c}\text { Average } \\
\text { Resistance }(\Omega)\end{array}$ & $\begin{array}{c}\text { Average } \\
\text { Signal }(\mu \mathrm{V})\end{array}$ & $\begin{array}{c}\text { Pre or Post } \\
\text { Aplanat }\end{array}$ \\
\hline $12 / 23 / 88$ & 0 & 82.6 & 0.186 & Pre \\
\hline $01 / 18 / 89$ & 25 & 82.3 & 0.198 & Pre \\
\hline $01 / 25 / 89$ & 32 & 82.1 & 0.196 & Pre \\
\hline $02 / 15 / 89$ & 52 & 79.3 & 1.779 & Post \\
\hline $08 / 01 / 89$ & 218 & 79.0 & 1.776 & Post \\
\hline $03 / 20 / 91$ & 818 & 59.8 & 0.573 & Post $(\text { ITT })^{++}$ \\
\hline with 8 & $\mathrm{~K}$ Temperature & ion 61.4 & 0.716 & Post (ITT) \\
\hline $06 / 12 / 91$ & 900 & 60.0 & 0.752 & Post \\
\hline
\end{tabular}

+ The entries "Pre" and "Post" identify whether a lens (the aplanat) was mounted on the detector housing. The presence of the lens increases the measured signal level from the detector (but affects the resistance minimally). The associated plot (Fig. 1) does not include the "Pre" entries for the signal level.

++ Measurement temperature is estimated to be $113 \mathrm{~K}$.

- Large changes in both resistance and signal are observed.

- There are two initial post-aplanat measurements, both made by the supplier, that are in agreement $(-1 \%)$, and both the temperature-corrected measurement at ITT ( 818 days) and the one at the supplier ( 900 days) are in agreement to within a few percent. 
- The post-aplanat raw signal decreased by $58 \%$ from $2 / 15 / 89$ to $6 / 12 / 91$; this decrease was the basis for ITT's report to NOAA of degradation in this detector.

- The actual signal variation must take into account the possibility of glint on the signals measured before September 1990 which may have been artificially too high by 0 to $25 \%$.

- Calculations with and without glint correction:
Signal (nV)/Date
Signal (nV)/Date
Ratio ( $\pm 20 \%)$
Signal
Reduction
no correction for glint -

$$
1779 /(2 / 15 / 89)
$$
$752 /(6 / 12 / 91)$
$(0.42 \pm 0.08)$
$(58 \pm 8) \%$
corrected for $25 \%$ glint -

$$
1423 /(2 / 15 / 89)
$$
$752 /(6 / 12 / 91)$
$(47 \pm 11) \%$

- Bounds of $\pm 20 \%$ on the ratio were obtained by applying the $\pm 10 \%$ bounds discussed previously to the numerator and denominator.

- Detector 11-105 thus demonstrates the existence of signal degradation because the signal reduction is greater than can be explained on the basis of glint and other measurement error. Note that if there were no signal reduction, the ratio would be 1.0 .

- This analysis shows that the signal reduction is greater than can be explained by the bounds for measurement uncertainty and repeatability and for the effects of glint, as assigned by those conducting the measurements. 


\section{Detector 12-102}

- This detector comes from wafer 非3948-33 and is from location C2 on the wafer map supplied by the manufacturer.

- The following average resistance and signal values were calculated from data obtained from ITT. All measurements were made by the supplier, except as indicated; measurements were made with the detectors held at $105 \mathrm{~K}$ except as noted:

\begin{tabular}{|c|c|c|c|c|}
\hline Date & Time (days) & $\begin{array}{c}\text { Average } \\
\text { Resistance }(\Omega)\end{array}$ & $\begin{array}{c}\text { Average } \\
\text { Signal }(\mu \mathrm{V})\end{array}$ & $\begin{array}{l}\text { Pre or Post } \\
\text { Aplanat }\end{array}$ \\
\hline $12 / 06 / 88$ & 0 & 39.0 & 0.233 & Pre \\
\hline $12 / 14 / 88$ & 8 & 39.6 & 0.216 & Pre \\
\hline $12 / 20 / 88$ & 14 & 39.1 & 0.205 & Pre \\
\hline $02 / 01 / 89$ & 55 & 38.8 & 1.233 & Post \\
\hline $07 / 24 / 89$ & 258 & 38.5 & 1.231 & Post \\
\hline $06 / 11 / 90$ & 551 & only 3 ele & ts measured & shown in graph \\
\hline $02 / 19 / 91$ & 805 & 36.8 & 0.424 & $\operatorname{Post}(\operatorname{ITT})^{+}$ \\
\hline with 8 & $\mathrm{~K}$ Temperature & ion 37.3 & 0.458 & Post (ITT) \\
\hline $06 / 12 / 91$ & 917 & 37.1 & 0.762 & Post \\
\hline
\end{tabular}

+ The associated plot (Fig. 2) does not include the "Pre" entries for the signal level.

+ Measurement temperature is estimated to be $113 \mathrm{~K}$.

- The resistance decreases slightly with time.

- The post-aplanat raw signal decreased by $38 \%$ from $2 / 1 / 89$ to $6 / 12 / 91$ and also was used in ITT's reports to NOAA. 
- Calculations with and without glint correction:

$$
\begin{array}{lllll}
\text { Signal (nV)/Date } & \text { Signal (nV)/Date } & \text { Ratio }( \pm 20 \%) & \begin{array}{c}
\text { Signal } \\
\text { Reduction }
\end{array} \\
\text { correction for glint - } & & & \\
1233 /(2 / 1 / 89) & 762 /(6 / 12 / 91) & (0.62 \pm 0.12) & (38 \pm 12) \%
\end{array}
$$

corrected for $25 \%$ glint

$$
986 /(2 / 1 / 89) \quad 762 /(6 / 12 / 91) \quad(0.77 \pm 0.20) \quad(23 \pm 20) \%
$$

- Detector 12-102 may have experienced only a slight signal reduction or a major one. The glint problem prevents a clear assessment of the amount of reduction.

\section{Detector $12-108(45758-4)$}

- This detector comes from wafer 非3948-33 and is from location D5 on the wafer map. No aplanat lens was ever installed and the signal strengths are correspondingly much lower than the previous two detectors. The detectors that do not have aplanat lenses can have experienced different ambient related phenomena and therefore their signal behaviors may not be directly comparable to those of the post-aplanat detectors.

- The following average resistance and signal values were calculated from data obtained from ITT. All measurements were made by the supplier except as indicated; all measurements were made with the detectors held at $105 \mathrm{~K}$ except one by Cincinnati Electronics (CE) on 12/12/90:

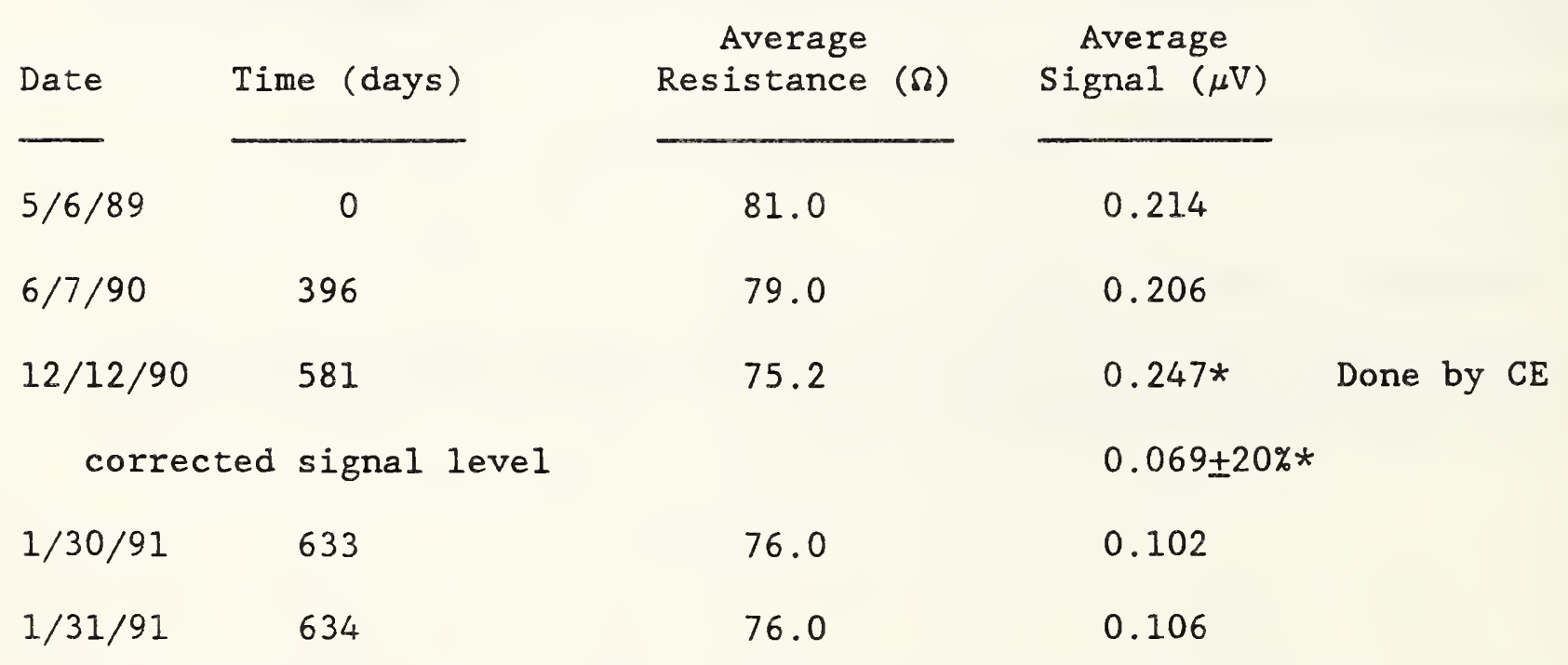

* Note that $\mathrm{CE}^{\prime}$ 's test conditions used greater flux levels incident on the 
detector. According to calculations by Jeff Derr of ITT, to normalize this signal with the other data, the level must be reduced by a factor of 3.6 (with an uncertainty $\pm 20 \%$ ).

- The associated plot is shown in Figure 3.

- The resistance decreases slightly with time.

- The raw signal decreases by $50 \%$ from $5 / 6 / 89$ to $1 / 31 / 91$; this decrease was the basis for ITT's report to NOAA of degradation in this detector.

- Calculations with and without glint correction:
Signal (nV)/Date
Signal (nV)/Date
$\operatorname{Ratio}( \pm 20 \%)$
Signal
$\overline{\text { orrection for glint. }}$

$$
214 /(5 / 6 / 89)
$$
$106 /(1 / 31 / 91)$
$(0.50 \pm 0.10)$
$(50 \pm 10) \%$
corrected for $25 \%$ glint -

$$
171 /(5 / 6 / 89)
$$
$106 /(1 / 31 / 91)$
$(0.62 \pm 0.12)$
$(38 \pm 12) \%$

- This analysis shows that the signal reduction is greater than can be explained by the bounds for measurement uncertainty and repeatability and for the effects of glint, as assigned by those conducting the measurements.

\section{Detector 12-112 (example from another wafer)}

- This detector was fabricated from a separate wafer 非-3968-37. No aplanat was installed and the signal strengths are correspondingly much lower than the first two detectors.

- The detectors that do not have aplanat lenses can have experienced different ambient related phenomena and therefore their signal behaviors may not be directly comparable to those of the post-aplanat detectors.

- The signal behavior shows a strong instability, with the signal decreasing by $-68 \%$ from $8 / 1 / 90$ to $11 / 9 / 90$ and then recovering to the original signal level by $4 / 22 / 91$. 
- The following were calculated from data obtained from ITT (all measurements were made by the supplier at $105 \mathrm{~K}$ ):

\begin{tabular}{lccc} 
Date & Time (days) & $\begin{array}{c}\text { Average } \\
\text { Resistance }(\Omega)\end{array}$ & $\begin{array}{c}\text { Average } \\
\text { Signal }(\mu \mathrm{V})\end{array}$ \\
\cline { 2 - 3 } $8 / 1 / 90$ & 0 & 90.8 & 0.179 \\
\cline { 3 - 4 } $9 / 11 / 90$ & 40 & 87.4 & 0.122 \\
$11 / 9 / 90$ & 98 & 82.7 & 0.056 \\
$12 / 5 / 90$ & 124 & 80.2 & 0.106 \\
$1 / 24 / 91$ & 173 & 79.3 & 0.131 \\
$1 / 25 / 91$ & 174 & 79.4 & 0.124 \\
$4 / 22 / 91$ & 291 & 76.0 & 0.186
\end{tabular}

- The associated data are shown in Figure 4.

- Note that the resistance continually decreases even though the signal later recovers its original strength. The amount of resistance change from $8 / 1 / 90$ to $4 / 22 / 91$ is $16 \%$, a significant drop in less than one year.

- The raw signal decreases from $8 / 1 / 90$ to $11 / 9 / 90 \quad-68 \%$ and this was also reported by ITT to NOAA. However, the detector appears to be unstable, and the signal recovered to its original value by $4 / 22 / 91$.

- Calculations with and without glint correction:
Signal (nV)/Date
Signal (nV)/Date
Signal
Ratio( $\pm 20 \%$ ) Reduction
no correction for glint.

$$
179 /(8 / 1 / 90)
$$
$56 /(11 / 9 / 90)$
$(0.31 \pm 0.06)$
$(69 \pm 6) \%$
corrected for $25 \%$ glint.

$$
143 /(8 / 1 / 90)
$$
$56 /(11 / 9 / 90)$
$(0.39 \pm 0.08)$
$(61 \pm 8) \%$

- This analysis shows that the signal reduction is greater than can be explained by the bounds for measurement uncertainty and repeatability and for the effects of glint, as assigned by those conducting the measurements. 


\section{SUMMARY AND CONCLUSIONS}

- NIST has studied the data furnished it by ITT on the variation of the resistance and signal of three sets of detectors over time ( $7 \mu \mathrm{m}, 11 \mu \mathrm{m}$, and $12 \mu \mathrm{m}$ wavelength bands). We have selected four detectors, which have exhibited large signal reduction, to present here. We have calculated the signal reduction for these detectors to be:

\begin{tabular}{|c|c|c|}
\hline Detector 非 & Amount of Signal Reduction & Elapsed Time (days) \\
\hline $11-105$ & $(47 \pm 11) \%$ & 900 \\
\hline $12-102$ & $(23 \pm 20) \%$ & 917 \\
\hline $12-108$ & $(38 \pm 12) \%$ & 634 \\
\hline $12-112$ & $(61 \pm 8) \%$ & 291 \\
\hline
\end{tabular}

- These results would refute a hypothesis that no signal reduction or instability has occurred in any of the detectors. Even when the maximum amount of signal difference associated with the "glint" problem and the maximum amount of measurement uncertainty are taken into account, these detectors demonstrate signal reduction/instability.

- NIST notes that its analysis could be improved with further experiments to define the measurement uncertainties better.

- We note that uncertainty about the magnitude of the glint problem could be reduced by doing careful experiments (with and without the baffles) at the supplier on several detectors.

- As seen from the four figures presented (uncorrected data), the variations in resistance and signal are similar for all four elements of each detector. Therefore, it is likely that the variations of the elements of a detector have a common origin. 
Detector 11-105
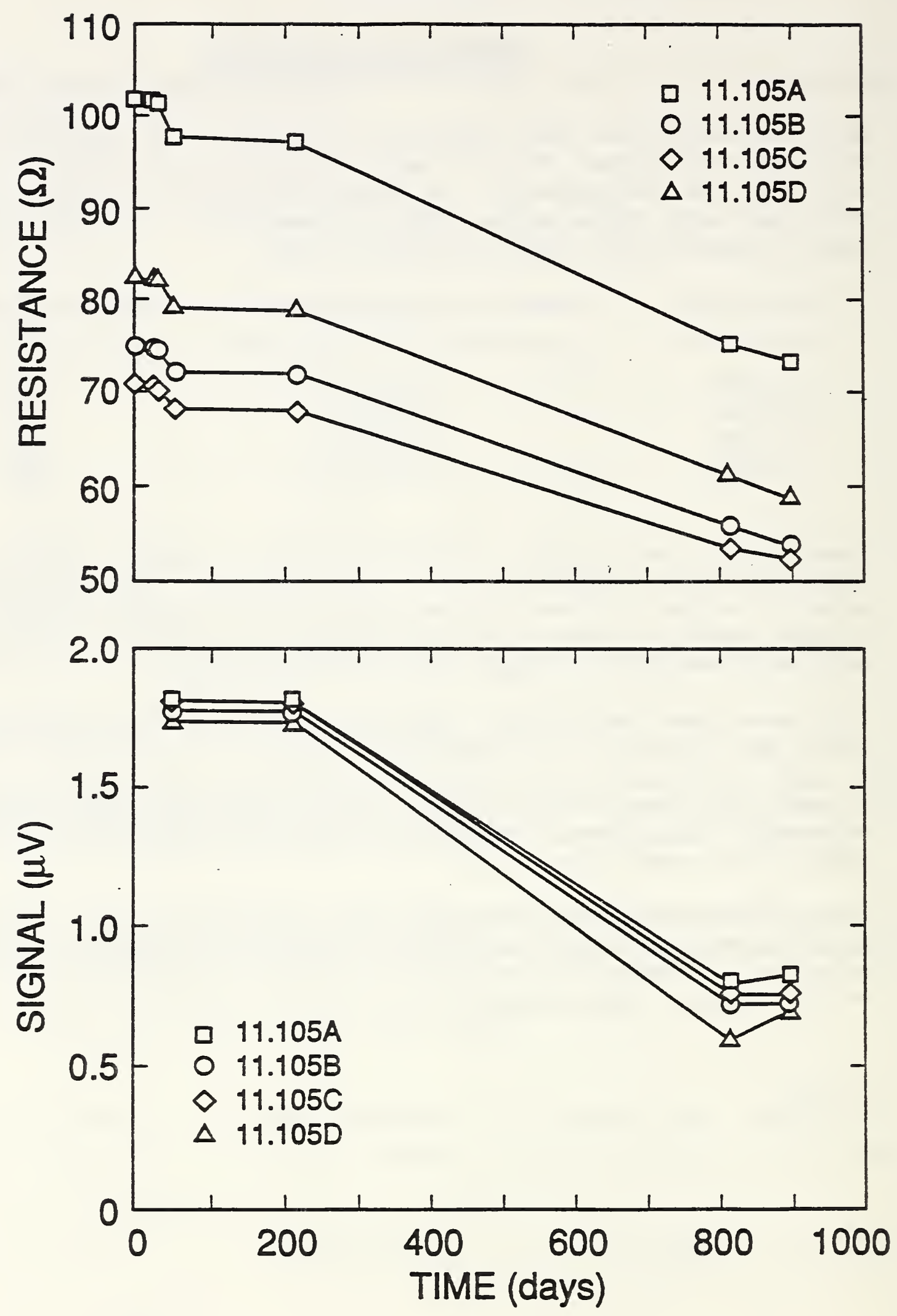

Figure 1. Variation of the resistance and signal of each element with time for detector 11-105 (a four element array) at a temperature of $105 \mathrm{~K}$. All data were obtained from records supplied by ITT. As noted in the Table for 11-105, all data were taken by the supplier, except for the measurements on $3 / 20 / 91$ ( 818 days) which were taken by ITT staff. Only the post-aplanat signal data are plotted. 
Detector 12-102
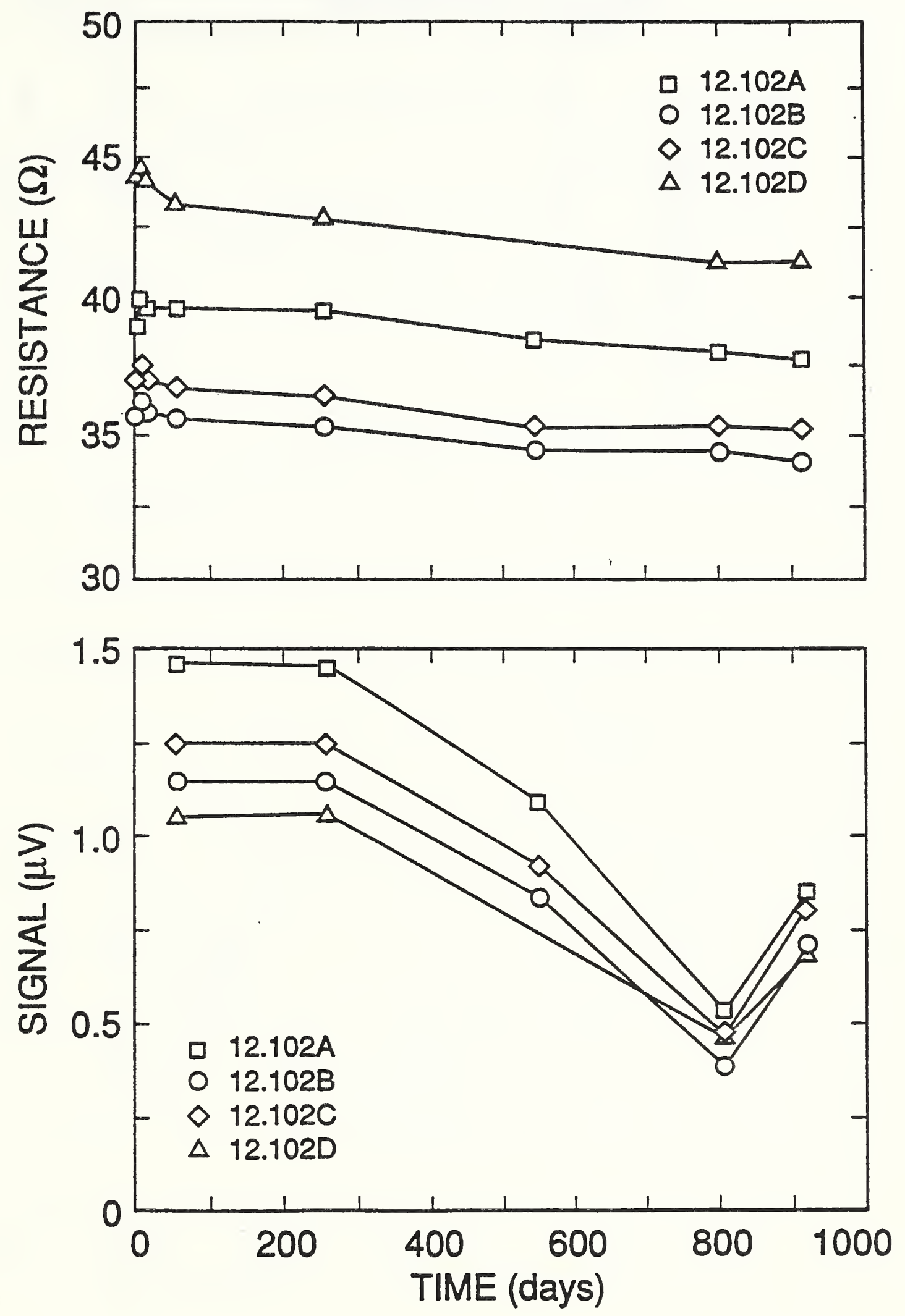

Figure 2. Variation of the resistance and signal of each element with time for detector 12-102 (a four element array) at a temperature of $105 \mathrm{~K}$. All data were obtained from records supplied by ITT. As noted in the Table for 12-102, all data were taken by the supplier, except for the measurements on $2 / 19 / 91$ (805 days) which were taken by ITT staff. Only the post-aplanat signal data are plotted. 

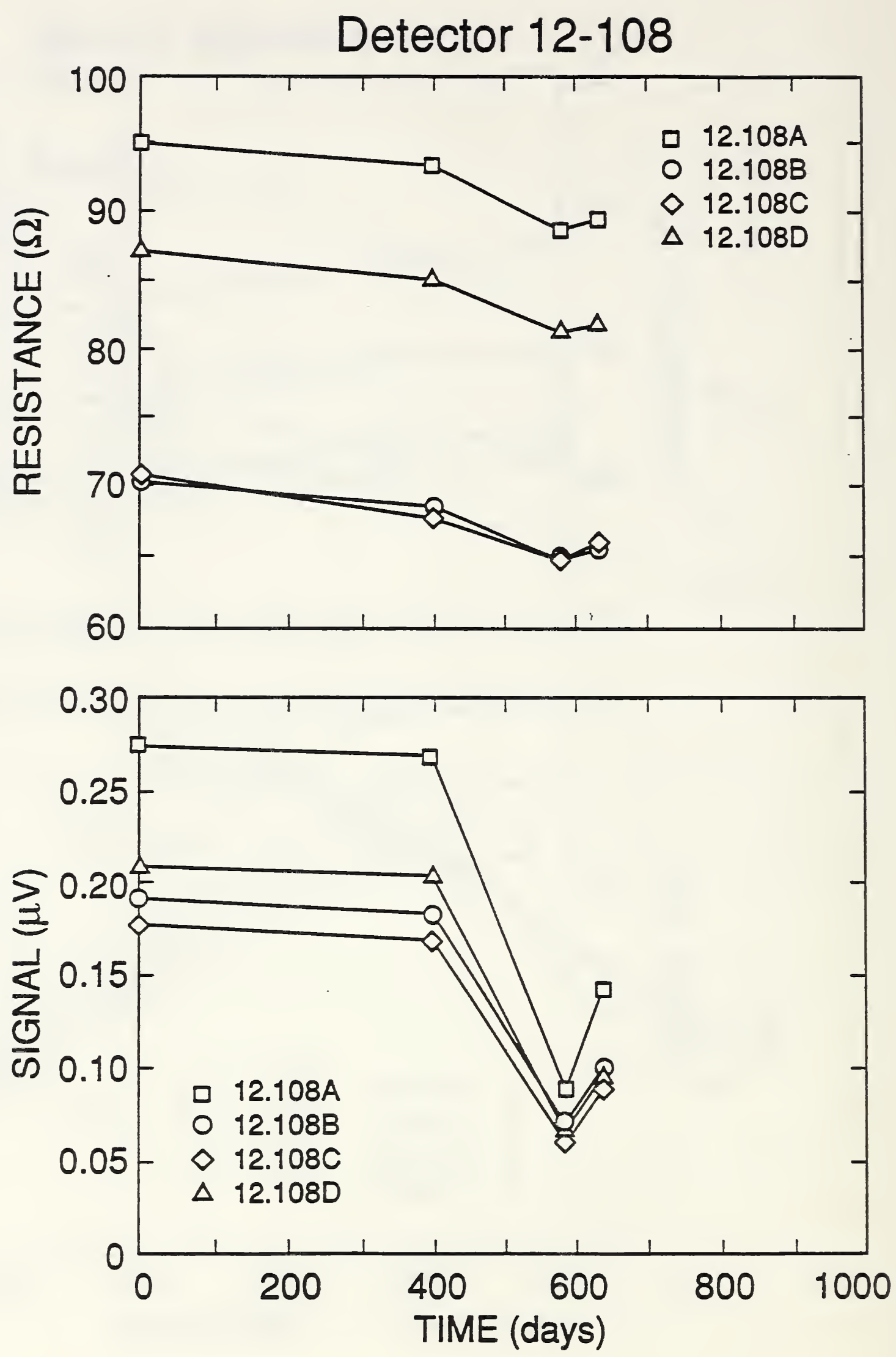

Figure 3. Variation of the resistance and signal of each element with time for detector 12-108 (a four element array) at a temperature of $105 \mathrm{~K}$. All data were obtained from records supplied by ITT. As noted in the Table for 12-108, all data were taken by the supplier, except for measurements on $12 / 12 / 90$ (581 days), which were taken by CE staff. This is a bare detector; no aplanat was ever installed. 

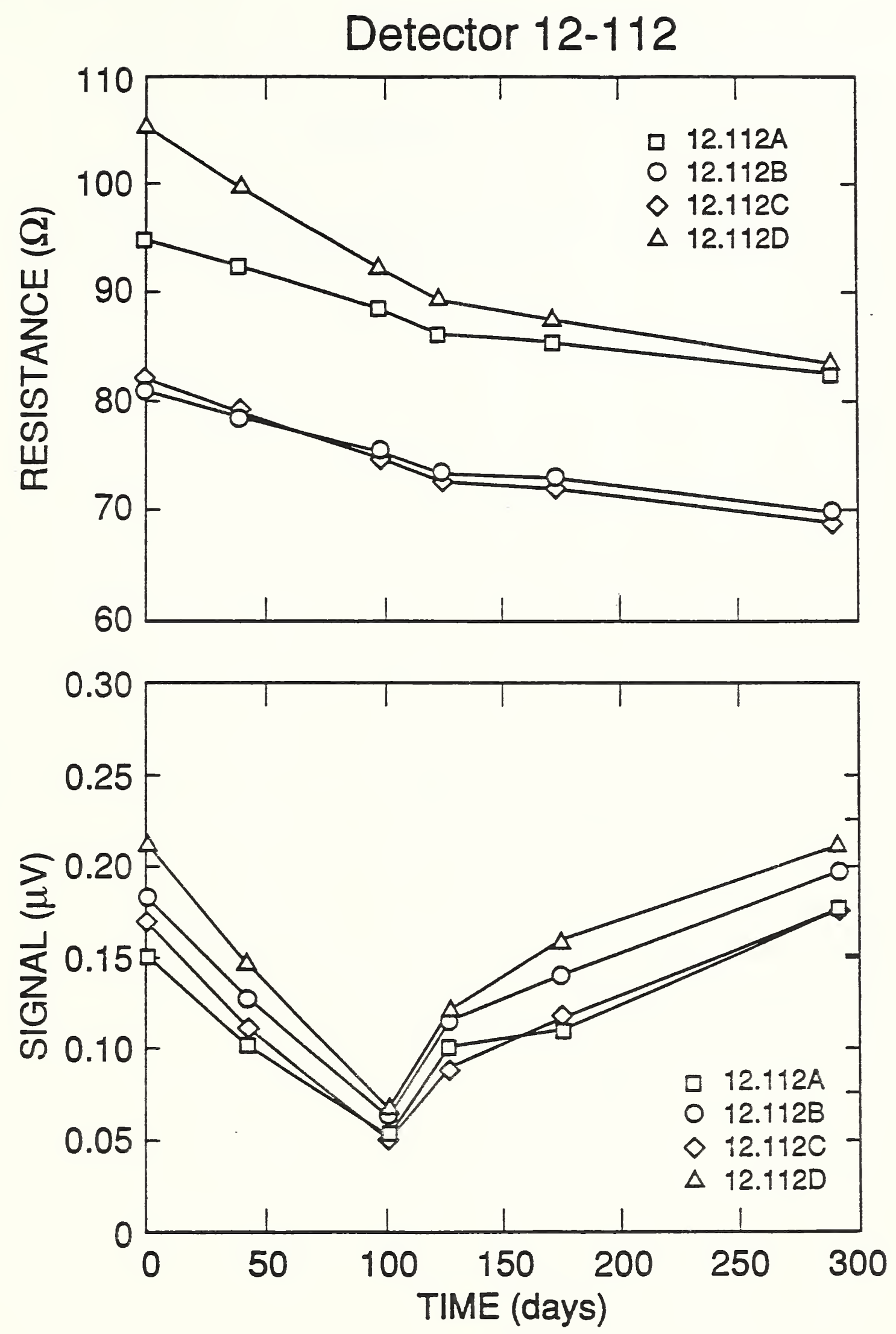

Figure 4. Variation of the resistance and signal of each element with time for detector 12-112 (four element array) at a temperature of 105 K. All data were obtained from records supplied by ITT. As noted in the Table for 12-108, all data were taken by the supplier. This is a bare detector; no aplanat was ever installed. 

Appendix B

Tables of Room-Temperature Resistances of the Imager Detectors at Various Dates and Times. 



\begin{tabular}{|c|c|c|c|c|c|c|c|c|c|c|}
\hline $\begin{array}{l}\text { Detector \# } \\
7-102\end{array}$ & $\begin{array}{l}\text { Area } \\
\text { A } \\
9.93 \\
9.93 \\
9.93\end{array}$ & $\begin{array}{c}E-05 c \\
B \\
10.10 \\
10.10 \\
10.10\end{array}$ & & $D$ & $\begin{array}{c}\text { Date } \\
\text { 09-Nov-88 } \\
23 \text {-Nov-88 } \\
27 \text {-Jul-89 }\end{array}$ & $\begin{array}{l}\text { Time } \\
0 \\
14 \\
260\end{array}$ & $\begin{array}{l}\text { A } \\
67.0 \\
66.0 \\
64.2\end{array}$ & $\begin{array}{c}\text { Resistance } \\
\text { B } \\
65.7 \\
64.5 \\
63.4\end{array}$ & C & $D$ \\
\hline $7-103$ & $\begin{array}{l}9.32 \\
9.32\end{array}$ & $\begin{array}{l}9.56 \\
9.56\end{array}$ & & & $\begin{array}{l}\text { 05-Dec-88 } \\
27-J u l-89\end{array}$ & $\begin{array}{r}0 \\
234\end{array}$ & $\begin{array}{l}51.3 \\
49.4\end{array}$ & $\begin{array}{l}50.8 \\
48.9\end{array}$ & & \\
\hline $7-104$ & $\begin{array}{l}9.32 \\
9.32\end{array}$ & $\begin{array}{l}9.32 \\
9.32\end{array}$ & & & $\begin{array}{l}05-\text { Dec }-88 \\
14-\text { Feb- } 90\end{array}$ & $\begin{array}{r}0 \\
436\end{array}$ & $\begin{array}{l}70.2 \\
69.0\end{array}$ & $\begin{array}{l}68.4 \\
67.2\end{array}$ & & \\
\hline $7-105$ & $\begin{array}{l}9.56 \\
9.56\end{array}$ & $\begin{array}{l}9.56 \\
9.56\end{array}$ & & & $\begin{array}{l}05-\text { Dec }-88 \\
04-\text { Oct-89 }\end{array}$ & $\begin{array}{r}0 \\
303\end{array}$ & $\begin{array}{l}63.3 \\
61.2\end{array}$ & $\begin{array}{l}61.9 \\
59.9\end{array}$ & & \\
\hline $7-107$ & $\begin{array}{l}9.56 \\
9.56\end{array}$ & $\begin{array}{l}10.10 \\
10.10\end{array}$ & & & $\begin{array}{l}28-\text { Feb- } 89 \\
06-\text { Oct- } 89\end{array}$ & $\begin{array}{r}0 \\
220\end{array}$ & $\begin{array}{l}94.9 \\
90.8\end{array}$ & $\begin{array}{l}97.6 \\
93.2\end{array}$ & & \\
\hline $7-111$ & $\begin{array}{l}9.32 \\
9.32\end{array}$ & $\begin{array}{l}9.32 \\
9.32\end{array}$ & & & $\begin{array}{l}06-\text { Dec }-88 \\
20-\text { Feb- } 90\end{array}$ & $\begin{array}{r}0 \\
441\end{array}$ & $\begin{array}{l}52.6 \\
55.5\end{array}$ & $\begin{array}{l}52.3 \\
55.2\end{array}$ & & \\
\hline $11-102$ & $\begin{array}{l}2.27 \\
2.27 \\
2.27\end{array}$ & $\begin{array}{l}2.27 \\
2.27 \\
2.27\end{array}$ & $\begin{array}{l}2.27 \\
2.27 \\
2.27\end{array}$ & $\begin{array}{l}2.09 \\
2.09 \\
2.09\end{array}$ & $\begin{array}{l}29-\text { Nov- } 88 \\
05-\text { DeC }-88 \\
14-F e b-90\end{array}$ & $\begin{array}{r}0 \\
6 \\
442\end{array}$ & $\begin{array}{l}19.4 \\
19.4 \\
17.2\end{array}$ & $\begin{array}{l}18.2 \\
18.2 \\
18.1\end{array}$ & $\begin{array}{l}18.3 \\
18.3 \\
17.9\end{array}$ & $\begin{array}{l}18.8 \\
18.8 \\
18.7\end{array}$ \\
\hline $11-103$ & $\begin{array}{l}2.15 \\
2.15 \\
2.15\end{array}$ & $\begin{array}{l}1.79 \\
1.79 \\
1.79\end{array}$ & $\begin{array}{l}1.79 \\
1.79 \\
1.79\end{array}$ & $\begin{array}{l}2.15 \\
2.15 \\
2.15\end{array}$ & $\begin{array}{l}\text { 06-Dec- } 88 \\
07-F e b-89 \\
27-J u l-89\end{array}$ & $\begin{array}{r}0 \\
63 \\
233\end{array}$ & $\begin{array}{l}20.4 \\
19.7 \\
19.3\end{array}$ & $\begin{array}{l}17.5 \\
16.8 \\
16.6\end{array}$ & $\begin{array}{l}17.0 \\
16.2 \\
16.6\end{array}$ & $\begin{array}{l}18.1 \\
17.6 \\
17.4\end{array}$ \\
\hline $11-104$ & $\begin{array}{l}2.15 \\
2.15\end{array}$ & $\begin{array}{l}2.26 \\
2.26\end{array}$ & $\begin{array}{l}2.26 \\
2.26\end{array}$ & $\begin{array}{l}2.21 \\
2.21\end{array}$ & $\begin{array}{l}16-F e b-89 \\
16-F e b-90\end{array}$ & $\begin{array}{r}0 \\
365\end{array}$ & $\begin{array}{l}18.3 \\
17.8\end{array}$ & $\begin{array}{l}18.1 \\
17.3\end{array}$ & $\begin{array}{l}19.8 \\
18.5\end{array}$ & $\begin{array}{l}26.4 \\
25.6\end{array}$ \\
\hline $11-105$ & $\begin{array}{l}2.09 \\
2.09 \\
2.09\end{array}$ & $\begin{array}{l}2.21 \\
2.21 \\
2.21\end{array}$ & $\begin{array}{l}2.21 \\
2.21 \\
2.21\end{array}$ & $\begin{array}{l}2.09 \\
2.09 \\
2.09\end{array}$ & $\begin{array}{l}23-\text { DeC- } 88 \\
18-\text { Jan- } 89 \\
03 \text {-Aug- } 89\end{array}$ & $\begin{array}{r}0 \\
26 \\
223\end{array}$ & $\begin{array}{l}69.3 \\
67.4 \\
66.3\end{array}$ & $\begin{array}{l}50.7 \\
49.0 \\
48.7\end{array}$ & $\begin{array}{l}49.0 \\
47.2 \\
48.0\end{array}$ & $\begin{array}{l}60.5 \\
58.6 \\
57.9\end{array}$ \\
\hline $11-106$ & $\begin{array}{l}2.21 \\
2.21 \\
2.21\end{array}$ & $\begin{array}{l}2.26 \\
2.26 \\
2.26\end{array}$ & $\begin{array}{l}2.32 \\
2.32 \\
2.32\end{array}$ & $\begin{array}{l}2.21 \\
2.21 \\
2.21\end{array}$ & $\begin{array}{l}23-\text { Jun }-89 \\
01-\text { Jun-90 } \\
19-\text { Dec-90 }\end{array}$ & $\begin{array}{r}0 \\
343 \\
544\end{array}$ & $\begin{array}{l}19.1 \\
18.9 \\
18.9\end{array}$ & $\begin{array}{l}17.6 \\
17.5 \\
17.5\end{array}$ & $\begin{array}{l}17.9 \\
17.7 \\
17.8\end{array}$ & $\begin{array}{l}20.5 \\
20.4 \\
20.3\end{array}$ \\
\hline $11-107$ & $\begin{array}{l}2.21 \\
2.21 \\
2.21\end{array}$ & $\begin{array}{l}2.32 \\
2.32 \\
2.32\end{array}$ & $\begin{array}{l}2.32 \\
2.32 \\
2.32\end{array}$ & $\begin{array}{l}2.21 \\
2.21 \\
2.21\end{array}$ & $\begin{array}{l}17-\text { Feb- } 89 \\
03-\text { Mar- } 89 \\
20-\text { Feb- } 90\end{array}$ & $\begin{array}{r}0 \\
14 \\
368\end{array}$ & $\begin{array}{l}20.9 \\
20.2 \\
20.1\end{array}$ & $\begin{array}{l}19.9 \\
19.1 \\
19.0\end{array}$ & $\begin{array}{l}22.1 \\
21.5 \\
21.2\end{array}$ & $\begin{array}{l}30.8 \\
30.3 \\
30.0\end{array}$ \\
\hline $11-110$ & $\begin{array}{l}2.15 \\
2.15 \\
2.15\end{array}$ & $\begin{array}{l}2.26 \\
2.26 \\
2.26\end{array}$ & $\begin{array}{l}2.21 \\
2.21 \\
2.21\end{array}$ & $\begin{array}{l}2.09 \\
2.09 \\
2.09\end{array}$ & $\begin{array}{l}22-\text { Feb- } 89 \\
06-\text { Mar }-89 \\
10-\text { Oct- } 89\end{array}$ & $\begin{array}{r}0 \\
12 \\
230\end{array}$ & $\begin{array}{l}56.5 \\
56.2 \\
52.6\end{array}$ & $\begin{array}{l}41.2 \\
40.8 \\
37.3\end{array}$ & $\begin{array}{l}40.0 \\
40.0 \\
36.8\end{array}$ & $\begin{array}{l}52.5 \\
52.3 \\
52.5\end{array}$ \\
\hline $11-112$ & $\begin{array}{l}2.15 \\
2.15 \\
2.15\end{array}$ & $\begin{array}{l}2.21 \\
2.21 \\
2.21\end{array}$ & $\begin{array}{l}2.26 \\
2.26 \\
2.26\end{array}$ & $\begin{array}{l}2.09 \\
2.09 \\
2.09\end{array}$ & $\begin{array}{l}01-\text { Mar-89 } \\
23-\text { Mar-89 } \\
23-\text { Oct }-89\end{array}$ & $\begin{array}{r}0 \\
22 \\
236\end{array}$ & $\begin{array}{l}56.3 \\
56.1 \\
52.6\end{array}$ & $\begin{array}{l}42.9 \\
42.7 \\
40.6\end{array}$ & $\begin{array}{l}45.0 \\
45.1 \\
42.4\end{array}$ & $\begin{array}{l}60.5 \\
60.5 \\
56.5\end{array}$ \\
\hline $11-116$ & $\begin{array}{l}2.21 \\
2.21 \\
2.21\end{array}$ & $\begin{array}{l}2.21 \\
2.21 \\
2.21\end{array}$ & $\begin{array}{l}2.15 \\
2.15 \\
2.15\end{array}$ & $\begin{array}{l}2.15 \\
2.15 \\
2.15\end{array}$ & $\begin{array}{l}\text { 08-Mar-89 } \\
18-\text { Apr-89 } \\
\text { 19-DeC-90 }\end{array}$ & $\begin{array}{r}0 \\
41 \\
651\end{array}$ & $\begin{array}{l}29.5 \\
29.1 \\
27.6\end{array}$ & $\begin{array}{l}26.6 \\
26.0 \\
24.6\end{array}$ & $\begin{array}{l}27.7 \\
27.3 \\
25.6\end{array}$ & $\begin{array}{l}37.5 \\
38.1 \\
35.8\end{array}$ \\
\hline $12-102$ & $\begin{array}{l}2.09 \\
2.09\end{array}$ & $\begin{array}{l}2.21 \\
2.21\end{array}$ & $\begin{array}{l}2.15 \\
2.15\end{array}$ & $\begin{array}{l}2.09 \\
2.09\end{array}$ & $\begin{array}{l}06-\text { Dec }-88 \\
14-\text { Dec- } 88\end{array}$ & $\begin{array}{l}0 \\
8\end{array}$ & $\begin{array}{l}20.7 \\
20.5\end{array}$ & $\begin{array}{l}19.7 \\
19.8\end{array}$ & $\begin{array}{l}21.7 \\
21.6\end{array}$ & $\begin{array}{l}31.2 \\
31.2\end{array}$ \\
\hline $12-103$ & $\begin{array}{l}2.21 \\
2.21\end{array}$ & $\begin{array}{l}2.26 \\
2.26\end{array}$ & $\begin{array}{l}2.45 \\
2.45\end{array}$ & $\begin{array}{l}2.21 \\
2.21\end{array}$ & $\begin{array}{l}23-\text { DeC }-88 \\
19-J a n-89\end{array}$ & $\begin{array}{r}0 \\
27\end{array}$ & $\begin{array}{l}73.6 \\
73.6\end{array}$ & $\begin{array}{l}56.1 \\
56.1\end{array}$ & $\begin{array}{l}56.7 \\
56.7\end{array}$ & $\begin{array}{l}76.0 \\
76.0\end{array}$ \\
\hline $12-104$ & $\begin{array}{l}2.32 \\
2.32 \\
2.32\end{array}$ & $\begin{array}{l}2.27 \\
2.27 \\
2.27\end{array}$ & $\begin{array}{l}2.21 \\
2.21 \\
2.21\end{array}$ & $\begin{array}{l}2.09 \\
2.09 \\
2.09\end{array}$ & $\begin{array}{l}16-\text { Feb-89 } \\
06-\text { Mar }-89 \\
14-\text { Feb- } 90\end{array}$ & $\begin{array}{r}0 \\
18 \\
363\end{array}$ & $\begin{array}{l}43.3 \\
43.8 \\
39.5\end{array}$ & $\begin{array}{l}37.4 \\
37.9 \\
34.7\end{array}$ & $\begin{array}{l}38.9 \\
39.1 \\
35.5\end{array}$ & $\begin{array}{l}52.4 \\
53 . \\
50.5\end{array}$ \\
\hline $12-105$ & $\begin{array}{l}2.21 \\
2.21 \\
2.21\end{array}$ & $\begin{array}{l}2.21 \\
2.21 \\
2.21\end{array}$ & $\begin{array}{l}2.39 \\
2.39 \\
2.39\end{array}$ & $\begin{array}{l}2.15 \\
2.15 \\
2.15\end{array}$ & $\begin{array}{l}22-\text { Feb- } 89 \\
09-\text { Mar }-89 \\
16-\text { Feb- } 90\end{array}$ & $\begin{array}{r}0 \\
15 \\
359\end{array}$ & $\begin{array}{l}62.1 \\
62.1 \\
56.8\end{array}$ & $\begin{array}{l}46.1 \\
46.1 \\
42.8\end{array}$ & $\begin{array}{l}46.7 \\
46.7 \\
43.9\end{array}$ & $\begin{array}{l}63.7 \\
63.7 \\
58.8\end{array}$ \\
\hline $12-106$ & $\begin{array}{l}2.15 \\
2.15\end{array}$ & $\begin{array}{l}2.27 \\
2.27\end{array}$ & $\begin{array}{l}2.33 \\
2.33\end{array}$ & $\begin{array}{l}2.15 \\
2.15\end{array}$ & $\begin{array}{l}23-F e b-89 \\
20-F e b-90\end{array}$ & $\begin{array}{r}0 \\
362\end{array}$ & $\begin{array}{l}61.3 \\
55.4\end{array}$ & $\begin{array}{l}46.9 \\
42.1\end{array}$ & $\begin{array}{l}50.4 \\
44.3\end{array}$ & $\begin{array}{l}69.7 \\
60.4\end{array}$ \\
\hline $12-108$ & $\begin{array}{l}2.14 \\
2.14\end{array}$ & $\begin{array}{l}2.27 \\
2.27\end{array}$ & $\begin{array}{l}2.19 \\
2.19\end{array}$ & $\begin{array}{l}2.27 \\
2.27\end{array}$ & $\begin{array}{l}06-\text { May- } 89 \\
01-J u n-90\end{array}$ & $\begin{array}{r}0 \\
391\end{array}$ & $\begin{array}{l}69.2 \\
68.7\end{array}$ & $\begin{array}{l}50.3 \\
49.6\end{array}$ & $\begin{array}{l}49.8 \\
49.3\end{array}$ & $\begin{array}{l}64.2 \\
63.7\end{array}$ \\
\hline $12-109$ & $\begin{array}{l}2.15 \\
2.15 \\
2.15\end{array}$ & $\begin{array}{l}2.45 \\
2.45 \\
2.45\end{array}$ & $\begin{array}{l}2.39 \\
2.39 \\
2.39\end{array}$ & $\begin{array}{l}2.15 \\
2.15 \\
2.15\end{array}$ & $\begin{array}{l}05-\text { May- } 89 \\
01-J u n-90 \\
18-D e c-90\end{array}$ & $\begin{array}{r}0 \\
392 \\
582\end{array}$ & $\begin{array}{l}33.2 \\
33.0 \\
32.8\end{array}$ & $\begin{array}{l}24.2 \\
24.2 \\
24.3\end{array}$ & $\begin{array}{l}24.1 \\
24.0 \\
24.0\end{array}$ & $\begin{array}{l}30.4 \\
30.2 \\
30.0\end{array}$ \\
\hline $12-112$ & $\begin{array}{l}2.09 \\
2.09\end{array}$ & $\begin{array}{l}2.33 \\
2.33\end{array}$ & $\begin{array}{l}2.27 \\
2.27\end{array}$ & $\begin{array}{l}2.26 \\
2.26\end{array}$ & $\begin{array}{l}15-\text { May-90 } \\
30-J u l-90\end{array}$ & $\begin{array}{r}0 \\
76\end{array}$ & $\begin{array}{l}85.9 \\
77.4\end{array}$ & $\begin{array}{l}66.7 \\
61.3\end{array}$ & $\begin{array}{l}65.6 \\
62.6\end{array}$ & $\begin{array}{l}81.9 \\
83.2\end{array}$ \\
\hline
\end{tabular}




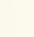


Appendix C

Tables of Resistances and Signals of Each Imager Detector Element at a Temperature of $105 \mathrm{~K}$ as a Function of Date and Time. 

อ

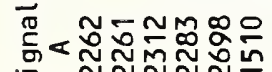

的等

产口

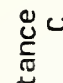

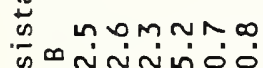

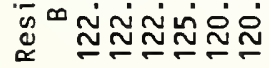

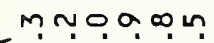

< ํํำฺั

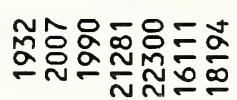

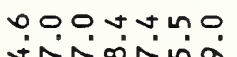

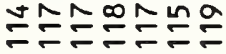

-NN nNom

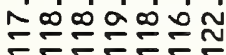

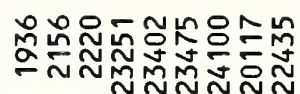

กิำกำㅇำ은

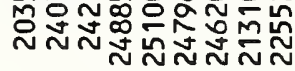

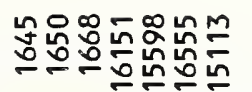

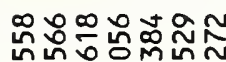

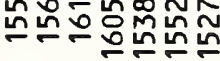

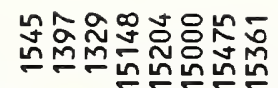

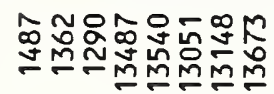

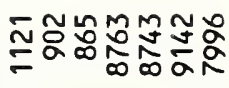

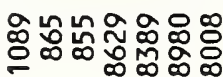

$\infty .-0.90,0 \infty$ мim

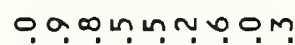

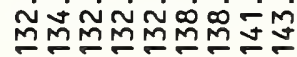

m.บํ.

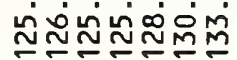
O vo oon un

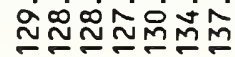

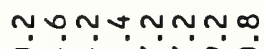

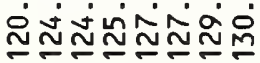
ก ก ง v00

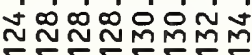

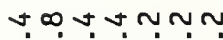

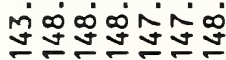
100000N

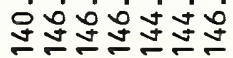

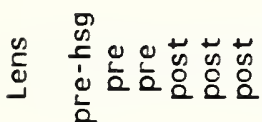

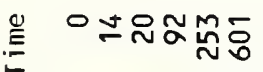

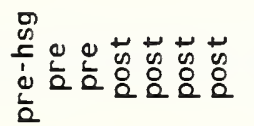

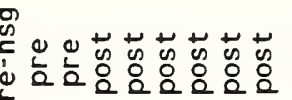 $\frac{1}{2}$

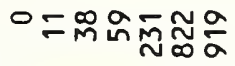

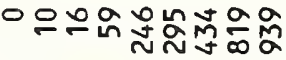

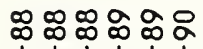

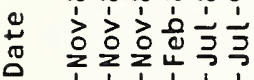
à่

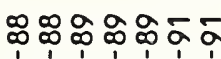

ن́⿺乚一匕

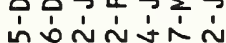

ஜ జూ జ

ن́⿺辶寸

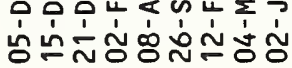

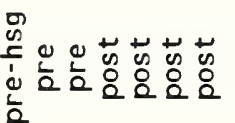

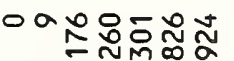

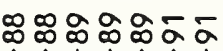

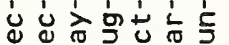

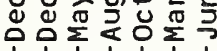

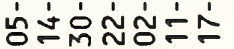

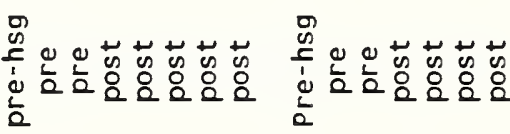

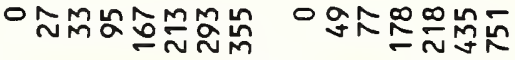

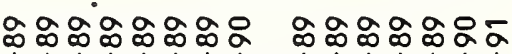

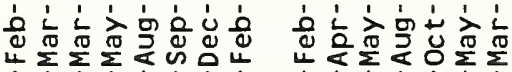

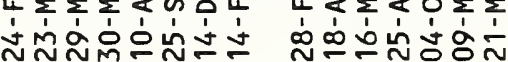

o

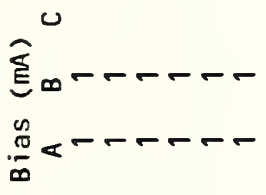

un mn m in un un ०ं0ं0ं0் ○

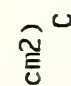
능 $\infty$ 음으으으으으 نํ. ํํํำํำํํํํำ ํำ ááááá ¿áááa

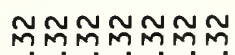
\& áááá araiciaia

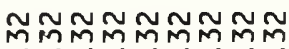
áááááá

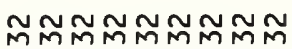
áááááá

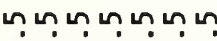
ó0ं0்00 un mun mun man '0ं0்0́0 un un mun un un un '0ं0'000் un mn m m un un ○ं 0ं0் un un un un un m ல் 0் 0் 0் un un m in un un m '0ं0்

*

$\frac{1}{\frac{1}{0}}$

$\stackrel{ }{\frac{0}{1}}$

$\stackrel{\circ}{i}$

$\frac{\hat{O}}{i}$

으으으으으으으 웡ㅇㅇㅇㅇ

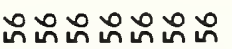
$\bar{\infty} \bar{\infty} \bar{\infty} \bar{\infty}$ ááááááa мамаммамама ํํํํํํํํํํํํํํํํำ

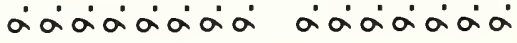
aंaरáa aadaaa 


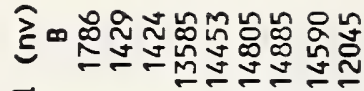

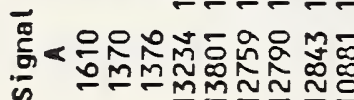

产口

¿ّ山

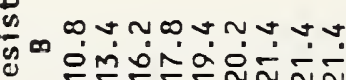

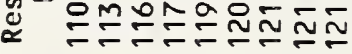
$\infty 0+n 000$ n

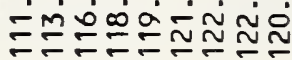

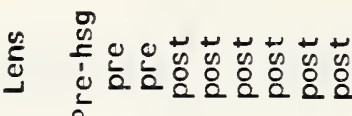

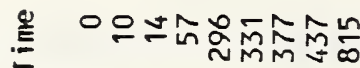

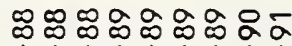

苋

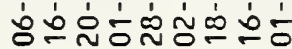

0

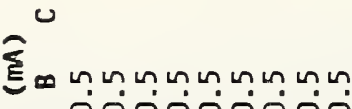
D 000000000

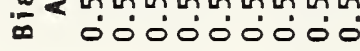

$\circ$

๓ิธ

นั

óajajajaja «

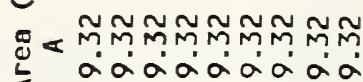

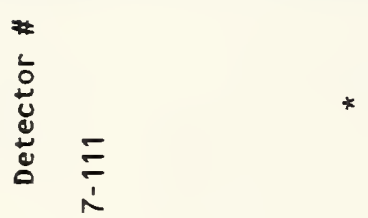

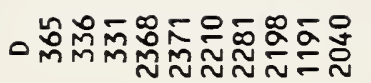

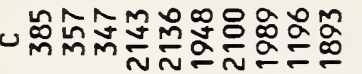

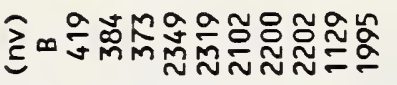

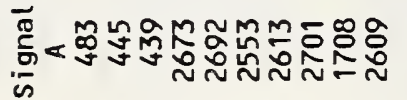

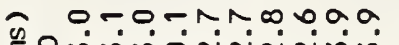

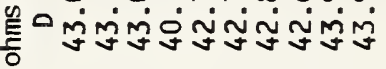

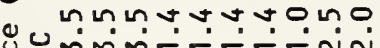

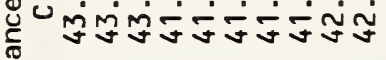

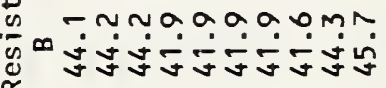

ก บ กนกนกน-R.

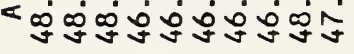

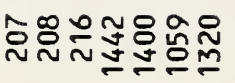

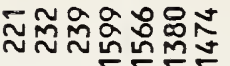

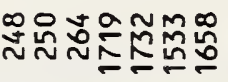

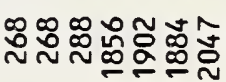

rum--

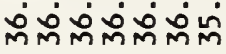

0.0ㅅ แ

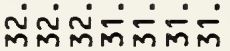

ᄀ $\infty \infty$ un un u

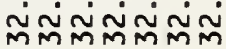

aagoumv

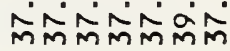

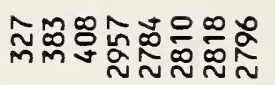

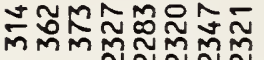

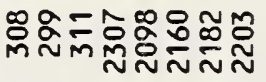

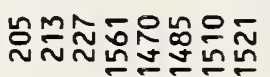

$m \infty N \sim n m=m$

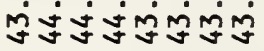

Noninommm

minmisiminisi

n. $00-\infty 000$

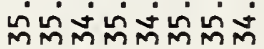

Jocosinnon

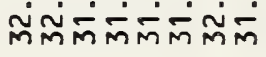

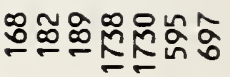

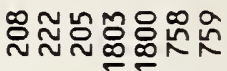

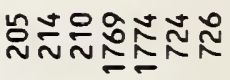

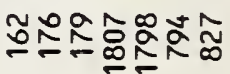

moor $-\infty$

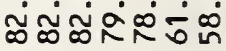

oNmm-

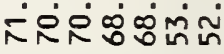

-rr-oma

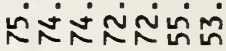

armm-ns

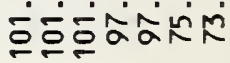

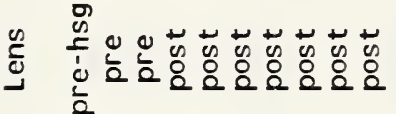

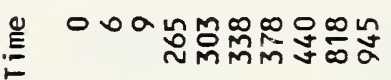

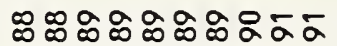

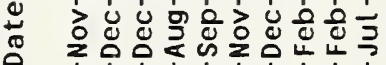

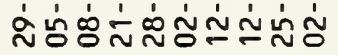

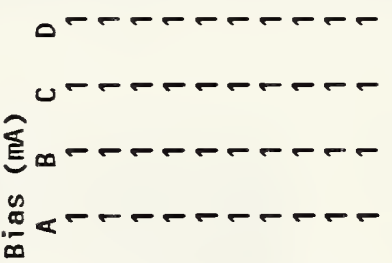

영영ㅁㅇㅁㅇㅇㅇ نñNiñNiñ

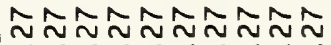

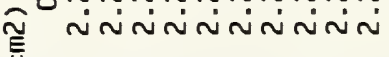
บักลกลกลกลกลก  ש

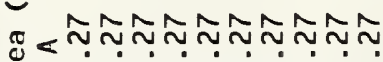
¿

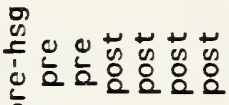
¿

ำㄴํํํํำํํำ

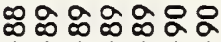

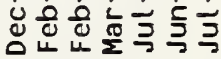

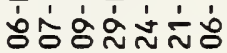

- - - -

NNNNNNN

NกNกN

nNNNMNN

\lfloor inininin

옷옷옷오숭 $\therefore \because \div-$

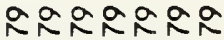
$\because \because-7-4$

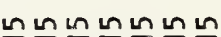
iñininin

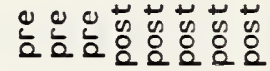

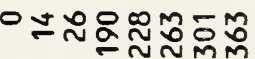

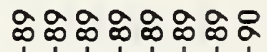

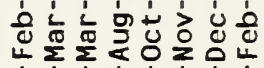

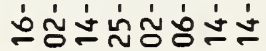

r-r.-

-ror-

r.- $-\cdots$

-ar-

$\bar{\sim} \bar{N} \bar{N} \bar{N} \bar{N} \bar{N}$

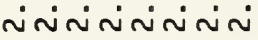

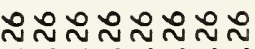
กñNiñn

నినినినిని نñNiñN 느느느는

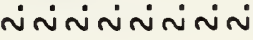

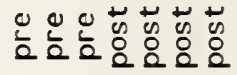

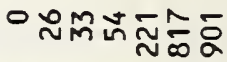

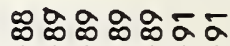

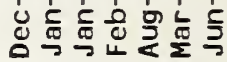

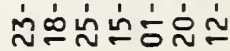

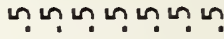

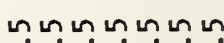
----.-

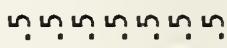
ininumininin

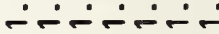

영영ㅇㅇㅇ iñinin

$\bar{\sim} \bar{N} \bar{N} \bar{N} \bar{N}$

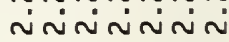

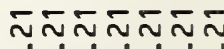
inininis 영영영ㅇ inininin
\#

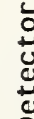

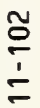

$\stackrel{m}{\underline{I}}$

$\frac{ \pm}{\frac{1}{1}}$

$\frac{\stackrel{n}{\circ}}{\frac{1}{}}$ 


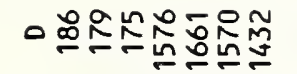

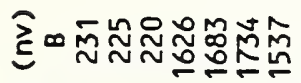

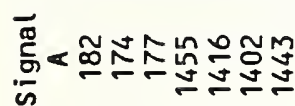

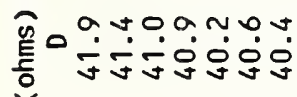

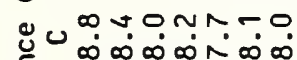

monotor

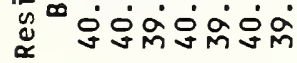

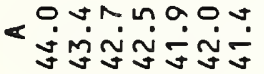

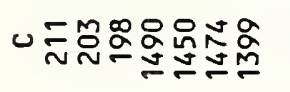

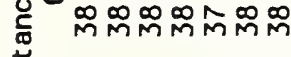

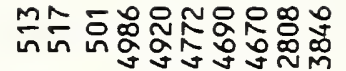

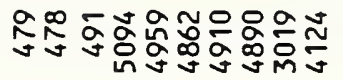

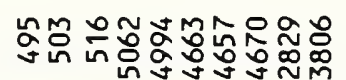

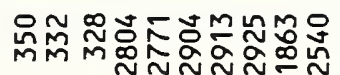

oa unoornan

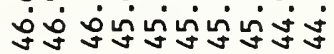

mum $0 \infty a \infty a n$ miñ

ง ? Y vo To

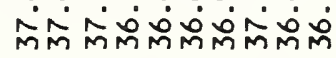

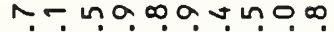

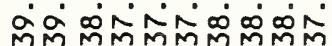

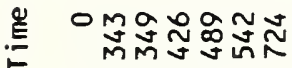

영ㅇㅈㅁ

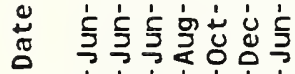

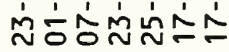

orr-r -

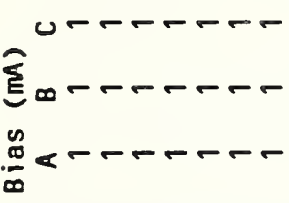

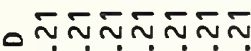

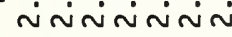

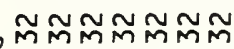

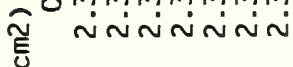

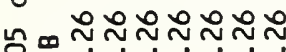

NंNiNiNi

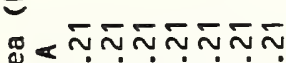

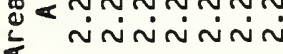

*

志

$\stackrel{8}{!}$

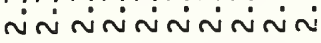
นññññ

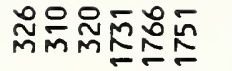

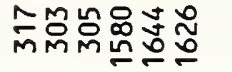

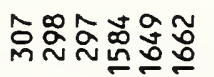

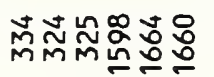

ง $\sim \sim \infty 0$

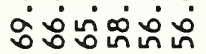

แn $-\infty \sim 0$

㶽约行守守

$\infty \infty \sim \infty \infty$.

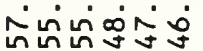

L $\sim \infty \cup \infty 0$

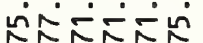

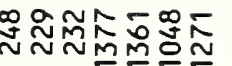

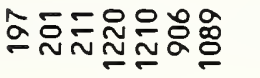

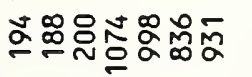

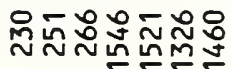

a a an- oo

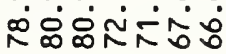

aกN n N M

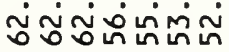

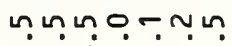

ถึผ

aganann

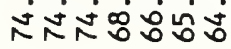

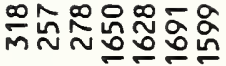

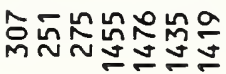

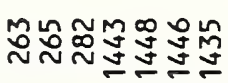

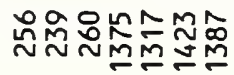

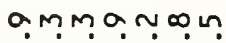
ผึ่

$\infty \infty n-1-$ nูํำ

$\because \multimap \infty m \infty m$

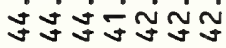

$\sim \infty \infty A m \sim$

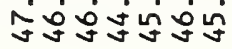

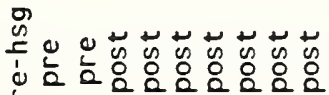
高

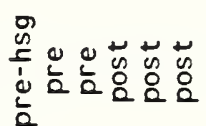

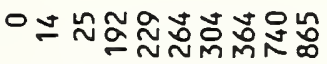

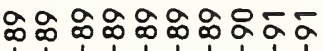

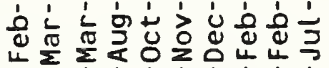

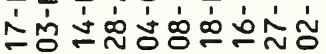

N N N N N N N

N N N N N N

N N UNNNNNN

N N N N N N N

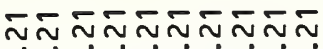
نñniñnin

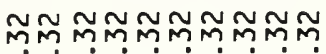

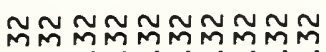

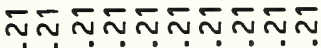
inininininin

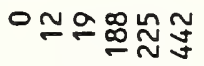

옿ㅎㅎㅎㅇㅇㅇ

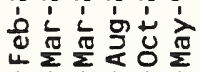

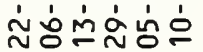

옹영영영 ininini

$\bar{\sim} \bar{n} \bar{n} \bar{n}$ กंinin

ํㅠㅁํํำ نññ

ำกㄴํำำำ ininin

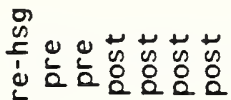
ㅇ.

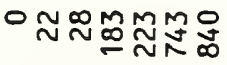

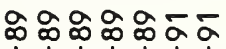

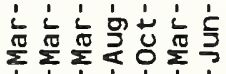

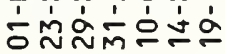

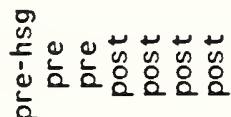

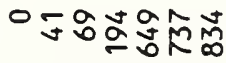

옹ㅇㅎ음주

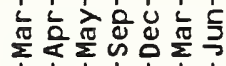

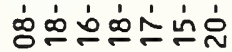
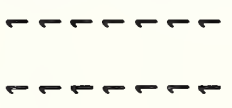

r- $-\cdots$

영영영영영영응 iñññ

웅ํㅠ문 inininin

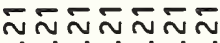
inivinis 느느는느느는든 inininin
ำำำ는ำ는 نंतinin

ํㅡ는ํำำำำ نññतi

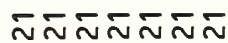
ヘññin

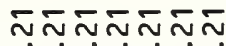
نัiñiñ

$\stackrel{\cong}{\check{1}}$

$\frac{\circ}{\frac{1}{1}}$ 


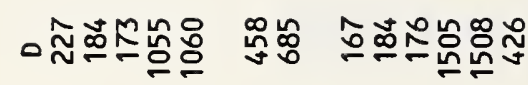

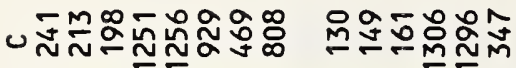

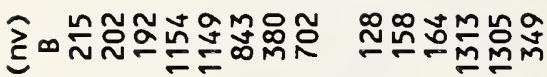

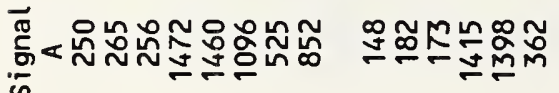

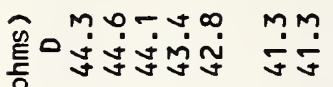

은

om 0 .

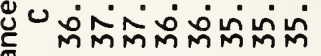

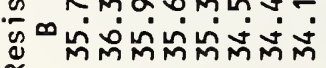

a. 0 , on $n-\infty$

<
O แn m n 000 N

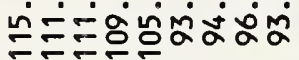

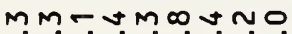

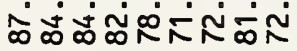
$0 \div 0-00 \infty-0$

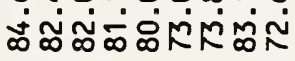
o o m o m $40 \forall \infty$

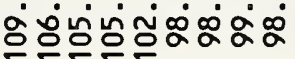

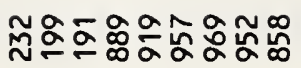

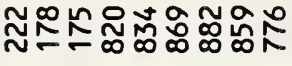

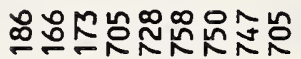

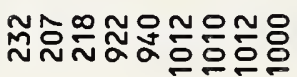

To 0000000

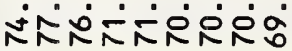

ง $0 \infty \wedge m m \sim N$

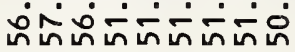
nnoagannm

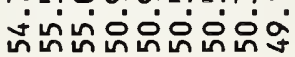
m-aummosoo sंo

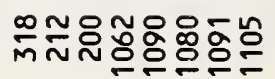
กิ๊

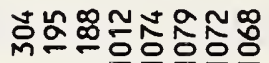

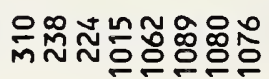
งn 0.0 .90 .04

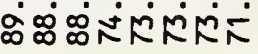

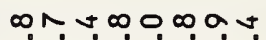

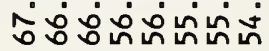
an- $-\sin 40$ में n moavomon

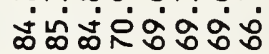

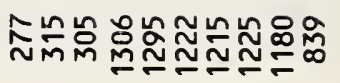

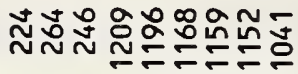

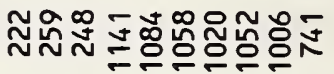

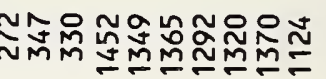
OoOm-Nama-

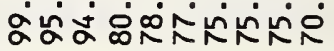
NhN. nn-a.t.

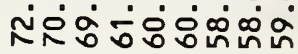
omoxin-onst

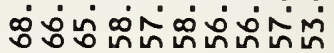
anvnona-b-

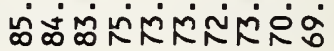

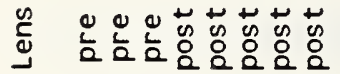

$\stackrel{\mathscr{E}}{:}$

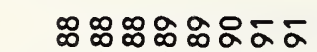

茂

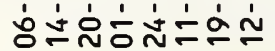
DNNNNNNNN UNNNNNNNN $\frac{\pi}{\infty}<\sim \sim N \sim \sim N \sim N$ 영영영영영 ininininis 뜨느느느느느느늠

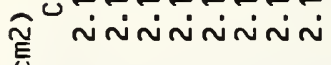
แñ $\bar{n} \bar{N} \bar{n} \bar{N} \bar{N} \bar{N}$

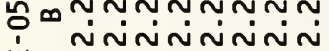
ש 중영영영영 ¿

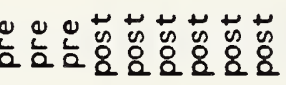

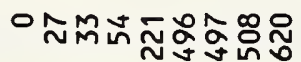

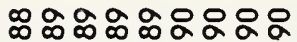

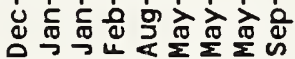

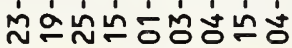
N N N N N N N N N N N N NNNNNNNNN

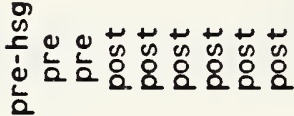

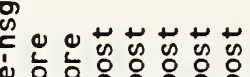
高

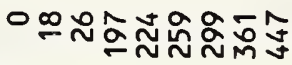

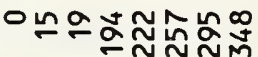

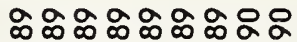

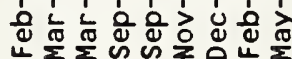

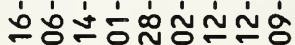
NNNNNNNNN NNNNNNNNN NNNNNNNNN NNNNNNNNN

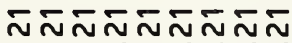
iñnininin

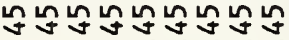

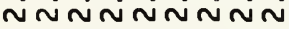

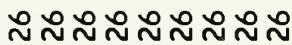
ininininin

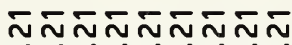
ññniniñ
NNNNNNNNN

옹영영영영영 ininininini

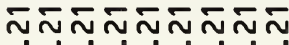

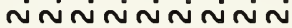

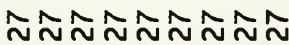
ininininin MNMNMNMNNM iñniññ
잉양ㅎㅀ옳영

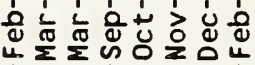

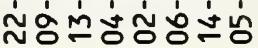

พ N N N N

NNNNNNNN

NNNNNNNN

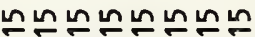
نंininiñ ññก⿻上丨

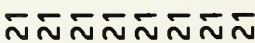
ininininin

$\bar{n} \bar{N} \bar{n} \bar{n} \bar{N}$ iñก⿻iñ
NNNNNNNN

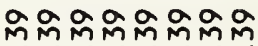

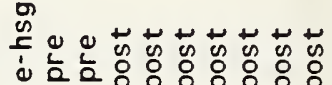
充

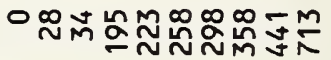

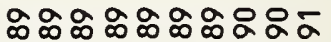
造专专

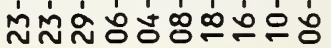
N N N N N N N NNNNNNNNNN NNNNNNNNNN N $N$ N $N$ N

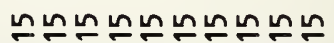
inininininin MMMMMMMMMM

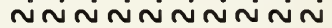

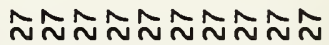
inininininin 뜨느느ำ느느는 iñnininini

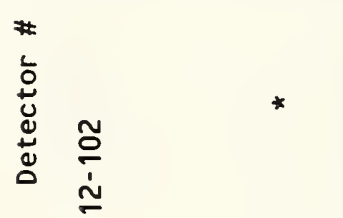

$\stackrel{m}{\stackrel{m}{\grave{s}}}$

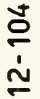

$\stackrel{n}{\check{1}}$

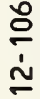




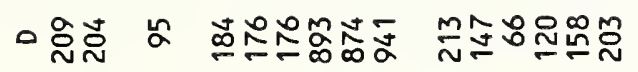

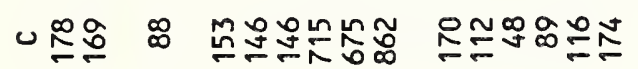

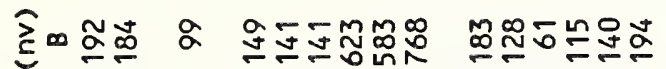

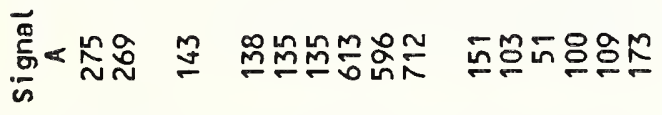

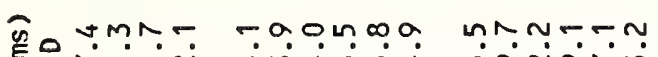

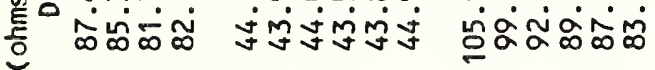

ษั

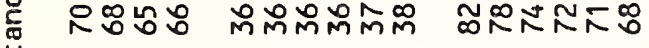

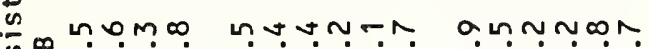

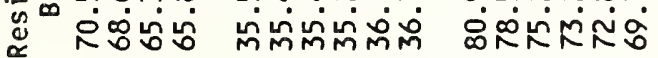

<m⿻

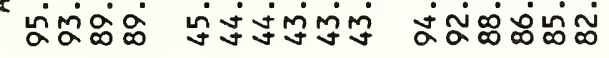

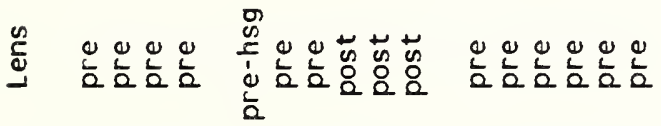

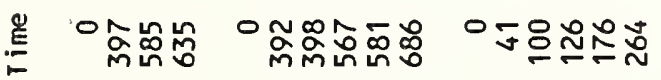

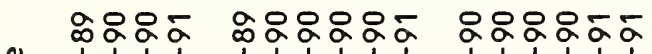

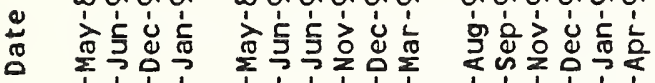

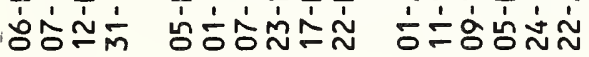

ONNNN NNNNNN NNNNNN

UNNNN NNNNNN NNNNNN

E

EDNNNN NNNNNN NNNNNN

$\frac{\Phi}{\infty}<\sim N N N$ NNNNNN NNNNNN

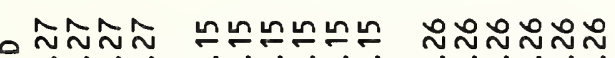
Ninin ninininin ininiñ

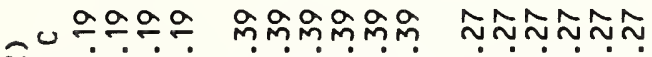

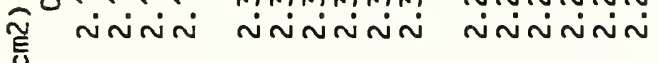

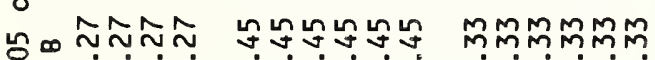

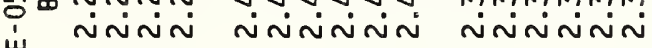

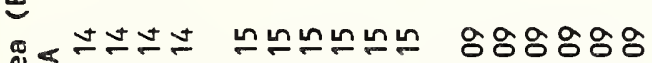

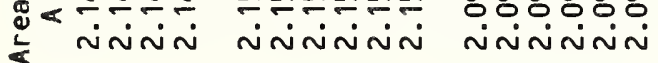

*

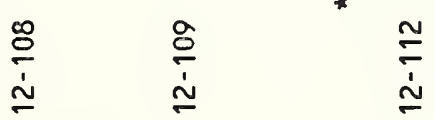


Appendix D

Graphs of the Variation with Time of the Resistances and Signals of the Imager Detectors 


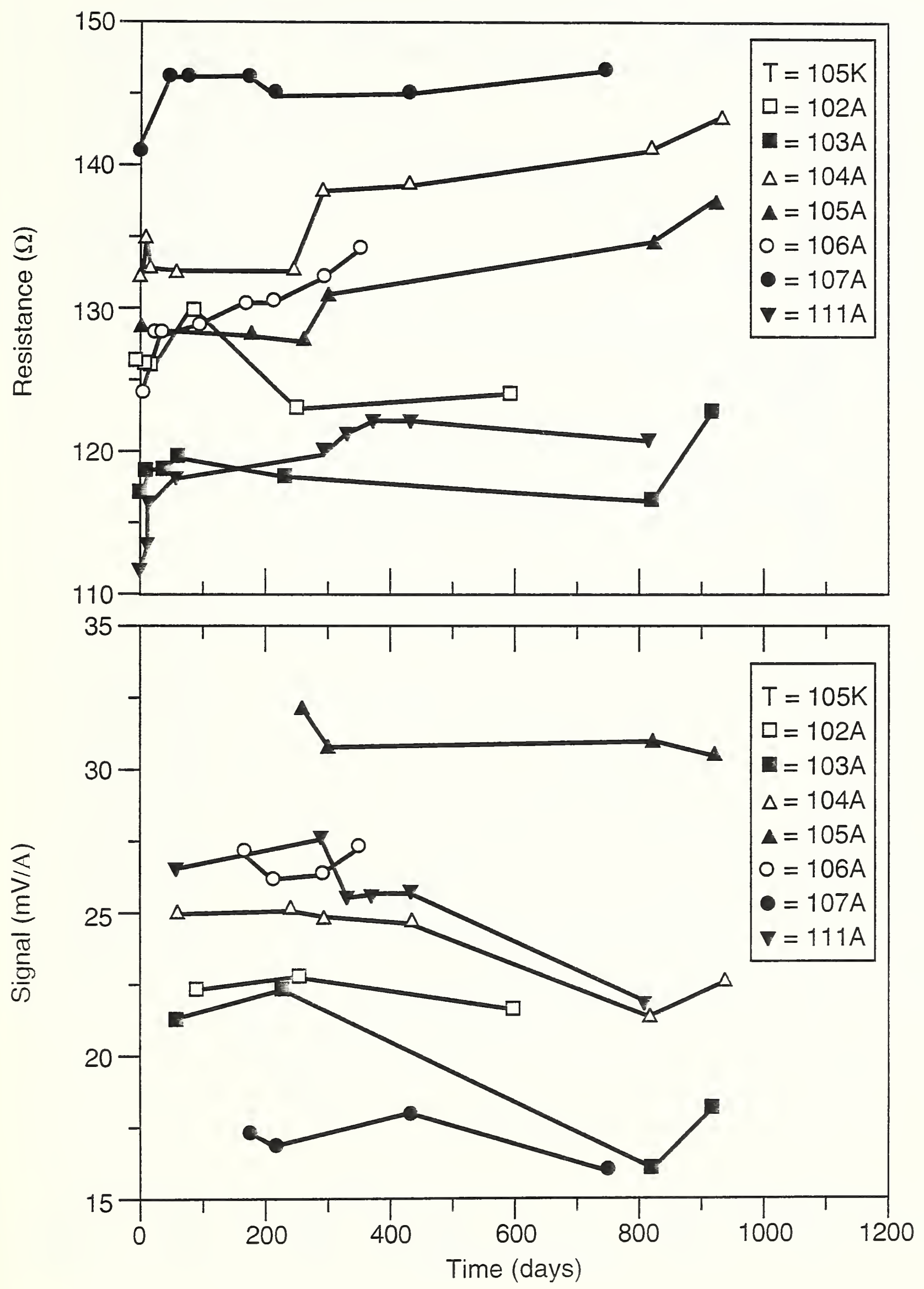

Figure D.1 Resistance (top) and signal (bottom) of element A of the 7- $\mu \mathrm{m}$ detectors with aplanat lens as a function of time. 

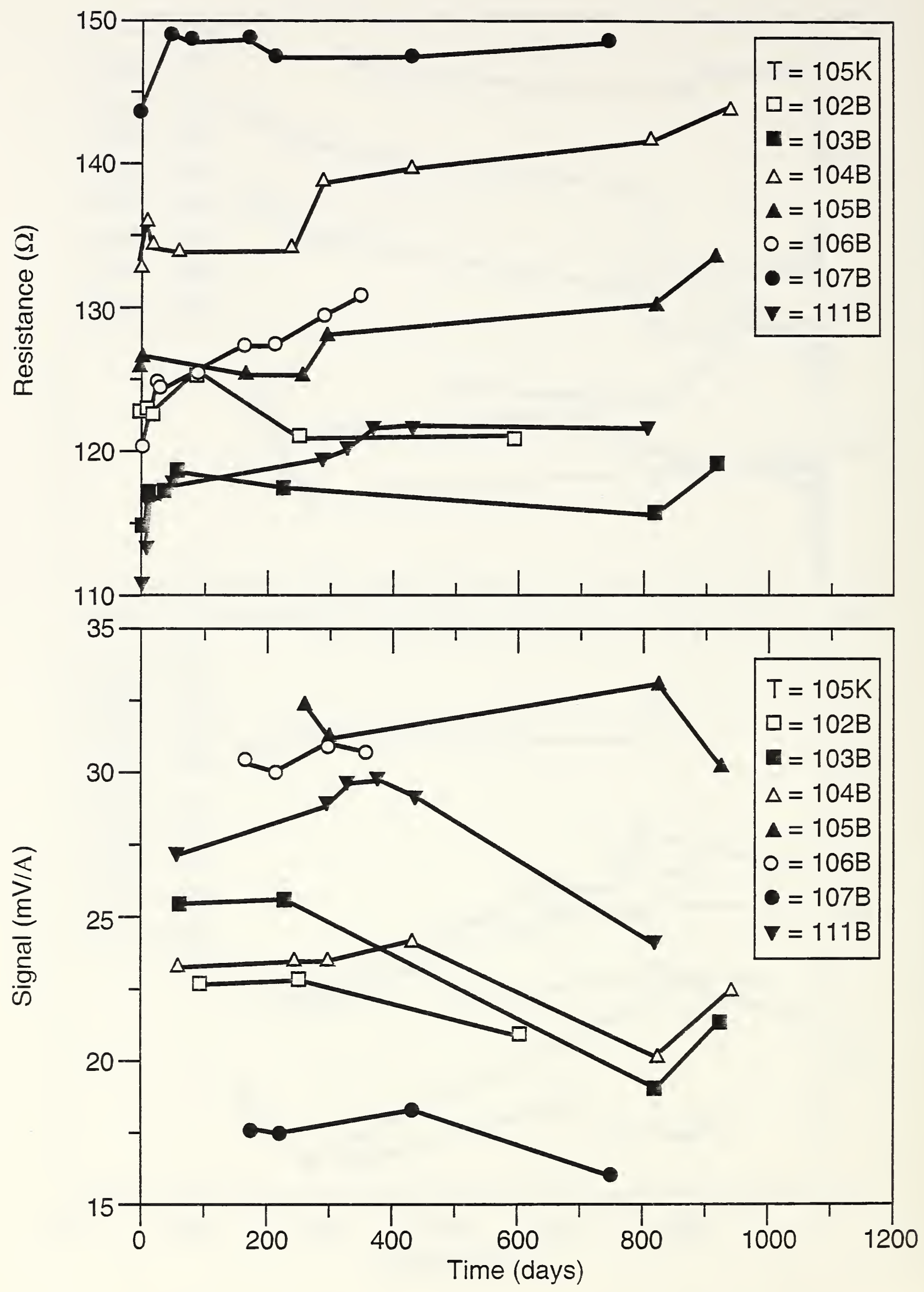

Figure D.2 Resistance (top) and signal (bottom) of element B of the $7-\mu \mathrm{m}$ detectors with aplanat lens as a function of time. 

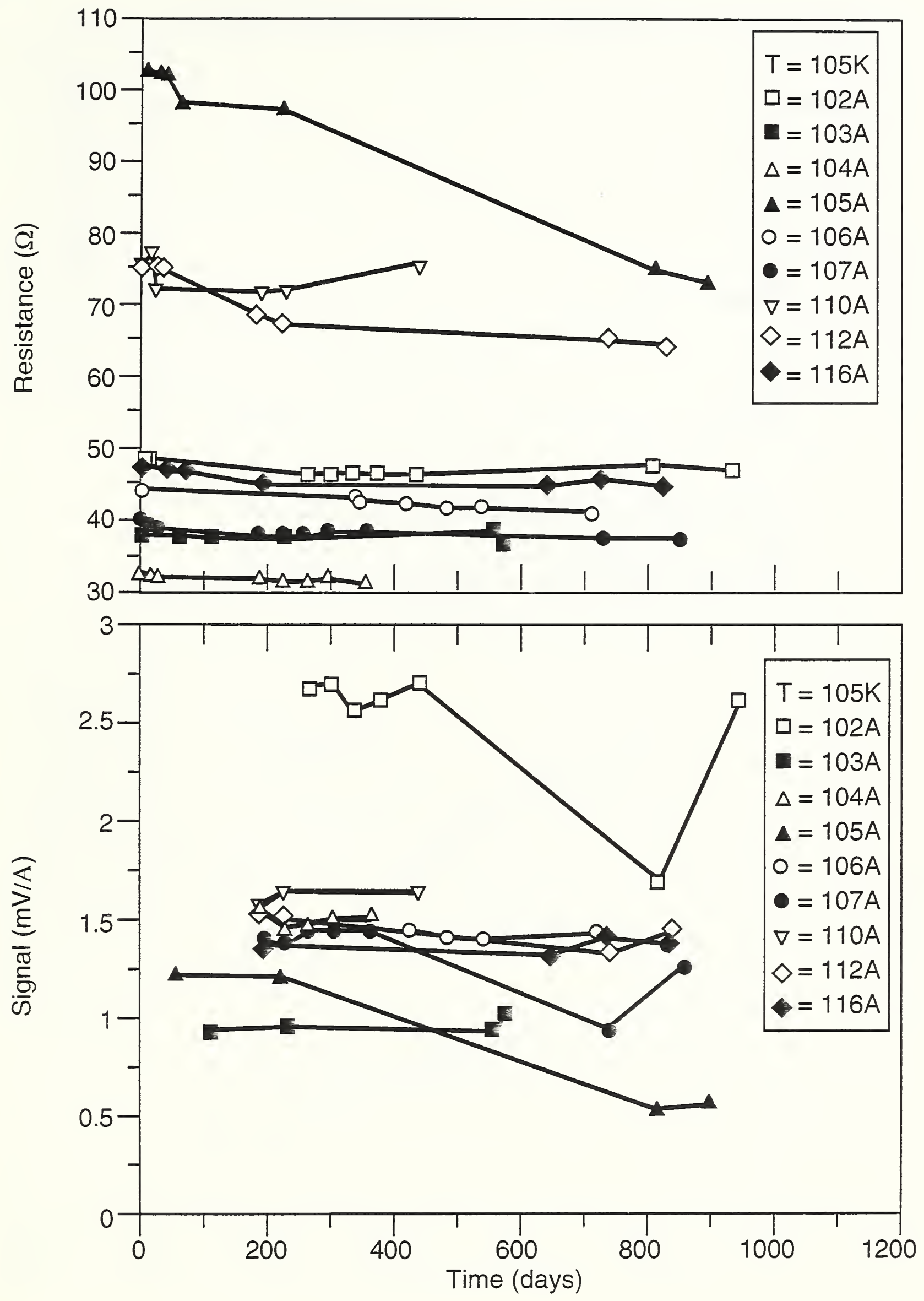

Figure D.3 Resistance (top) and signal (bottom) of element A of the $11-\mu \mathrm{m}$ detectors with aplanat lens as a function of time. 

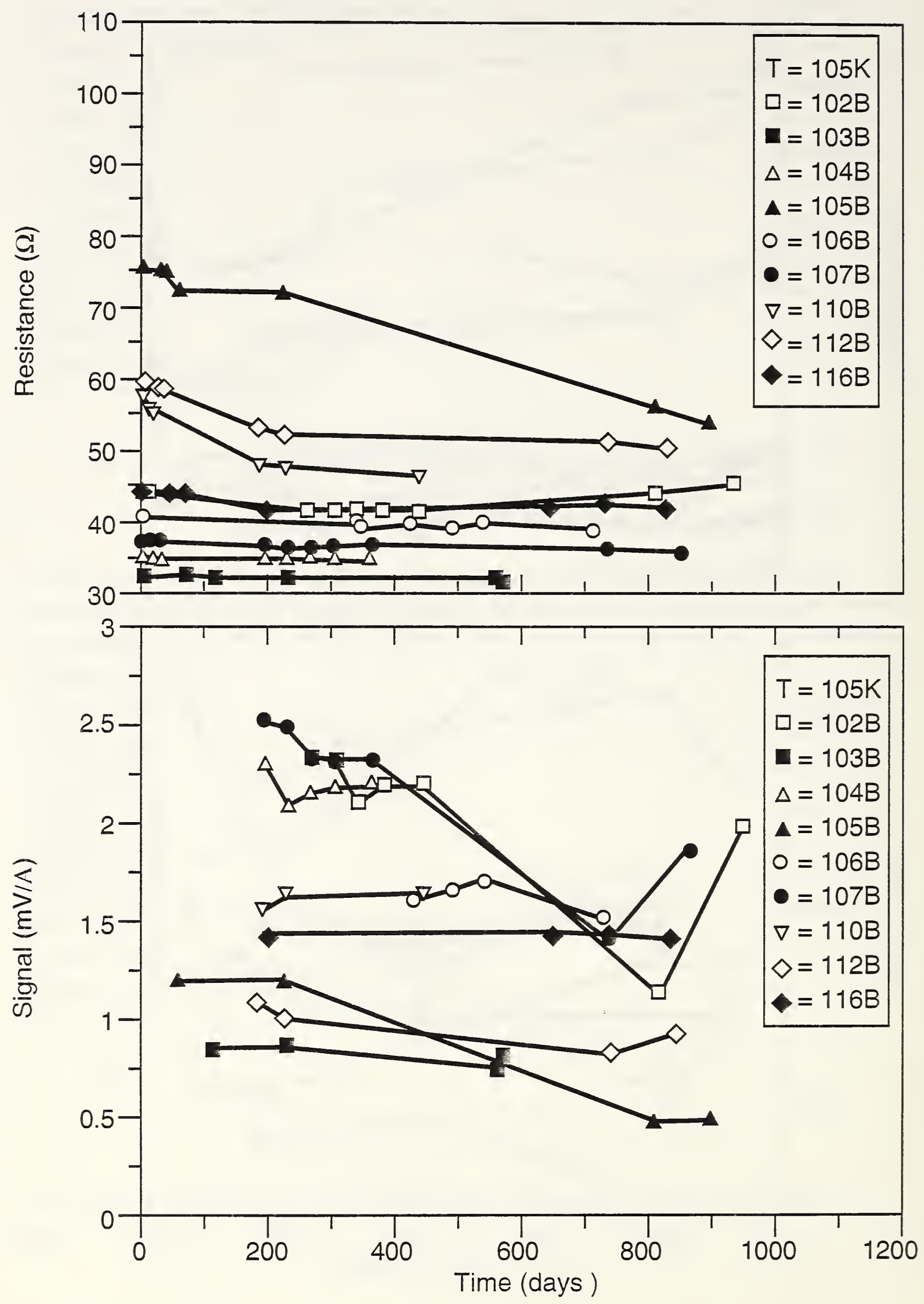

Figure D.4 Resistance (top) and signal (bottom) of element B of the $11-\mu \mathrm{m}$ detectors with aplanat lens as a function of time. 

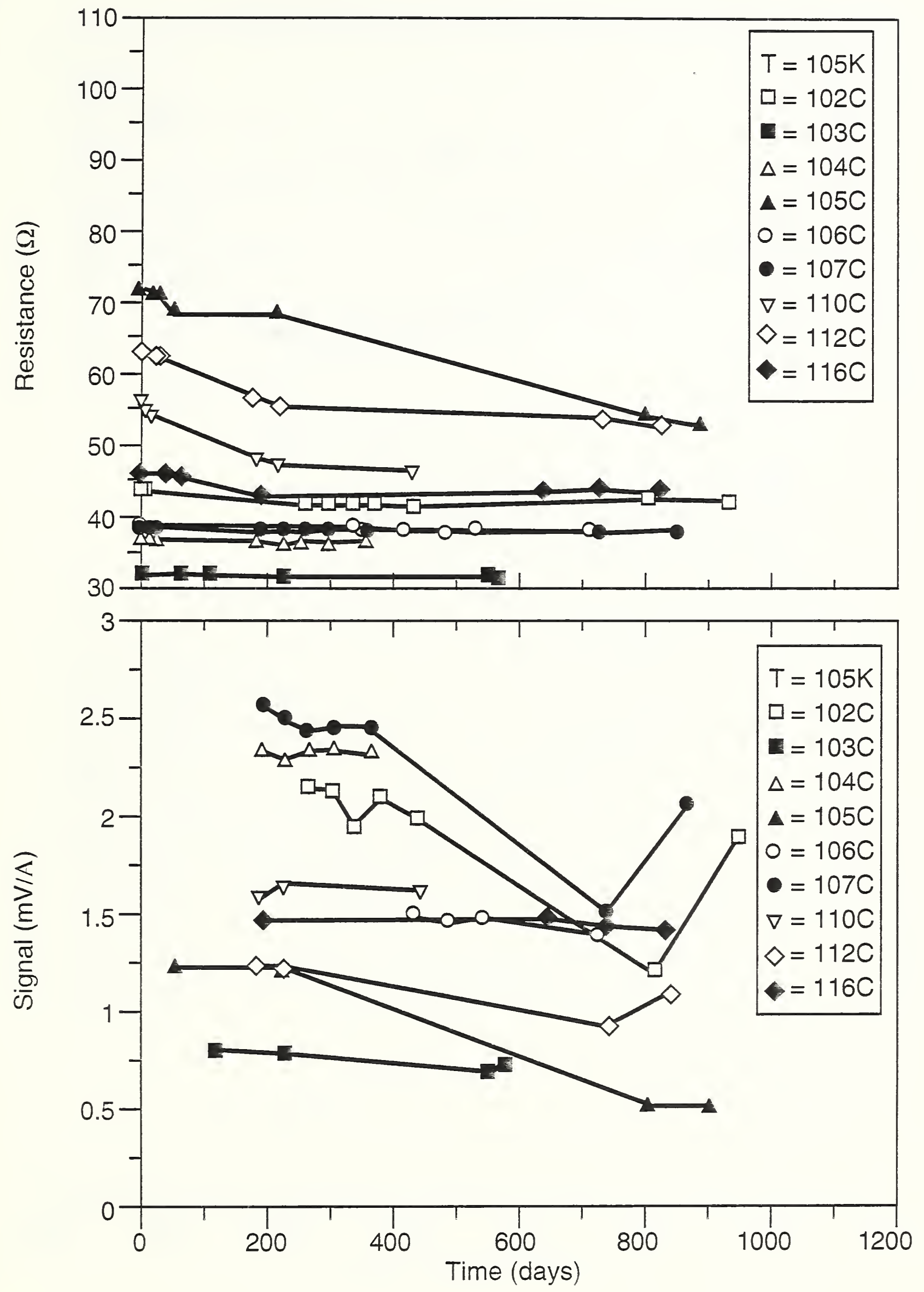

Figure D.5 Resistance (top) and signal (bottom) of element $C$ of the $11-\mu \mathrm{m}$ detectors with aplanat lens as a function of time. 

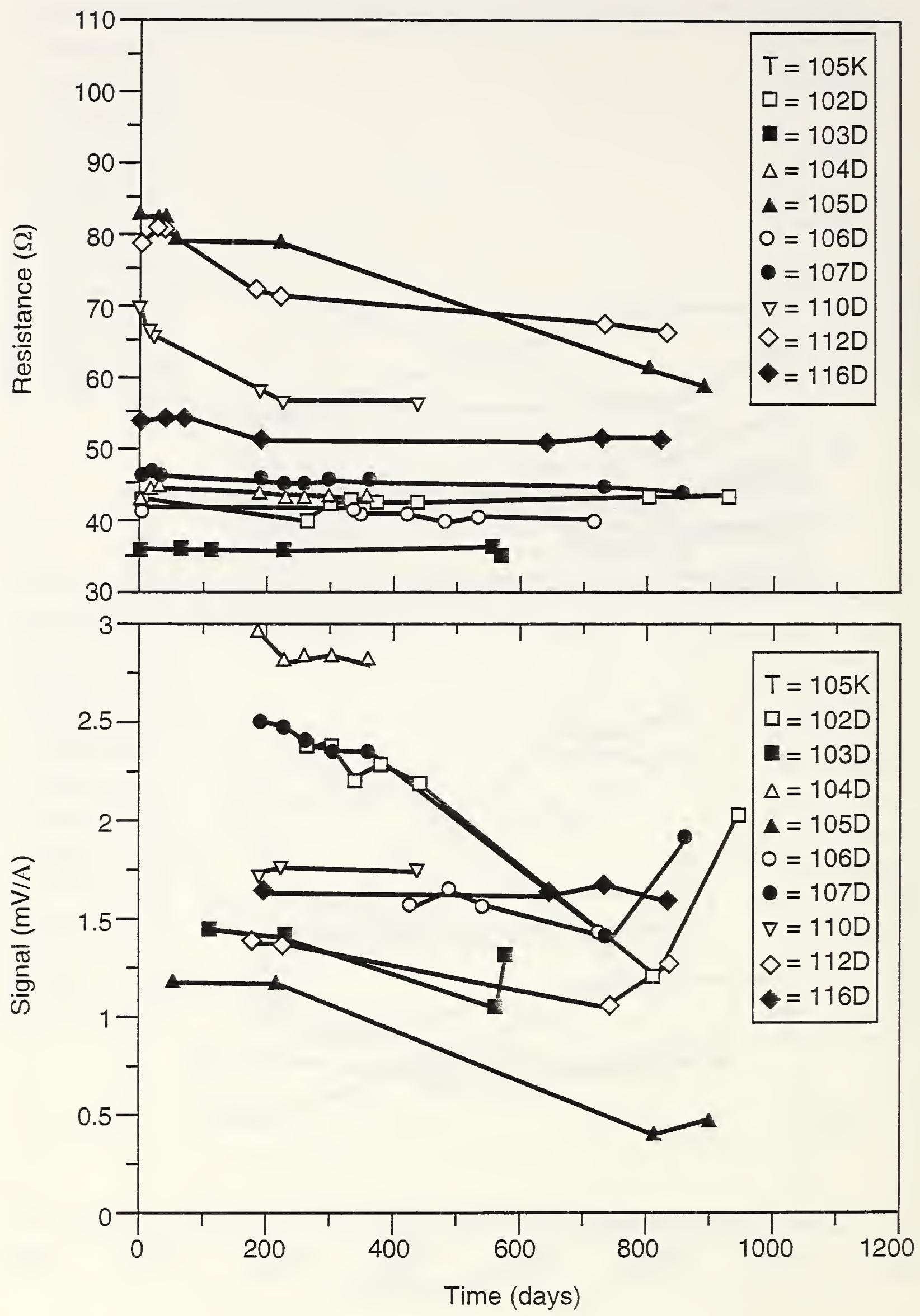

Figure D.6 Resistance (top) and signal (bottom) of element D of the $11-\mu \mathrm{m}$ detectors with aplanat lens as a function of time. 


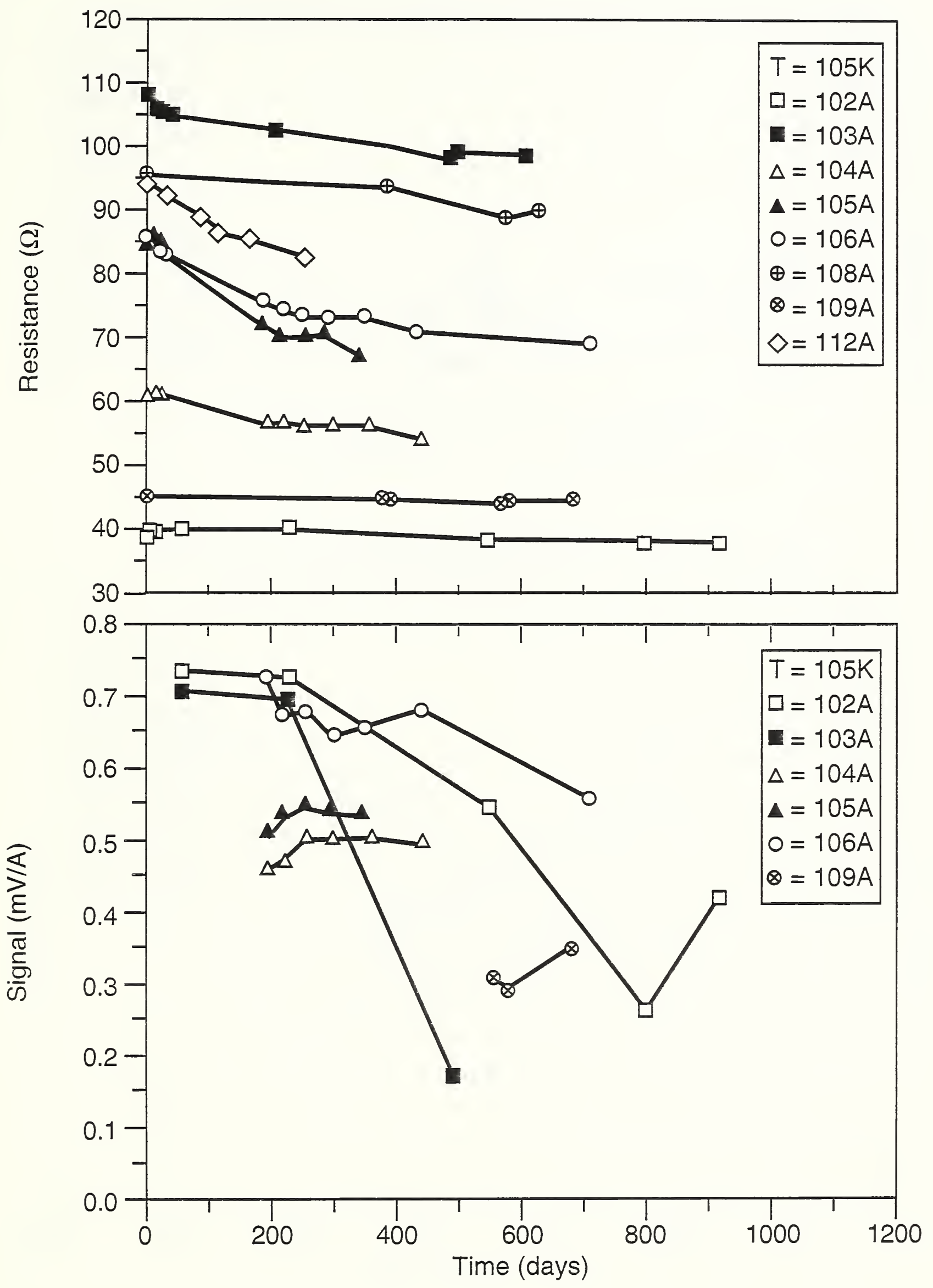

Figure D.7 Resistance (top) and signal (bottom) of element A of the $12-\mu \mathrm{m}$ detectors with aplanat lens as a function of time. 

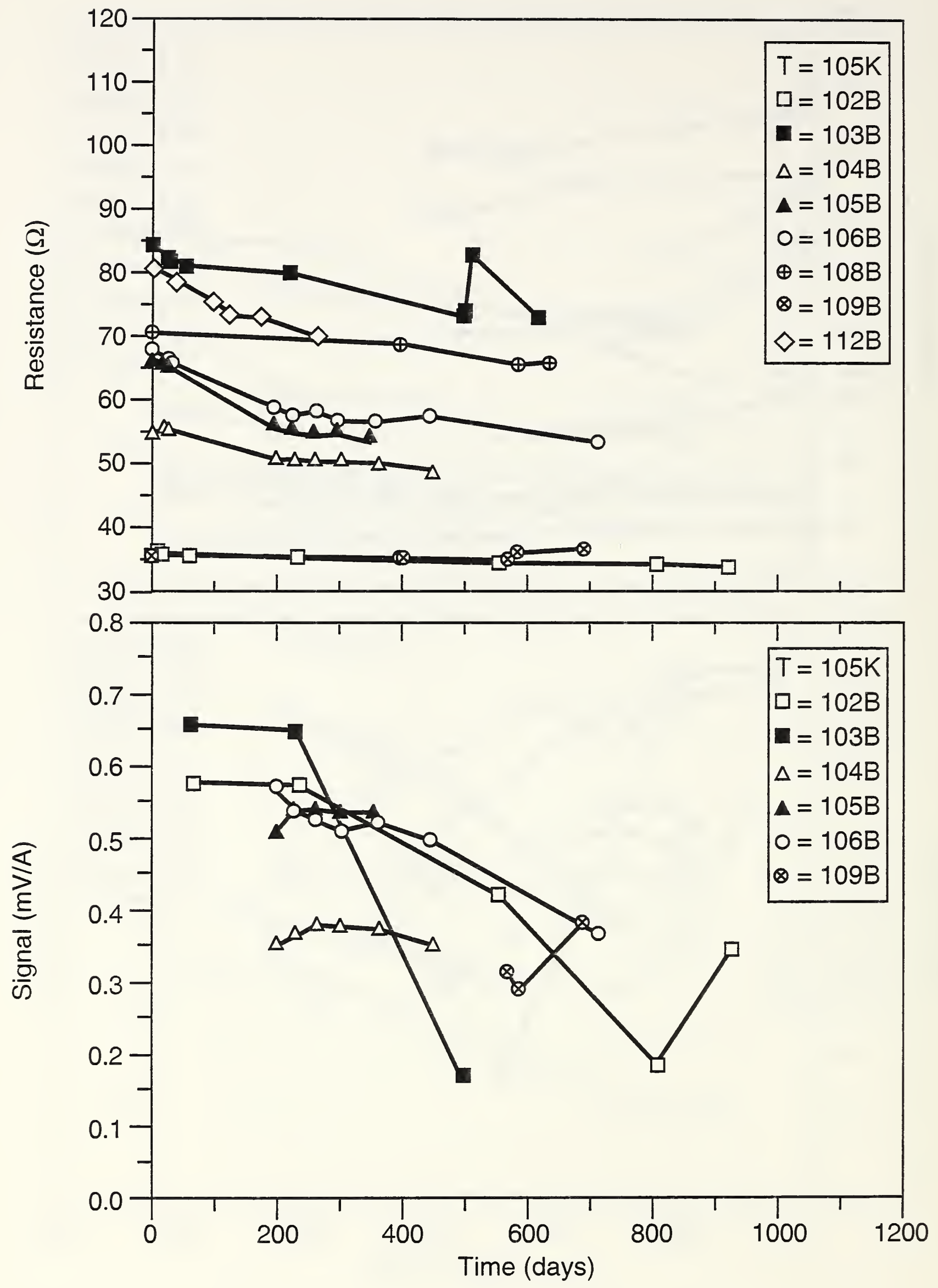

Figure D.8 Resistance (top) and signal (bottom) of element B of the $12-\mu \mathrm{m}$ detectors with aplanat lens as a function of time. 

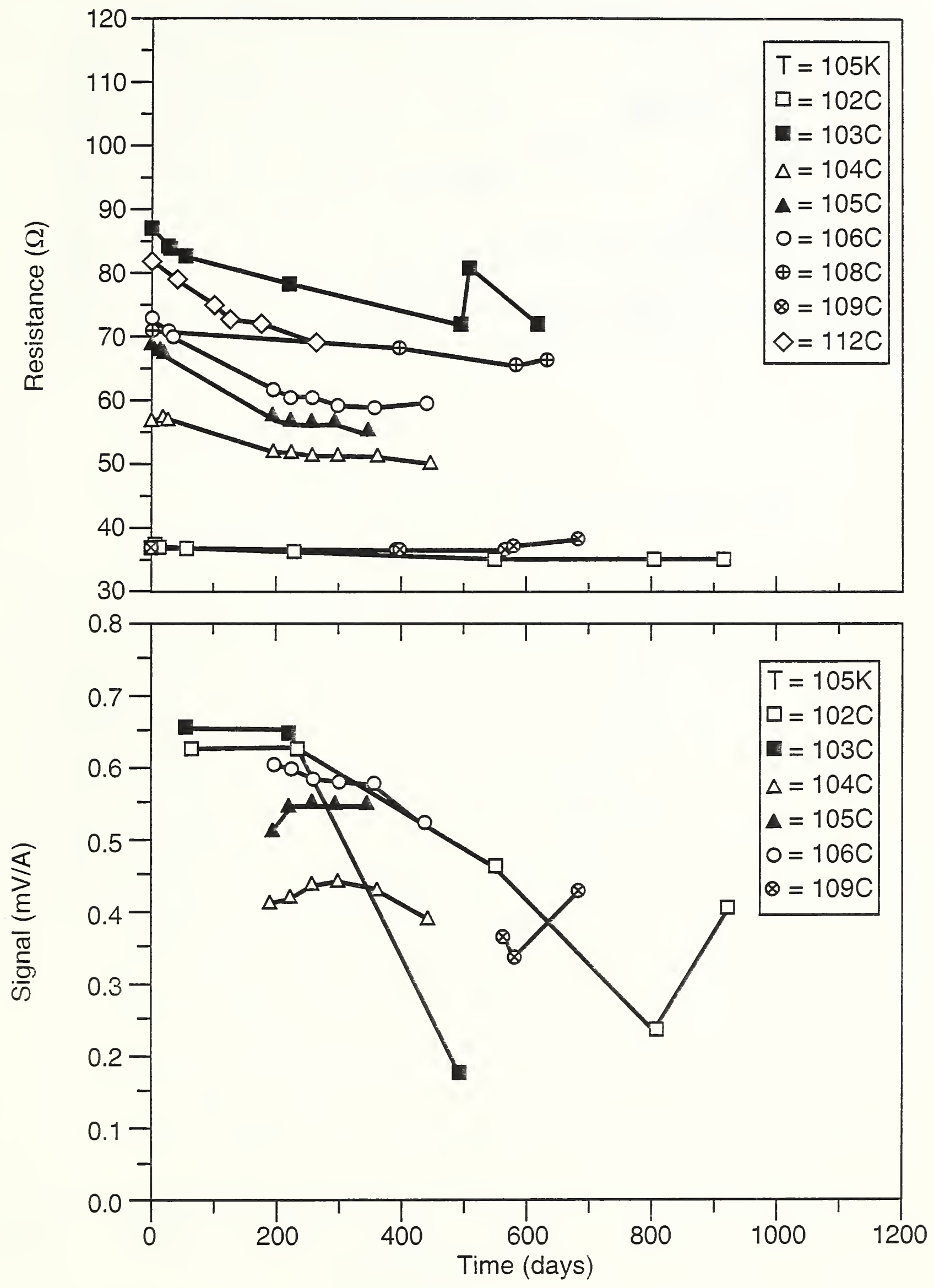

Figure D.9 Resistance (top) and signal (bottom) of element $C$ of the $12-\mu \mathrm{m}$ detectors with aplanat lens as a function of time. 

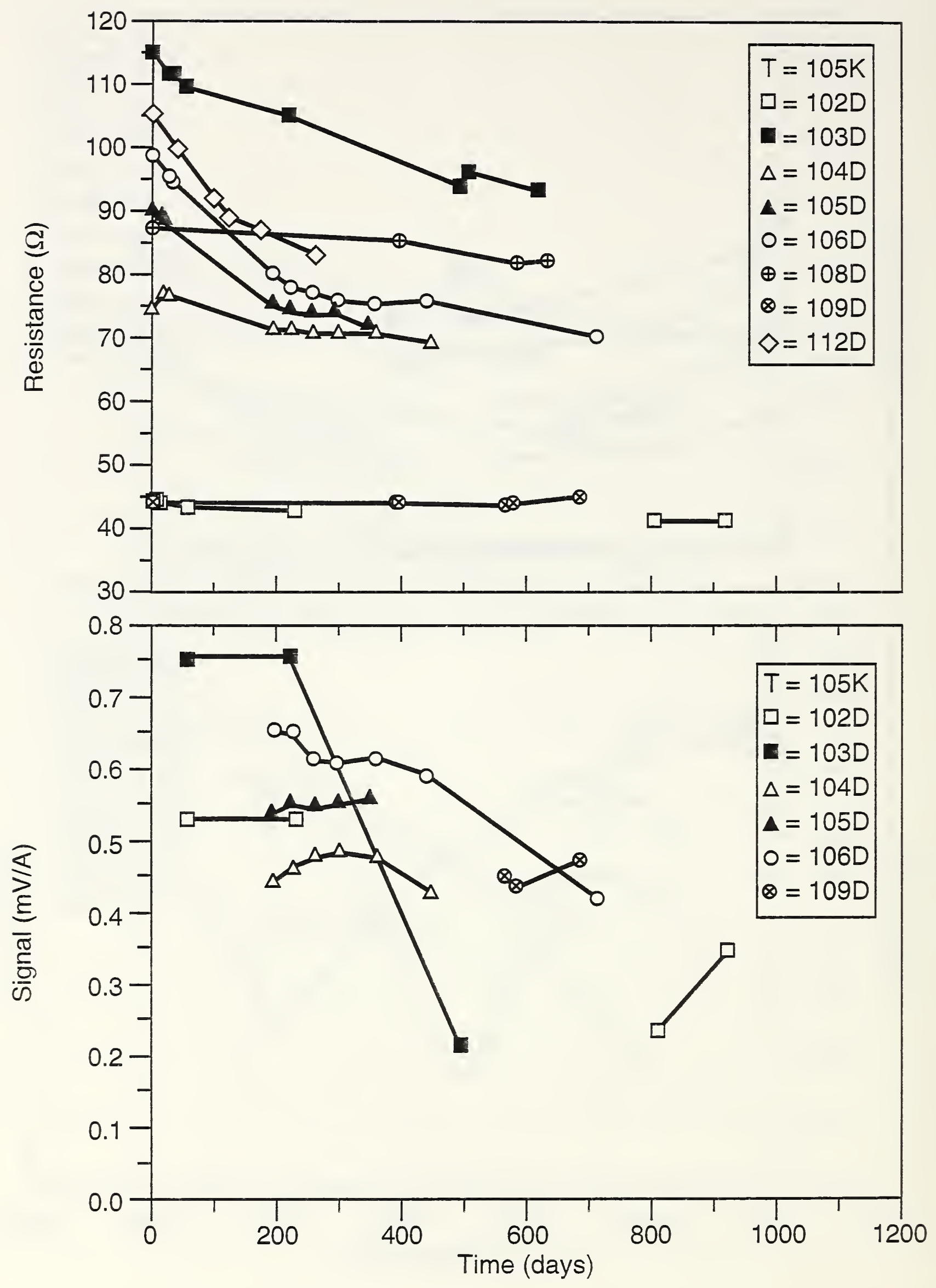

Figure D.10 Resistance (top) and signal (bottom) of element D of the $12-\mu \mathrm{m}$ detectors with aplanat lens as a function of time. 


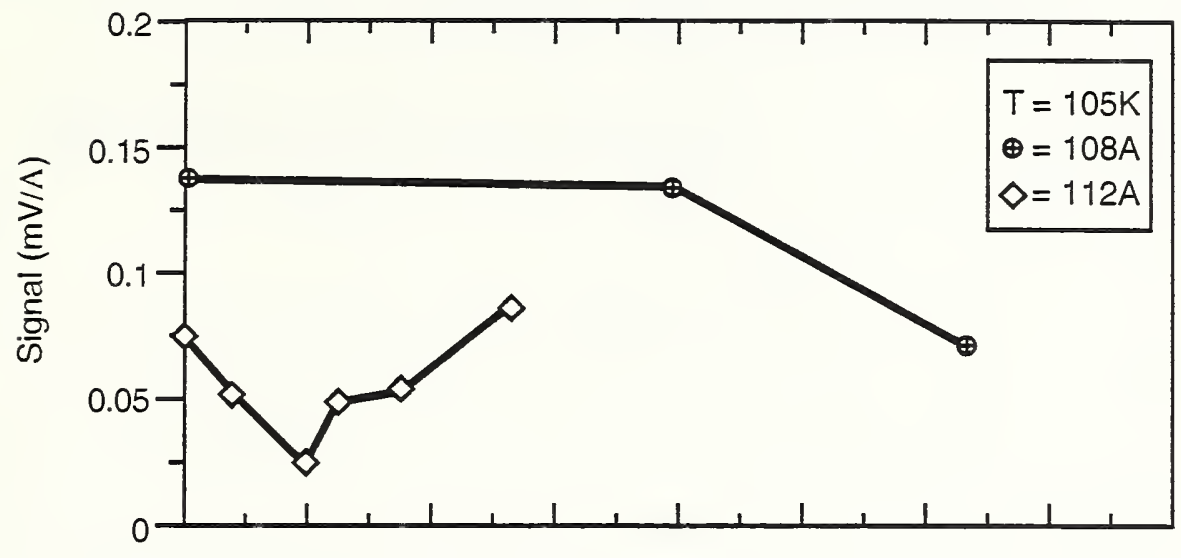

(a)

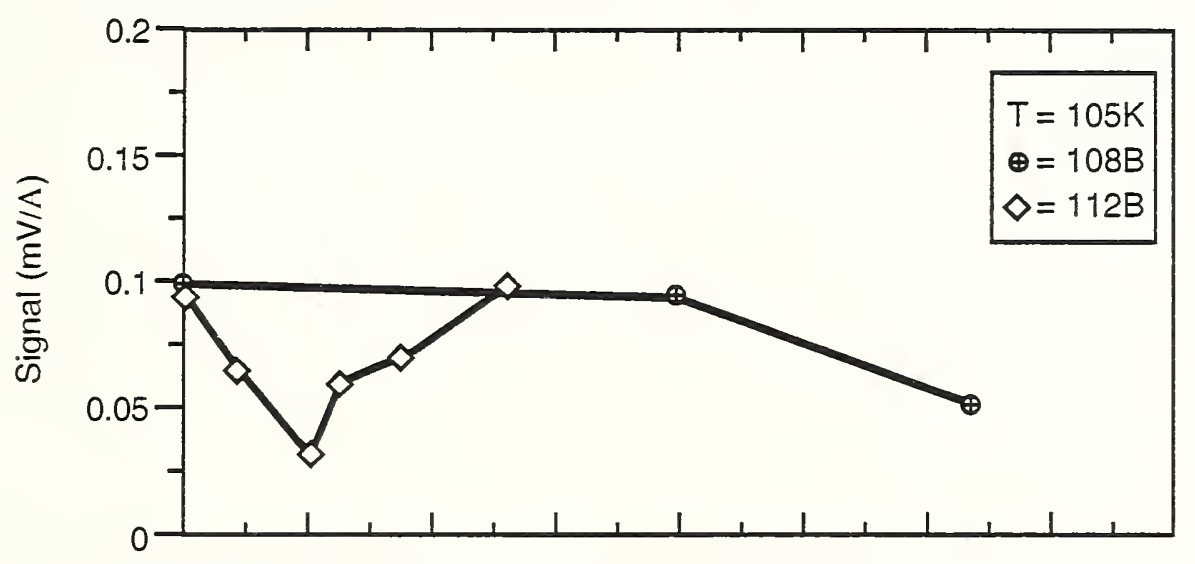

(b)
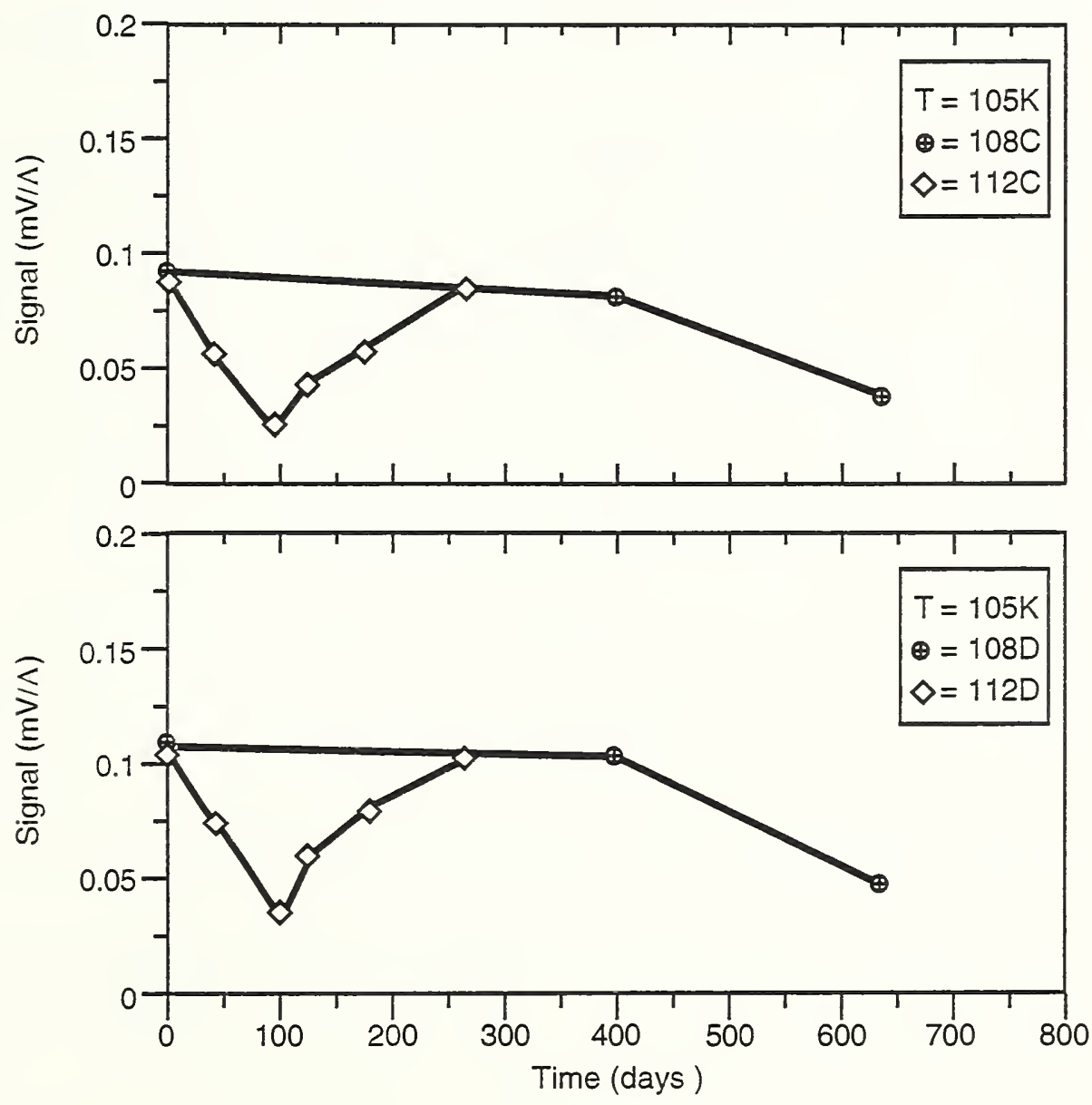

(c)

Figure D.11 Signals of elements of the $12-\mu \mathrm{m}$ detectors without aplanat lens as a function of time. (a) Element A, (b) Element B, (c) Element C, and (d) Element D. 


$$
\text { . }
$$


NIST-114A

(REV. 3-90)
U.S. DEPARTMENT OF COMMERCE NATIONAL INSTITUTE OF STANDARDS AND TECHNOLOGY

\section{BIBLIOGRAPHIC DATA SHEET}

1. PUBLCATION OR REPORT NUMBER

NISTIR 4687

2 PERFORMING ORGANIZATION REPORT NUMBER

3. PUBLCATION DATE

September 1991

4. TITLE AND SUBTITLE

HgCdTe Detector Reliability Study for the GOES Program

5. AUTHOR(S)

D. G. Seiler, G. G. Harman, J. R. Lowney, S. Mayo, and W. S. Liggett, Jr.

6. PERFORMING ORGANIZATION (IF JOINT OR OTHER THAN NIST, SEE INSTRUCTIONS)

U.S. DEPARTMENT OF COMMERCE

NATIONAL INSTITUTE OF STANDARDS AND TECHNOLOQY

GAITHERSBURG, MD 20899

7. CONTRACT/GRANT NUMBER

8. TYPE OF REPORT AND PERIOD COVERED

9. SPONSORING ORGANIZATION NAME AND COMPLETE ADDRESS (STREET, CITY, STATE, ZIP)

National Oceanic and Atmospheric Administration

Department of Commerce

Washington, D.C.

10. SUPPLEMENTARY NOTES

11. ABSTRACT (A 200-WORD OR LESS FACTUAL SUMMARY OF MOST SIGNIFICANT INFORMATION. IF DOCUMENT INCLUDES A SIGNIFICANT BIBLOGRAPHY OR UTERATURE SURVEY, MENTION IT HERE.)

This report summarizes the results of a special assessment carried out by the National Institute of Standards and Technology (NIST) at the request of the National Oceanic and Atmospheric Administration of the reliability of certain infrared detectors for the Geostationary Operational Environmental Satellite system. The data made available by ITT on detector resistances and signals support the conclusion that degradation of some detector responses has occurred, even when the estimated measurement uncertainty is included. Statistical analysis of the $11-\mu \mathrm{m}$ detectors confirmed that detector 11-105 decreased in signal with time. The existing data available to NIST is not sufficient to identify uniquely the cause of degradation or unstable behavior present in a number of detectors. NIST's physical examination of several detectors by optical and SEM microscopy methods and an examination and analysis of the Detector Measurement Database has yielded several plausible possible mechanisms for the observed degradation. These possible mechanisms are related to the detector fabrication or processing steps and include: Incomplete or poor passivation procedures, excess mercury diffusion resulting from the ion-beam milling fabrication step, poor indium electrical contacts produced by the indium-plated fabrication step, and delamination of the ZnS antireflection optical coating. Other observed problems were poor wire bonding, use of tin-lead solder to couple the fine gold wire (bonded to the detector) to the package terminal, and use of silicone RTV to stake the bond wires to the edge of the $\mathrm{ZnS}$ substrate.

12. KEY WORDS (6 TO 12 ENTRIES; ALPHABETICAL ORDER; CAPITALZE ONLY PROPER NAMES; AND SEPARATE KEY WORDS BY SEMICOLONS)

degradation; Geostationary Operational Environmental Satellite; HgCdTe detector; indium-plated contacts; ion-beam milling; passivation

\begin{tabular}{|c|c|c|}
\hline \multicolumn{2}{|c|}{ 13. AVAILABILTY } & \multirow{2}{*}{$\begin{array}{l}\text { 14. NUMBER OF PRINTED PAGES } \\
\qquad \mathcal{S}\end{array}$} \\
\hline$y$ & UNLMITED & \\
\hline & $\begin{array}{l}\text { ORDER FROM SUPERINTENDENT OF DOCUMENTS, U.S. GOVERNMENT PRINTINO OFFICE, } \\
\text { WASHINOTON, DC } 20402 \text {. }\end{array}$ & \multirow[t]{2}{*}{ 15. PRICE } \\
\hline $\mathrm{x}$ & ORDER FROM NATIONAL TECHNICAL INFORMATION SERVICE (NTIS), SPRINGFIELD, VA 22161. & \\
\hline
\end{tabular}




